Maestría en Economía

Facultad de Ciencias Económicas

Universidad Nacional de La Plata

TESIS DE MAESTRÍA

Título

La economía informal y el mercado laboral en la Argentina:

Un análisis desde la perspectiva del trabajo decente

\author{
Alumna \\ Mónica Jiménez \\ Director \\ Dr. Jorge A. Paz
}

Noviembre de 2010 


\title{
La economía informal y el mercado laboral en la Argentina: Un análisis desde la perspectiva del trabajo decente
}

Mónica Jiménez*

Director: Dr. Jorge A. Paz

\begin{abstract}
Resumen
El objetivo de este estudio es explorar, desde una perspectiva dinámica, el impacto del fenómeno de la informalidad, analizado en términos de déficit de trabajo decente, en la estructura del mercado laboral argentino. Con este fin, se estiman matrices de transición, brechas salariales y modelos mixtos finitos, que permiten estimar el número de posibles segmentos existentes en ese sector. El resultado más relevante es la evidencia encontrada a favor de la segmentación del sector formal. La importancia de este hallazgo radica en sus implicaciones respecto de un grupo de trabajadores - los asalariados no registrados - que permanecen bajo condiciones laborales desfavorables.
\end{abstract}

\footnotetext{
* Agradezco a mi director, Dr. Jorge Paz, por su permanente disposición y apoyo.
} 


\section{Índice}

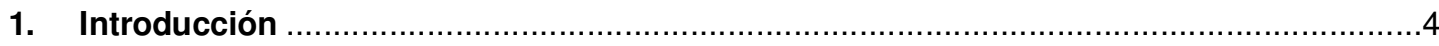

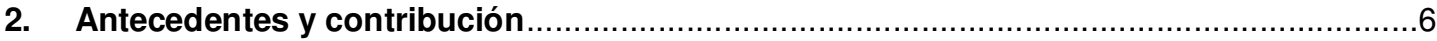

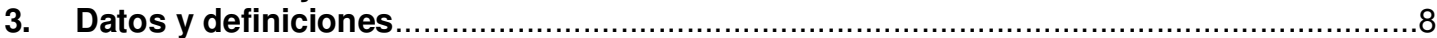

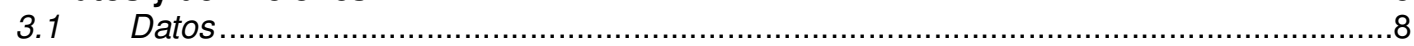

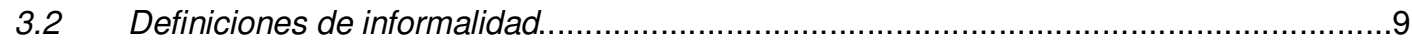

3.3 La perspectiva de trabajo decente y la economía informal ..........................................12

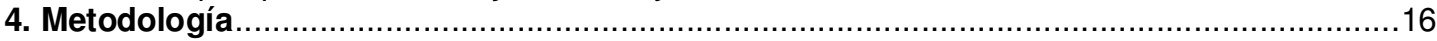

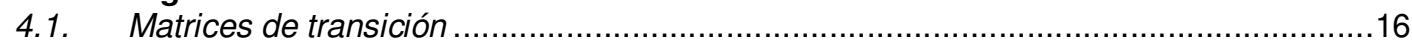

4.2. Estimación de brechas de ingreso mediante el modelo de efectos fijos .........................17

4.3. Exploración de la estructura del mercado laboral y de la cantidad de segmentos del

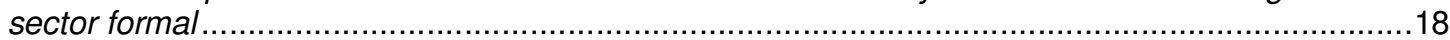

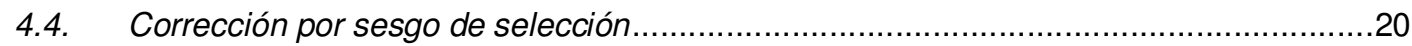

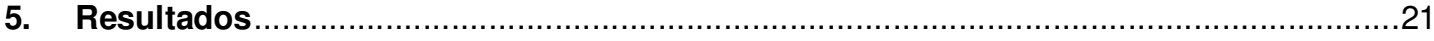

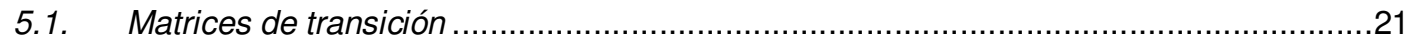

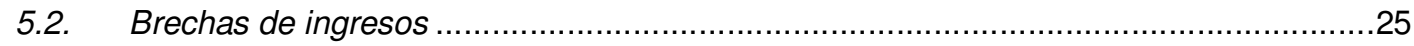

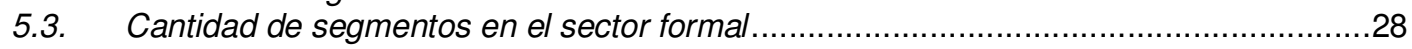

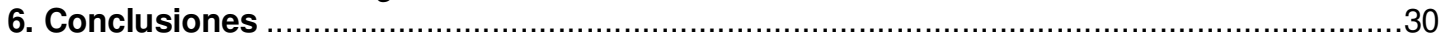

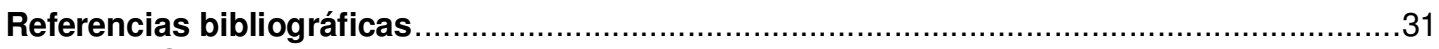

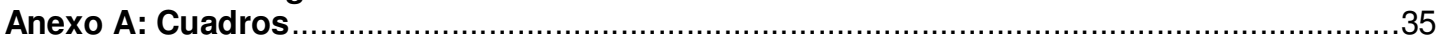

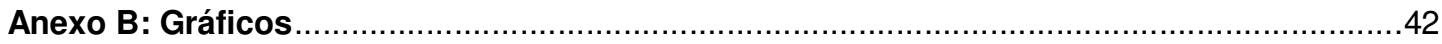




\section{Introducción}

El objetivo general del presente estudio es explorar, desde una perspectiva dinámica, el impacto del fenómeno de la informalidad, analizado en términos de déficit de trabajo decente, en la estructura del mercado laboral argentino. Específicamente, se examinará la hipótesis de segmentación del sector formal que implica considerarlo como un sector no homogéneo con una estructura compleja diferente a la que le asignó tradicionalmente la literatura.

El análisis de la informalidad adquiere actualmente particular importancia por ser uno de los problemas más graves y complejos del mercado laboral que afecta hoy a muchos trabajadores tanto en Argentina como en América Latina. Su crecimiento en los últimos años lo muestra como un fenómeno que no puede ser considerado como temporal o marginal. En efecto, el incremento de la economía informal en las áreas urbanas de América Latina fue desde un 57\% en 1990 a un $63.3 \%$ en 2005 y estuvo acompañado de un respectivo aumento del empleo en el sector informal urbano y de trabajadores informales en empresas formales (Tokman, 2009). Además, la evidencia de las dos últimas décadas sugiere que no existen signos de un patrón consistente de reducción de la informalidad laboral en Latinoamérica (Gasparini y Tornarolli, 2007). En el caso de la Argentina, entre mayo y octubre del 2002, se produjo una caída de los puestos registrados con el consecuente aumento de las ocupaciones precarias. Si bien, los empleos formales e informales se expandieron desde octubre 2002 hasta el último trimestre de 2004, los últimos lo hicieron más aceleradamente que los primeros: $11,2 \%$ frente a $7 \%$ por año. Así, los puestos no registrados alcanzaron, en el segundo trimestre de 2006, niveles semejantes a los de mayo de 2002, esto es, entre un 41 y $42 \%$ (Beccaria, 2007).

El problema de la informalidad laboral ha persistido más de 30 años y sigue planteando un importante desafío en numerosos países que buscan reducirla progresivamente. Aunque la informalidad es ampliamente reconocida como un fenómeno complejo, multicausal y heterogéneo, no existe consenso entre los autores en las formas de concebir y de medir el fenómeno. Justamente la gran labilidad del concepto de informalidad se traduce en una variada y no siempre coherente gama de soluciones para remediar el problema.

La definición de informalidad ha evolucionado a lo largo del tiempo. Así, el término "sector no estructurado" que fue acuñado por la OIT a principios de la década del setenta en el informe sobre Kenia, está ya desfasado y en la actualidad se está restringiendo el de "sector informal". Esta última expresión es considerada inadecuada, e incluso errónea, para capturar el proceso de informalización del empleo de los últimos años y para reflejar los aspectos dinámicos, heterogéneos y complejos de un fenómeno que trasciende los límites de un sector. Por lo tanto, también el término "sector informal", profusamente usado, es limitado teniendo en cuenta las actividades de un grupo cada vez más numeroso y diverso de trabajadores y empresas desarrolladas no en un único sector de la economía, sino en varios. Dado que una definición basada en las empresas del sector informal es insuficiente para reflejar la multiplicidad de formas que reviste la informalidad laboral, la OIT (2002) propuso desarrollar un enfoque teórico más amplio que permita relacionar el concepto de empleo en el sector informal basado en la empresa con el concepto más amplio de empleo informal basado en el puesto trabajo (Hussmanns, 2004). Desde este nuevo enfoque, la OIT (2002) define al empleo informal como el conjunto de puestos de trabajo informales desarrollados tanto en empresas formales como informales. Por esto, propone el término "economía informal" para hacer referencia al conjunto de actividades económicas desarrolladas por los trabajadores y las unidades productivas que, tanto en la legislación como en la práctica, están insuficientemente contempladas por los sistemas formales o no lo están en absoluto. Este último concepto de informalidad es más general, pues incluye tanto las relaciones de producción como las relaciones de empleo. Sin embargo, esta nueva visión no implica eliminar el término "sector informal" sino incluirlo en el de "economía informal" para considerar a todos los trabajadores que no están suficientemente cubiertos por las leyes laborales, incluso a quienes se encuentren empleados en unidades formales de producción. Por lo tanto, desde este nuevo enfoque conceptual, el empleo total puede ser analizado a partir de dos dimensiones: según el tipo de trabajo o según el tipo de unidad de producción, que incluye a las empresas del sector formal, del sector informal y a los hogares (Tokman, 2009).

Los trabajadores que desarrollan sus actividades en la economía informal no sólo sufren un vacío jurídico caracterizado por la inadecuada seguridad y protección social, sino que además, la mayor parte de ellos no gozan de condiciones laborales óptimas. De ello se deduce que el cumplimiento de los derechos y normas en el trabajo es una condición necesaria pero no suficiente para obtener un empleo con calidad laboral. Por esta razón, la forma más consistente de analizar la situación de quienes se encuentran en la economía informal es en términos de déficit de trabajo decente (OIT, 
2002). La noción de trabajo decente (TD) ha sido introducida por el Director General de la OIT en su Memoria a la $87^{\text {a }}$ Conferencia Internacional del Trabajo (1999). El aspecto novedoso de este concepto radica en su carácter multidimensional. En efecto, la definición de TD incorpora cuatro dimensiones principales. La primera hace referencia al trabajo y al empleo en sí mismos con una noción más amplia de participación en la economía y la comunidad. En la segunda dimensión se incluyen los derechos fundamentales en el trabajo. El concepto de TD requiere en este nivel que tales derechos no se agoten en los derechos laborales básicos sino también que éstos provean una base sobre la cual se puedan fundar y construir otros derechos y capacidades. En la tercera dimensión se reconoce que tanto la extensión de la protección social como la promoción de prácticas y condiciones de trabajo seguras son necesidades imperiosas para el concepto de TD cuya esencia en esta dimensión, es proteger a todos, de los diferentes riesgos y contingencias que surgen en el trabajo, independientemente de dónde se realice. La última dimensión, relativa a la representación y el diálogo social, tiene como objetivo crear un marco que respalde los derechos de asociación y permita la participación del trabajador en las estructuras y los procesos de diálogo social. Aunque estas cuatro dimensiones del TD tienen sus propias características, cada una se complementa o se combina con otra, pues están estrechamente interrelacionadas y promueven juntas diversos fines sociales y económicos tales como el desarrollo, la integración social, la erradicación de la pobreza y la realización individual.

América Latina reconoce, a partir del 2003, que la generación de TD es una de las mejores vías para superar la pobreza y afianzar la gobernabilidad democrática (OIT, 2006). En el mismo año, el gobierno argentino ${ }^{1}$ acuerda con el Sistema de Naciones Unidas incluir entre los Objetivos de Desarrollo del Milenio la promoción del TD para todos los habitantes del país (OIT, 2008). "La razón de escoger un objetivo tan vasto es que conviene que el enfoque abarque a todos.... El mundo de la globalización económica, con todas sus oportunidades y todos sus problemas, exige una comprensión también mundial de la importancia que reviste el TD y de las múltiples exigencias que entraña éste en las esferas económica, política y social. Reconocer esa necesidad universal es ya de por sí un comienzo esperanzador" (Sen, 1999, p.9).

El déficit de TD no es un problema que concierne solamente a la economía informal sino que también es común en algunos sectores de la economía formal. Además, el proceso de informalización del sector formal ${ }^{2}$ que se ha observado en América Latina en los últimos años implica que dentro de éste último sector coexistan trabajadores que desarrollan actividades en puestos informales y formales. En Argentina, la tasa de informalidad en las grandes firmas se duplicó de 1980 a 2003. Actualmente, si bien el empleo informal en esas firmas disminuyó del 31\% a 18\% entre 2004 y 2009 , este porcentaje, aún resulta llamativo en firmas que se suponen más visibles y controlables por el gobierno. Además, el déficit de TD en las grandes firmas permaneció en niveles elevados desde 2004 al 2009- entre un 30\% a un 66\%, de los empleados en empresas de gran tamaño presentan déficit en alguna dimensión de trabajo decente. Por eso, se entiende que el conjunto de asalariados en unidades productivas formales sean el objetivo más inmediato de programas de inspección laboral (Perry et al., 2007). En este contexto, el presente plan de investigación se focaliza en examinar las implicancias de la adopción del concepto de TD en relación con la estructura del mercado laboral argentino, particularmente, con la hipótesis de segmentación del sector formal. Un mercado laboral segmentado implica la existencia de distintos sectores con características y condiciones de trabajo diferentes y escasa movilidad de los trabajadores entre los sectores. Todo esto, por supuesto, tiene consecuencias importantes en la calidad del empleo y también en la salud del tejido social puesto que un mercado de trabajo segmentado es un impedimento para una sociedad integrada y para la promoción del TD.

La importancia cada vez mayor que ha cobrado la economía informal sumada a la multiplicidad de sus consecuencias negativas son razones suficientes para que la promoción del TD sea un objetivo en cualquier sociedad. Desde esta nueva visión, el trabajo debe ser sinónimo de la dignidad esencial y respeto hacia todo hombre, de su libertad de elección, de la satisfacción de las necesidades de las familias, del consentimiento a que los trabajadores se organicen libremente y hagan oír su voz, capaz de asegurar una condición digna a los trabajadores que llegan a la jubilación y dejar espacio para reencontrarse adecuadamente con las propias raíces en el ámbito personal, familiar y espiritual. Las

\footnotetext{
${ }^{1}$ El artículo 7 de la ley de ordenamiento laboral 25877 introduce el concepto de TD al prever que el Ministerio de Trabajo y Seguridad Social promoverá la inclusión del concepto de TD en las políticas públicas.

"Así como el término "sector informal" no fue eliminado por el de "economía informal", el término "sector formal" es igualmente válido para hacer referencia a todas las empresas formales. En general, el término "sector" es utilizado a efectos estadísticos, para agrupar, dentro de un mismo análisis, a empresas que comparten ciertas características comunes en términos de objetivos económicos, funciones y comportamiento, como en el caso de este estudio (OIT, 2002). Por lo tanto, se puede utilizar el término "sector formal" o "sector informal" para analizar un determinado "segmento" de la economía informal. Sin embargo, sería erróneo considerar que la economía informal se compone de un único "sector": el informal.
} 
numerosas desventajas asociadas al empleo en la economía informal impiden que ese trabajo sea calificado como decente.

Esta investigación está organizada de la siguiente manera. En la próxima sección se enuncian las principales teorías del mercado laboral referidas a la naturaleza del empleo informal y se realiza una breve revisión de la literatura relacionada al tema. A continuación, se describen los datos utilizados y algunas definiciones relevantes para el estudio de la informalidad laboral analizada desde la perspectiva del TD. Luego, se describen los métodos implementados para cumplir con el objetivo propuesto y obtener los principales resultados que se presentan y analizan a continuación. Finalmente, se formulan las principales conclusiones de la investigación.

\section{Antecedentes y contribución}

En la literatura existen varias teorías sobre el mercado laboral que explican la naturaleza del denominado "sector informal". Una de ellas es la teoría o hipótesis de la segmentación que concibe al mercado de trabajo como un conjunto de (valga la redundancia) segmentos, antes que como un agregado homogéneo. Los pilares teóricos que dieron origen a las corrientes de mercado de trabajo segmentado se sustentan en los trabajos desarrollados por Kerr (1954) y Doeringer y Piore (1971) quienes presentaron el primer modelo de mercado de trabajo dual. Para sus primeros proponentes, en la estructura dual del mercado de trabajo es posible identificar dos grandes sectores, el primario y el secundario, entre los cuales existen importantes diferencias estructurales que implican mecanismos de determinación salariales distintos. Esta propuesta dio lugar a las teorías segmentalistas que comparten un mismo supuesto: no existe un solo mercado sino varios.

Según Doeringer y Piore (1971) las características duales del mercado laboral se originan por la existencia de mercados laborales internos y externos. En los mercados laborales internos la asignación del trabajo y del salario junto con las rigideces y el racionamiento del empleo están gobernadas por un conjunto de reglas y procedimientos distintos a los de la teoría económica convencional. Estos mercados operan dentro de grandes firmas que se caracterizan por entrenar a su fuerza de trabajo, ofrecer mejores condiciones de empleo y protegerse del mercado labor externo. Esto implica que los trabajadores empleados en ese mercado no siempre tienen libre acceso a los mercados laborales internos debido a que en este primer submercado se concentran grupos de trabajadores entrenados para una profesión específica.

En esta primera visión se ubican las teorías de mercado de trabajo dual que prevalecieron en la literatura del desarrollo económico desde el estudio seminal de Lewis (1954). Según estas teorías, el sector urbano industrializado coexiste con áreas rurales desventajadas en economías poco desarrolladas. Para muchos trabajadores provenientes de esas áreas, existe racionamiento de trabajo en el sector moderno de la economía pues los salarios están establecidos por encima de los precios que limpian el mercado a causa de razones institucionales o de salarios de eficiencia. Conforme con esta visión, el empleo formal urbano atrae a trabajadores que se desplazan desde el sector tradicional al sector moderno en búsqueda de mejores condiciones salariales (Harris y Todaro, 1970). Sin embargo, para aquellos que migraron pero no encontraron empleo en las áreas urbanas, el sector informal urbano se presenta como una alternativa de último recurso, una opción de las estrategias de generación de ingreso de las que dispone el trabajador. Esto puede implicar que el trabajador termine aceptando condiciones inferiores a las predominantes en el sector formal (Fields, 1975).

Otro de los estudios seminales es el del antropólogo Hart que fue el primero en utilizar el término "sector informal urbano" en 1970. En su artículo sobre el empleo urbano en Ghana, Hart (1973) afirma que el sector moderno de la economía está constituido por empresas que funcionan con algún grado de burocracia, mientras que aquellas que no lo hacen son incluidas dentro del "sector urbano de baja productividad" o el "sector urbano tradicional". El autor menciona dos visiones enfrentadas sobre el sector informal. La primera considera que la dominación capitalista extranjera de las economías subdesarrolladas determina el alcance del desarrollo del sector informal o formal condenando a la mayoría de la población urbana a la privación y explotación. La segunda visión más optimista, afirma que las actividades informales son oportunidades de empleo conseguidas por el esfuerzo autónomo de las economías subdesarrolladas. El autor advierte que antes de adoptar algunas de esas visiones es necesaria una mayor investigación empírica.

El estudio de Hart de 1970 inspiró el informe de la Oficina Internacional del Trabajo (OIT) sobre Kenia en 1972. Según este informe el sector no estructurado o sector informal está conformado por trabajadores pobres que desarrollan actividades no reguladas por las autoridades públicas y que perciben insuficientes ingresos por su reducida productividad. Tokman (2001) señala que el aporte conceptual del mencionado informe de la OIT consistió en llamar la atención sobre el problema de empleo en los países en desarrollo, que en ese momento no era tanto el de la desocupación sino los 
insuficientes ingresos que recibían algunos ocupados. Según el autor, a partir del informe sobre Kenya se desarrollaron en América Latina una serie de contribuciones que visualizaban la informalidad desde una doble perspectiva. La primera considera que el sector informal es el resultado del excedente de mano de obra que no puede acceder a buenos empleos en los sectores modernos mientras que la segunda, es la de descentralización productiva desarrollada por Portes, Castells y Benton (1989). Conforme con esta visión, el sector informal es resultado de la descongestión de los procesos de producción y del trabajo que da lugar a la subcontratación de mano de obra y de productos y genera mayores posibilidades de evasión de las obligaciones laborales.

Otra de las teorías que explican la naturaleza del sector informal es la denominada teoría o hipótesis de la ventaja comparativa que considera el empleo informal como resultado de una elección voluntaria de los trabajadores basada en la maximización del ingreso o la utilidad (Maloney, 1999, 2004; Bosch y Maloney, 2006; Patrap y Quintín, 2001, 2006). En línea con esta hipótesis se encuentra el trabajo seminal de Roy (1951) que propone la existencia de múltiples sectores a los que los trabajadores se asignan acorde a sus ventajas comparativas. Por lo tanto, para esta segunda teoría el sector informal es elegido voluntariamente por los trabajadores al ponderar los costos privados y los beneficios de operar informalmente. Desde esta visión, Maloney (1999) desarrolla el primer estudio de transiciones entre sectores utilizando datos de panel para México. Uno de los resultados más importantes hallados por este autor es que los patrones de movilidad obtenidos señalan una pequeña evidencia a favor de la visión dualística pero, según el autor, no sugieren que el mercado laboral de México sea rígido o esté segmentado conforme con la división entre sector formal e informal. En un trabajo más reciente, Bosch y Maloney (2006) estudian también la dinámica del mercado laboral mexicano, analizando la movilidad de los trabajadores entre el sector formal e informal. Los patrones de transición encontrados no se corresponden con la idea tradicional del sector informal como un sector inferior del mercado laboral segmentado.

Las teorías más recientes sobre mercados laborales urbanos en los países en desarrollo combinan los puntos de vista polares de los mercados laborales competitivos y segmentados. Estas teorías enfatizan en la existencia de dos segmentos en el sector informal, uno que representa la parte competitiva en la que los trabajadores se encuentran voluntariamente y otro que recibe a los individuos expulsados del sector formal (Fields, 2004; Günther y Launov, 2007, entre otros).

En la Argentina son varios los trabajos que abordan el tema de la segmentación del mercado laboral. En su trabajo empírico, Patrap y Quintín (2003) evalúan la hipótesis que los trabajadores informales esperan altos salarios en el sector formal. Mediante la utilización de un test paramétrico encuentran que el premium salarial del sector formal permanece aun controlando por características individuales y del establecimiento, mientras que, los resultados obtenidos con métodos semiparámetricos sugieren que no existen diferencias significativas en las medidas de satisfacción laboral entre los dos sectores. Esto implicaría que la hipótesis de mercados laborales competitivos en Argentina no puede ser rechazada cuando se considera que los trabajadores informales se encuentran típicamente mejor fuera de ocupaciones formales y se utilizan proxies, como la búsqueda de otro empleo adicional al existente y la disposición a trabajar más horas, para comparar las dimensiones no pecuniarias asociadas con las condiciones de trabajo.

Desde una perspectiva opuesta a la anterior, Beccaria et al. (2006) consideran que la informalidad y la pobreza son manifestaciones de un mercado de trabajo que no genera los suficientes puestos de calidad en un contexto de insuficientes políticas y acumulación de capital. El principal objetivo de este estudio es analizar, para el período 1993-2005, la existencia de un diferencial salarial asociado a la informalidad y su efecto sobre la pobreza en la Argentina. Para explorar la hipótesis de segmentación del mercado de trabajo, Beccaria et al. (2006) estiman brechas individuales de ingreso que permitan responder en qué medida la informalidad constituye una fuente de bajos ingresos adicional a los factores tradicionalmente considerados en la determinación de las remuneraciones. Los resultados demuestran que la penalización promedio de la informalidad se ha incrementado desde 1993 y que, si se eliminan estas brechas, la incidencia de la pobreza se reduciría en un tercio en 2005 . Además, la intensidad del diferencial de remuneraciones asociado a la informalidad, sugiere la presencia de segmentación en el mercado laboral argentino.

En la misma línea, se encuentra el trabajo de Waisgrais (2001) que intenta confirmar, a partir de un estudio dinámico, la hipótesis que la dicotomía economía formal-informal es parte de un proceso de segmentación en el mercado laboral argentino. Con este objetivo, el autor examina si el sector de empleos formales con buenas condiciones laborales no es accesible para aquellos trabajadores que desarrollan sus actividades en la economía informal. Los resultados obtenidos a partir de las matrices de transición convalidan parcialmente la hipótesis de segmentación del mercado laboral en Argentina porque los movimientos desde la economía informal hacia la formal son muy limitados en términos de probabilidades. 
Arias y Escudero (2007) examinaron la relación entre informalidad laboral, ingresos relativos entre formales e informales y desempleo. Siguiendo una cohorte de individuos a lo largo de tres décadas, 1985-2003, se construyeron pseudo paneles para el GBA a partir de los datos de la Encuesta Permanente de Hogares (EPH). Estos datos permiten implementar el método Panel VAR en el análisis empírico. El estudio muestra evidencia a favor de la visión de la exclusión o de segmentación cuando las unidades de observación son los asalariados informales. Por lo tanto, los resultados son consistentes con la idea que esos trabajadores son empujados hacia la informalidad no por una elección individual sino más bien por las decisiones de la firma y las pérdidas de oportunidades de empleo que se presentan cuando los niveles de desocupación son elevados. Aunque la hipótesis voluntaria parece cumplirse para la mayoría de los independientes existe un grupo minoritario de ellos que a pesar de aspirar a un puesto asalariado formal son expulsados hacia el trabajo autónomo por los movimientos contracíclicos de la economía.

En su estudio empírico, Alzúa (2008) asume que el mercado laboral argentino se ha comportado diferente a lo largo del período 1975-2001 en el GBA, siendo competitivo durante 1975-1991 y dual a partir de 1992. Para probar la hipótesis de mercado dual estima junto con dos ecuaciones salariales: una para el sector primario y otra para el secundario, un endogenous switching model con régimen desconocido para los periodos 1970-1990 y 1991-2000. Además, para explorar si existen barreras a la entrada a puestos de trabajo en el sector primario, realiza un test de racionamiento mediante una regla de asignación que indica que los trabajadores se emplean en el sector que maximiza su utilidad. Los resultados encontrados aportan evidencia de dualismo en el mercado laboral argentino para ambos períodos considerados y la hipótesis de libre elección al sector deseado por parte del trabajador es rechazada.

Finalmente, Arias y Khamis (2008) examinan cómo afecta un mercado laboral competitivo y segmentado la elección de participación y los ingresos de los trabajadores formales e informales. A partir de datos provenientes de la EPH y del Módulo de informalidad diseñado en el cuarto trimestre de 2005 para el GBA, emplea algunos modelos econométricos de efectos tratamiento marginales y encuentra que los resultados son consistentes tanto con la hipótesis de ventaja comparativa, cuando se observan las diferencias de ingreso ente los empleados formales y los trabajadores independientes, como con las consideraciones de segmentación cuando se consideran a los asalariados informales.

Todas las teorías y los estudios empíricos previamente enunciados, consideran que el sector formal es homogéneo. Sin embargo, indagar la existencia de una estructura segmentada en el mercado laboral, particularmente del sector formal tiene particular importancia para la comprensión de la naturaleza de la informalidad así como para la formulación de políticas públicas. Otro aspecto novedoso de la presente investigación es la incorporación de la perspectiva del TD en el estudio de la informalidad y de la estructura del mercado laboral argentino. Este concepto relativamente reciente tiene validez universal.

\section{Datos y definiciones}

\subsection{Datos}

El análisis empírico de esta investigación se basa en los microdatos para el área urbana de la Argentina provenientes de la Encuesta Permanente de Hogares (EPH) conducida por el Instituto Nacional de Estadística y Censos (INDEC) desde 1973.

En su modalidad original, esta encuesta se realizaba bajo una metodología puntual relevando información dos veces al año, en mayo y octubre. Pero, desde el 2003, el INDEC encaró un proceso de reformulación integral de la EPH que incluyó el cambio de la modalidad puntual a la continua. Bajo este nuevo esquema, los hogares son entrevistados a lo largo del año e ingresan en la muestra por dos trimestres consecutivos, se retiran durante el mismo tiempo y luego, regresan durante otros dos trimestres consecutivos. De esta forma, existe un $50 \%$ de muestra común entre un trimestre y el siguiente así como entre un trimestre y el mismo del año siguiente. Con este nuevo esquema, un hogar puede ser observado a lo largo de un año y medio como en el caso de la EPH puntual.

Por lo tanto, teniendo en cuenta estas características y los fines de la presente investigación se construyeron tres paneles rotativos anuales para obtener el mayor número de observaciones posibles de las unidades de análisis del estudio, utilizando los datos obtenidos del cuarto trimestre de la EPH continua para el período 2004-2009.

El período elegido para el análisis permite explorar el comportamiento relativamente reciente del mercado laboral y de la economía informal, particularmente del trabajo asalariado en el sector formal 
durante el lapso de tiempo en que la economía argentina supera la crisis económica del 2001/2002 y se encamina en un sendero de recuperación posterior.

La construcción de cada panel requirió un ordenamiento de variables conforme con el código de matching necesario para identificar a un individuo en función de los códigos que identifican la vivienda dentro del aglomerado, el hogar y el número de componente dentro del hogar. Asimismo, para asegurar que los datos enlazados se refieran a la misma persona, se verificó la consistencia en cada panel. Como resultado, se eliminaron las observaciones inconsistentes en variables relacionadas con el género y la edad.

Un problema común en todo panel es el sesgo potencial por desgranamiento o attrition que produce una diferencia entre la proporción efectiva de hogares y personas que se reentrevista y el porcentaje teórico que se espera encontrar luego de realizar el matching de datos - $50 \%$-. En los tres paneles construidos la tasa de desgranamiento muestral de las unidades de análisis en ningún caso supera los $9 \%$. Como la attrition fue modesta en cada panel, se supone que sus efectos en las estimaciones no son suficientemente serios como para justificar la aplicación de procedimientos correctivos al posible sesgo que este desgranamiento causaría en los resultados estimados.

Conforme con el Cuadro A1, las unidades de análisis de esta investigación, los asalariados del sector formal, sobre los cuales se concentra el análisis empírico de esta investigación ${ }^{3}$ suman un total de 7043 ocupados en el 2004; 3373, en el 2005; 11095, en el 2006; 4830, en el 2007; 11036, en el 2008 y 4722 , en el 2009 y representan a 23434149, 8952489, 24039574, 8482452, 24510898 y 9026171 de asalariados en la Argentina, respectivamente. En cada uno de los paneles considerados, los empleados en empresas formales constituyen más del $58 \%$ del total de asalariados y superan el $66 \%$ del total de trabajadores en una unidad productiva. Por lo tanto, las conclusiones derivadas a partir de los resultados obtenidos incumben a la mayor parte de los asalariados durante todo el período bajo análisis. En el Cuadro A2 se presentan las definiciones y los valores medios de las principales variables usadas en esta investigación ${ }^{4}$.

\subsection{Definiciones de informalidad}

El concepto de informalidad ha dado lugar a muchas discusiones, tanto teóricas como empíricas. En general, la informalidad laboral es definida desde dos perspectivas que a pesar de considerar distintos aspectos del mercado laboral son complementarias: la productiva y la legal. Una de ellas es la definición "productiva" que califica como trabajadores informales al conjunto de ocupados pertenecientes a una clase desventajada y marginal, de baja productividad y calificación, empleados en firmas de pequeña escala o en actividades basadas en la familia con tecnologías poco productivas. Esta definición ha sido tradicionalmente empleada por la OIT y por autores como Marcoullier et al. (1997), Monza (2000), Galli y Kucera (2004), entre otros. Por otra parte, la definición "legal" considera informales a los trabajadores que no disfrutan de los beneficios que otorga el cumplimiento de las reglas laborales. Esta noción de informalidad está relacionada con la falta de protección laboral y beneficios de seguridad social y está más centrada en el bienestar del trabajador en sí mismo (o quizás en la calidad del trabajo) que en la naturaleza de su empleo. Además, la visión legal de la informalidad es consistente con el enfoque más reciente adoptado por la OIT (2002) sobre trabajo decente y economía informal que asocia esta segunda visión con el incumplimiento por parte de los empresarios o de los trabajadores, de todas o algunas de las reglas o regulaciones del cuerpo de legislación nacional, local, comercial y/o de la legislación laboral. Este nuevo enfoque permite expandir la definición productiva e incluir arreglos contractuales informales en empresas formales.

Teniendo en cuenta las limitaciones de la EPH y los objetivos del estudio, se utilizaron tanto la definición productiva como la legal para operacionalizar el concepto de trabajador y de empresa informal. En lo que respecta al conjunto de trabajadores, se distingue, en primer lugar, a los asalariados informales en firmas de cualquier tamaño de los trabajadores independientes 0 autoempleados informales ${ }^{5}$ a partir de distintos criterios que se describen a continuación, ya que esta división es central para el análisis (OIT, 2002). En cuanto al primer grupo de trabajadores, la noción de asalariado informal adoptada está en línea con la denominada definición legal. Por lo tanto, se califica a un asalariado como informal si no está registrado. Dada la información disponible en la EPH,

\footnotetext{
${ }^{3}$ El estudio empírico de la hipótesis de segmentación en esta investigación requiere dos niveles de análisis: el correspondiente a los empleados y el de las empresas. Por lo tanto, no se incluyen a los trabajadores independientes porque no es posible clasificarlos como mano de obra contratada trabajando dentro de empresas.

4 Para el cómputo de todas las estimaciones realizadas se utilizaron las ponderaciones correspondientes al período base de cada panel porque los hogares son seleccionados o ingresan a la muestra en función de la población de ese período. Los resultados son relativamente similares cuando se ponderan las estimaciones con la ponderación correspondiente al período final del panel.

${ }^{5}$ Los trabajadores independientes son incluidos en el análisis empírico de esta investigación con el objetivo de examinar los movimientos de las principales unidades de análisis del estudio, los asalariados del sector formal, hacia otras categorías o estados ocupacionales. Para más detalles ver sección 4.1 y 5.1 .
} 
se considera que un asalariado no está registrado cuando no tiene descuentos jubilatorios. Una vasta literatura emplea esta definición (Beccaria y Groisman, 2007; Arias y Escudero, 2007; Gasparini y Tornarolli, 2007; Arias y Khamis, 2008; Gasparini et al. 2007; Galiani y Weinschelbaum, 2007; entre otros) pues tiene implicancias importantes para el bienestar del individuo y sus familias. Además, como se mencionó anteriormente, la visión legal admite que existan empleados informales aún en empresas formales que son las principales unidades de análisis conforme con el objetivo de este estudio. Al mismo tiempo, Gasparini y Tornarolli (2007) consideran que el estudio de la informalidad es más interesante desde el punto de vista legal y más relevante para la formulación de diversas políticas públicas. En relación a esto, Perry et al. (2007) señala la necesidad de implementar un conjunto de medidas para una protección social más eficaz de los ciudadanos de gran parte de América Latina y el Caribe, que favorezca a los trabajadores, les brinde incentivos a la formalidad y se coordine con otros objetivos de política socioeconómica.

Por su parte, los trabajadores independientes son altamente heterogéneos pues abarca desde patrones en grandes y pequeñas empresas hasta trabajadores por cuenta propia con inserciones socio-ocupacionales tan dispares como las profesionales junto con pequeños comerciantes, albañiles y vendedores ambulantes (MTEySS-OIT, 2007). Esta gran diversidad se traduce en una muy desigual distribución de ingresos, riesgos y vulnerabilidad que fundamenta la necesidad de un análisis que distinga dentro de este grupo a los cuenta propias de los patrones. Las limitaciones informativas de la EPH no permiten operacionalizar la noción de informalidad aplicada al trabajo independiente desde el punto de vista legal. En particular, la encuesta no indaga sobre los aportes al sistema de seguridad de los autónomos. Por lo tanto, debió recurrirse a la denominada visión productiva. Sin embargo, su implementación empírica es muy difícil puesto que, como señalan Gasparini y Tornarolli (2007), no existe información sobre dotación de capital en las encuestas, las nociones como "productividad" son inobservables y otras como "actividades marginales" son difíciles de definir. La definición operativa implementada está asociada con el grado de calificación de la tarea y el tipo de unidad económica (sector público o privado, tamaño de la firma), por lo que se considera como informales a los trabajadores independientes no profesionales que trabajan en establecimientos no públicos de menos de seis personas (Beccaria y Groisman, 2007; Gasparini, 2000; Monza, 2000 y Maloney, 1999). Este criterio está en línea con el propuesto por la OIT en sus primeros estudios sobre economía informal ${ }^{6}$. Naturalmente, esta es una aproximación muy rudimentaria, justificada únicamente por la falta de información. Un argumento subyacente a esta última definición radica en aislar al conjunto de profesionales, entre otras cuestiones, porque sus remuneraciones pueden ser elevadas y estar por encima de la media. Además, como mencionan Gasparini y Tornarolli (2007) este grupo de trabajadores suelen ser altamente productivos y estar plenamente incorporados en la economía moderna. Sin embargo, estos trabajadores pueden no cumplir con las regulaciones para el desarrollo de sus actividades y, aunque el subregistro tributario, laboral o la evasión voluntaria pueden implicar ingresos medios o altos, también puede estar asociado a situaciones de inestabilidad (Waisgrais y Sarabia, 2008). Por otro lado, el supuesto básico para considerar el tamaño de la unidad productiva es que la mayor parte de las actividades definidas como informales son desarrolladas por empresas pequeñas, debido a su menor visibilidad, su mayor flexibilidad y mejores posibilidades de eludir los controles gubernamentales. Se supone que las empresas más grandes son más vulnerables a las regulaciones estatales y menos propensas a correr el riesgo de penalizaciones. Por lo tanto, es menos probable que se aboquen directamente a las actividades informales, aunque siempre pueden subcontratar a empresas más pequeñas que operan informalmente (Bergesio et al., 2007).

Por otro lado, conforme con la práctica usual, los patrones se incluyeron dentro del grupo de trabajadores formales mientras que los trabajadores sin remuneración fueron considerados como parte de la economía informal. Además, los patrones se caracterizan por la disponibilidad de capital y por ingresos más altos en relación con los cuenta propias mientras que los trabajadores sin salarios suelen tener empleos sin vínculos laborales formalizados y con menor grado de protección laboral y social.

Las definiciones de inactividad y desocupación empleadas en este estudio corresponden a las adoptadas por la EPH, en su modalidad continua, que considera inactivos a los individuos que no trabajaron ni buscaron trabajo en el mes previo a la realización de la encuesta y desocupados a quienes no trabajaron pero estuvieron buscando trabajo en el mes de referencia (INDEC, 2003).

En síntesis, las categorías o estados ocupacionales que se consideran en el análisis empírico son las siguientes:

\footnotetext{
${ }^{6}$ La $15^{\text {a }}$ Conferencia de Estadísticos del Trabajo en 1993 definió el sector informal en términos de las características de las unidades de producción en que tenían lugar las actividades e introdujo el tamaño de la empresa, medido por el número de trabajadores, como uno de los criterios definitorios de la informalidad. Sin embargo, como señala Hussmanns (2004), esta definición de sector informal debe ser complementada con la de empleo informal.
} 
- Desocupados

- Inactivos

- Asalariados registrados (AR)

- Asalariados no registrados (ANR)

- Trabajadores por cuenta propias informales (CPI)

- Trabajadores por cuenta propias formales (CPF)

- Patrones

- Asalariados registrados que trabajan en hogares (ARH)

- Asalariados no registrados que trabajan en hogares (ANRH)

- Trabajadores familiares sin remuneración (TFSR)

Ahora bien, una comprensión adecuada de la informalidad requiere de un análisis que no sólo se concentre en el trabajador, sino también en la unidad productiva. De esta manera se tiene en cuenta la economía informal tanto del lado de la oferta como de la demanda. En línea con la definición productiva de informalidad y siguiendo una práctica estándar ${ }^{7}$, las nociones de empresas formales (EF) e informales (EI) se construyeron teniendo en cuenta el tamaño del establecimiento definido a partir del número de empleados ${ }^{8}$ y del tipo de empresa (pública o privada). Específicamente, se consideraron como informales a las firmas no públicas con menos de 6 empleados. El supuesto implícito para considerar el tamaño de la unidad productiva previamente mencionado en la definición operativa de autónomos informales, se aplica también aquí. Esto es, la informalidad probablemente aumenta a medida que disminuye el tamaño de la firma y su productividad. En efecto, según Perry et al. (2007), el cumplimiento de algunos aspectos de la legislación laboral tiende a mejorar con el tamaño de la empresa, su longevidad y con la productividad laboral. Las unidades productivas de pequeño tamaño casi nunca están registradas ni figuran en las estadísticas oficiales, suelen tener poco o ningún acceso a los mercados organizados y a las instituciones de crédito, además de que no están reconocidas, ni reglamentadas por el estado y son menos susceptibles de ser detectadas por los inspectores. Además, la formalidad para las pequeñas empresas suele considerarse un insumo costoso y difícil de adquirir por los trámites y operaciones administrativas. Pero no todas las empresas pequeñas realizan actividades informales ni todas las firmas grandes se desempeñan en la economía formal. Esto último sugiere una posible sobreestimación del sector formal e informal. Sin embargo, se espera que este sesgo sea pequeño e irrelevante dada las razones previamente mencionadas. Además, es lógico esperar una alta correlación entre el incumplimiento de las normas y regulaciones administrativas, laborales y contables por parte de la unidad productiva ${ }^{9}$ y su tamaño usado como proxy de la productividad -. Para evaluar empíricamente esta correlación se utilizaron los datos del Módulo de Informalidad relevado conjuntamente con la EPH en el 2005 para el GBA.

Cuadro 1

Correlación entre la definición productiva y legal de empresa informal

\begin{tabular}{|c|c|c|c|c|c|c|c|}
\hline Definición legal & \multicolumn{2}{|c|}{ Definición productiva } & Total & Definición legal & \multicolumn{2}{|c|}{ Definición productiva } & Total \\
\hline & Empresa informal & Empresa formal & & & Empresa informal & Empresa formal & \\
\hline Empresa informal & 75.18 & 24.82 & 100 & Empresa informal & 28.49 & 2.53 & 8.03 \\
\hline Empresa formal & 16.46 & 83.54 & 100 & Empresa formal & 71.51 & 97.47 & 91.97 \\
\hline Total & 21.17 & 78.83 & 100 & Total & 100 & 100 & 100 \\
\hline \multicolumn{2}{|c|}{ Test de Pearson } & $\begin{array}{c}267.90 \\
(0.00) \\
\end{array}$ & & & \multicolumn{2}{|c|}{ Spearman's rho } & $\begin{array}{c}0.39 \\
(0.00) \\
\end{array}$ \\
\hline
\end{tabular}

Nota: entre paréntesis se reportan los $p$-value.

Fuente: Elaboración propia en base a Módulo de Informalidad - EPH (INDEC).

Conforme con los resultados reportados en el Cuadro 1, de la totalidad de empresas calificadas como formales desde el punto de vista productivo, el $97.5 \%$, también resultaron empresas definidas como formales desde el punto de vista legal. Asimismo, del $100 \%$ de empresas que son formales considerando la noción legal de informalidad, el 83.54\% resultaron firmas formales desde la visión productiva. Además, los resultados del test de Pearson permiten rechazar la hipótesis nula de independencia de la definición legal con relación a la noción productiva. En síntesis, la evidencia

\footnotetext{
${ }^{7}$ Ver, por ejemplo, Decimoquinta Conferencia Internacional de Estadísticos del Trabajo en 1993 (15th CIET).

${ }^{8}$ Cabe aclarar que cuando las empresas se definen como informales basándose únicamente en el criterio del tamaño pueden aparecer categorías ocupacionales como la de los empleados que trabajan en empresas informales pero ocupan puestos formales. Para más detalles véase OIT (2002).

9 El módulo de Informalidad de la EPH considera, con fines operativos, que una unidad productiva es informal cuando no emite facturas y/o tickets, no lleva registros contables y no tienen ningún empleado registrado.
} 
presentada en el cuadro 1 muestra una elevada correlación entre la definición de unidad productiva informal implementada en este estudio y la asociada con la visión legal.

La matriz del Cuadro 2 resume gráficamente el marco conceptual para la economía informal implementado en esta investigación, siguiendo el propuesto por el Informe VI de la OIT (2002) y el Hussmanns (2004).

Cuadro 2

Matriz: un marco conceptual para la economía informal

\begin{tabular}{|c|c|c|c|c|c|c|}
\hline \multirow{2}{*}{$\begin{array}{c}\text { Unidades de } \\
\text { producción por } \\
\text { tipo }\end{array}$} & \multicolumn{2}{|c|}{ Cuenta propias } & \multirow{2}{*}{$\begin{array}{c}\text { Patrones } \\
\text { Formal }\end{array}$} & \multirow{2}{*}{$\begin{array}{c}\begin{array}{c}\text { Trab. fam. sin } \\
\text { rem. }\end{array} \\
\text { Informal }\end{array}$} & \multicolumn{2}{|c|}{ Asalariados } \\
\hline & Informal & Formal & & & Informal & Formal \\
\hline $\begin{array}{l}\text { Empresas del } \\
\text { sector formal }\end{array}$ & & & 4 & 1 & 2 & \\
\hline $\begin{array}{c}\text { Empresas del } \\
\text { sector informal }\end{array}$ & 3 & & & 5 & 6 & 7 \\
\hline Hogares & 8 & & & & 9 & \\
\hline
\end{tabular}

\subsection{La perspectiva de trabajo decente y la economía informal}

El trabajo como actividad puede desarrollar sentido de servicio, justicia e integridad o, por el contrario, puede deteriorar al trabajador si no encuentra en aquél un medio que dignifique su condición humana, lo integre en la vida social y contribuya al bien de la comunidad. Por ello, en esta investigación la calidad de la inserción laboral de los trabajadores, particularmente de quienes se encuentran en la economía informal, es analizada no sólo desde su condición de no registración sino desde el enfoque más amplia de trabajo decente. Este concepto, integrador, multidimensional y dinámico, comprende diversos objetivos, valores y políticas, a la vez que evoluciona con el progreso social y económico de un país (Uriarte, 2000). La noción de TD se estructura en torno a cuatro dimensiones u objetivos estratégicos: la promoción del empleo; el respeto de los derechos fundamentales en el trabajo; la extensión de la seguridad laboral y la protección social; y el fortalecimiento de la representación y el diálogo social. Cualquiera de ellas encierra un alto contenido ético: promover un TD supone la adopción clara de una posición valorativa íntimamente relacionada con la dignidad y la calidad de vida de los seres humanos (Somavia, 2000). El paradigma de TD requiere dos niveles de análisis: el primero evalúa la existencia de suficientes oportunidades de trabajo para las personas que buscan y desean trabajar, mientras que el segundo, analiza que esas oportunidades se ajusten a criterios normativos particularmente relacionados con leyes estándares de trabajo (Salvia y Lepore, 2008).

La operacionalización del concepto de TD está sujeta a los datos que ofrece la EPH. La información proveniente de la encuesta no es suficiente para incluir empíricamente el vasto conjunto de aspectos que integra la noción de TD. Sin embargo, dado el objetivo principal del estudio, la EPH es la fuente de datos disponible en nuestro país más pertinente hasta el momento.

En el primer nivel de análisis del paradigma de TD se incluye la dimensión "promoción del empleo"10 que abarca una noción más amplia del lugar que le corresponde al trabajo en la vida del hombre. Una mayor calidad de empleo no implica meramente un salario adecuado y justo, sino también la creación y persistencia de oportunidades apropiadas para realizar una labor productiva bajo condiciones de libertad y equidad, que otorgue un sustento de vida digno y posibilite el desarrollo personal de las capacidades y funcionamientos individuales. A su vez, el acceso a un empleo de calidad y cantidad suficiente, no se reduce, desde la perspectiva del TD, a que la decisión de trabajar sea voluntaria y acorde a la edad mínima legal de ingreso al mercado laboral sino que involucra el cumplimiento de tres aspectos igualmente importantes relacionados con la posibilidad de: 1) realizar una actividad productiva en el sistema económico formal, 2) obtener, a través de ella, autonomía económica en términos de satisfacción de necesidades individuales y familiares y 3) conseguir un grado aceptable de satisfacción personal y reconocimiento social. En esta dimensión, se pretende

\footnotetext{
${ }^{10}$ Se implementaron diferentes criterios de operacionalización para esta dimensión obteniendo resultados econométricos similares.
} 
examinar la calidad del trabajo desde las condiciones objetivas del empleo de buena calidad (acceso a buenos salarios, horas trabajadas dignas y justas, estabilidad de la relación laboral, etc.) así como desde las apreciaciones subjetivas con respecto a la satisfacción con el empleo.

El primer aspecto es un elemento esencial en el concepto de TD. La existencia de oportunidades de empleo para todas las personas que buscan trabajo y están dispuestas a trabajar permite identificar posibles discrepancias en las condiciones que enfrentan los individuos a la hora de obtener y mantener un empleo, acceder a recursos y participar en la vida económica y social. Mejorar la empleabilidad implica, entonces, centrar la atención en el trabajador condicionado por procesos que ocurren a nivel normativo, económico y cultural así como por factores de carácter personal que se articulan con contextos de vida concretos.

Para definir operativamente el déficit de oportunidades de empleo se utilizan un conjunto de variables asociadas con el grado de satisfacción personal con el trabajo, la extensión e intensidad de la jornada de trabajo y la estabilidad laboral. Dado que la encuesta no indaga directamente sobre la satisfacción personal del trabajador con su empleo se estudia este aspecto en relación con la jornada laboral. Así, se considera que un individuo se encuentra insatisfecho con su trabajo y tiene un jornada laboral no decente cuando trabajando menos de 48 horas, buscó trabajar más horas en la semana de referencia ${ }^{11}$ u otro empleo además del principal, independientemente si está o no disponible para hacerlo. Esta definición operativa intenta capturar la insatisfacción con el empleo por razones económicas o por tener un entorno laboral no decente. Por otra parte, también se considera que un individuo tiene una jornada laboral no decente cuando, conforme con la Ley № 11.544, es mayor a 48 horas semanales. La jornada laboral decente es considerada por la mayoría de los autores ${ }^{12}$ como un factor importante de este aspecto del TD, pues un individuo que trabaja una excesiva cantidad de horas puede ver perjudicada no sólo su salud física y mental, sino también, su vida familiar. Además, la cantidad de horas trabajadas puede reflejar, indirectamente, una remuneración injusta en un contexto de escasas oportunidades de empleo. Sin embargo, podrían existir personas que trabajan más de 48 horas por razones voluntarias tales como la ambición o la pasión por el trabajo pero la EPH no permite identificar a estos ocupados. Entonces, para excluir estos casos y bajo el supuesto de que el ocio es un bien normal, se considera que todas aquellas personas que trabajan una excesiva cantidad de horas, es decir, más de 48 y perciben un ingreso laboral mensual menor al salario mínimo vital y móvil vigente, tienen una jornada laboral no decente. El objetivo de esta definición operativa es intentar separar a los sobreocupados por razones voluntarias de aquellos que trabajan más de 48 horas por razones económicas o involuntarias ${ }^{13}$ relacionadas con percibir un ingreso menor al necesario para la subsistencia, o bien, con la propia naturaleza del trabajo, circunstancias excepcionales, o ciertas normas corporativas, etc ${ }^{14}$.

Finalmente, se define a un trabajo como inestable cuando tiene período de finalización. Sin embargo, podrían existir empleos que a pesar de tener un período de duración no calificarían como no decentes ya que, por ejemplo, puede tratarse de consultorías u otros servicios realizados por algunos trabajadores profesionales que probablemente tengan suficientes oportunidades de empleo dado su nivel educativo. Por esta razón, se incluyó en la definición anterior la calificación de la tarea, considerando como inestable aquella ocupación realizada por un no profesional que tiene un tiempo de finalización. Un trabajo decente debe ser estable, entre otras razones, porque incluye el cumplimiento de ciertas disposiciones institucionales que protegen a los trabajadores de quedar injustamente desempleados. La pérdida del empleo no sólo implica costos económicos más allá de la ausencia de una remuneración sino también estrés. Otras consecuencias negativas de un trabajo inestable es la interrupción del proceso de acumulación de capital humano específico junto con la pérdida de los beneficios laborales que podrían perjudicar no sólo al trabajador sino también a sus familias (Anker et al., 2002). La acumulación de capacidades relacionadas con la noción de capital humano y social ocupa un lugar central en la configuración de las oportunidades laborales pues son factores que definen las posibilidades de realización en el mundo del trabajo.

El segundo aspecto de la primera dimensión del TD es el acceso a una ocupación justamente remunerada que asegure condiciones de vida dignas para los trabajadores y sus familias. Obtener un salario decente es otro elemento de la calidad laboral y un derecho constitucionalmente reconocido. Salvia y Lepore (2008) consideran al ingreso laboral un "factor constitutivo del proceso de desarrollo humano y social, que encuentra en el logro de una adecuada inserción en el mercado laboral, un potente factor de defensa frente a la pobreza y un factor de inclusión social a través del despliegue de proyectos de vida con autonomía de agencia". Sin embargo, el valor específico que se identifique

\footnotetext{
11 La EPH indaga a los ocupados que trabajaron en la semana de referencia por el deseo de trabajar más horas en ese periodo mientras que la pregunta al total de ocupados se refiere a la búsqueda de más horas de trabajo en el mes previo a la entrevista.

12 Ver Anker et al.(2002), Bescond et al.(2003), OIT (2008), entre otros.

${ }^{13}$ LA EPH no permite capturar a los sobreocupados por razones involuntarias.

${ }^{14}$ Para más detalles ver Anker et al. (2002).
} 
como "retribución decente" varía según cada provincia y depende del nivel de desarrollo económico del país. Una alternativa es considerar que un trabajador recibe una remuneración adecuada cuando es igual o mayor al salario mínimo vital y móvil (SMVM) $)^{15}$ teniendo en cuenta las horas trabajadas. Para ello se consideró que un trabajador subocupado en forma involuntaria, sobreocupado ${ }^{16} \mathrm{u}$ ocupado pleno con un ingreso laboral menor al SMVM tiene una remuneración no decente. Las razones por la cual el SMVM es elegido, en la literatura de $\mathrm{TD}^{17}$, como umbral de una retribución justa son varias. Primero, aunque discutible, el salario mínimo se asocia a problemáticas como la informalidad, la pobreza, el desempleo y la distribución del ingreso. Segundo, hay quienes atribuyen al salario mínimo un efecto de regulación del mercado laboral o un efecto incentivo a trabajar cuando éste supera el monto de los subsidios o asistencia sociales (Camargo y García, 1992; Paz, 2009, Marshall y Perelman, 2006, entre otros). Tercero, el salario mínimo es un importante factor institucional por su impacto en el nivel global de salarios, en el desempleo y en la distribución del ingreso ${ }^{18}$. Además, el SMVM es una fuente potencial de reducción de la pobreza en los países en desarrollo y juega un rol central en las políticas del mercado laboral (Freeman, 1993; McLeod y Lustig, 1997). Así, Los policy makers tienen en cuenta los cambios ocurridos en el salario mínimo por los impactos que generan en los costos laborales y fiscales de las prestaciones. Finalmente, el SMVM puede ser un indicador de cuánto la economía valora el trabajo o qué tan justa es la sociedad para compensar a sus ocupados por tener ciertas habilidades. Por todo esto el SMVM es un factor determinante de las condiciones laborales de una economía.

El segundo nivel de análisis, que examina si las oportunidades de empleo se ajustan a criterios normativos relacionados con leyes estándares de trabajo, comprende la segunda y tercera dimensión concernientes al cumplimiento, en el ámbito laboral, de los derechos innatos de todo trabajador. Ambas dimensiones son aspectos importantes en la noción de TD que requiere eliminar las llamadas "zonas grises en el empleo". A pesar de que hay quienes argumentan que tener cualquier trabajo es mejor que no tener ninguno, el ejercicio de los derechos básicos en el trabajo o, de modo más general, el cumplimiento de los derechos humanos fundamentales no puede ser exigible sólo en algunos empleos. El concepto de TD trasciende el respeto de los principios y derechos fundamentales vigentes en la legislación nacional, pues abarca la esfera de los principios éticos que va más allá del reconocimiento jurídico. "El hecho de que la sociedad respalde dichos derechos se puede entender como una invitación a que el Estado se ponga a la altura de la ética social" (Sen, 1999, p.4).

El enfoque legal del concepto de trabajo decente enfatiza en el respeto y cumplimiento de los derechos establecidos en los estándares laborales internacionales que forman la base de la declaración de los principios y derechos fundamentales del trabajo. A diferencia de las normas y leyes laborales de cada país que generalmente son exigibles sólo a los trabajadores y empresas de la economía formal, los derechos establecidos por las leyes laborales internacionales y sus convenios son aplicables a todos los trabajadores. El déficit de derechos se produce en los planos nacional y local, y puede detectarse según el modo en que se materializan, aplican y exigen los derechos a través de las leyes y las prácticas nacionales y locales. La noción de TD incluye en esta dimensión el derecho a la igualdad de oportunidades y tratamiento, la eliminación del trabajo forzoso y del trabajo infantil, las posibilidades de entrenamiento, la seguridad laboral y la salud del trabajador, la protección a la maternidad, entre otros. Con la limitada información disponible en la EPH se operacionaliza la segunda dimensión de TD - "respeto de los derechos fundamentales en el trabajo"- considerando el acceso por parte de los trabajadores a días pagos por enfermedad, vacaciones pagas y la percepción de aguinaldo. Muchas veces es crucial para el cumplimiento de los derechos laborales que exista una legislación laboral efectiva y adecuada y un gobierno capaz de exigir su implementación de forma práctica y eficaz.

Los más perjudicados por las desventajas en términos de déficit en derechos son también probablemente los más perjudicados en términos de déficit en protección social. Las condiciones de trabajo con seguridad laboral preservan y promueven la integridad física y psicológica del trabajador

\footnotetext{
${ }^{15}$ La información relativa al salario mínimo vital y móvil vigente en cada una de los trimestres considerados en este estudio proviene de las resoluciones legales respectivas publicadas en el Boletín Oficial y emitidas por el Consejo Nacional del Empleo, la Productividad y el Salario Mínimo, Vital y Móvil que es el organismo encargado de fijar para todos los trabajadores comprendidos en la Ley de Contrato de Trabajo № 20.744, de la Administración Pública Nacional y de todas las entidades y organismos en que el Estado Nacional actué como empleador, el Salario Mínimo, Vital y Móvil.

${ }_{17}^{16} \mathrm{La}$ EPH no provee información sobre la voluntariedad de la sobreocupación, por lo tanto, no pudo ser considerada en la definición operativa.

${ }_{17}$ OIT, 2008; Lanari, 2005; Ghai, 2003; Bonnet et al., 2003; Bescond et al., 2003; entre otros, adoptan y justifican el uso del salario mínimo como medida de la obtención de ingresos laborales suficientes que proporcionan, al menos, la satisfacción de las necesidades básicas del trabajador y su familia.

${ }^{8}$ Sin embargo, según Maloney y Nuñez (2002) el SMVM puede generar rigideces en el mercado laboral y un decrecimiento potencial de las oportunidades de empleo que compensaría las ganancias obtenidas de una distribución del ingreso adecuada. Sin embargo, estos efectos dependen de la estructura del mercado. Si bien, el aumento del salario mínimo causa rigideces en un mercado de trabajo competitivo esto no sucede necesariamente en otros tipos de mercados laborales, como por ejemplo, en uno monopólico (Cahuc y Zylberberg, 2004).
} 
mientras que el acceso a una adecuada protección social garantiza el bienestar general, la productividad y la calidad de vida de ellos y sus familias, ante situaciones apremiantes e imprevisibles. La falta de cobertura de seguridad social es un aspecto estrechamente vinculado a la informalidad, la exclusión social y la vulnerabilidad laboral. La presencia de un elevado número de trabajadores desprotegidos en la economía informal puede convertirse en una amenaza para la economía formal. "El ámbito de la protección social ilustra el interés directo y muy real, por parte de los trabajadores con un empleo normal y de sus organizaciones, en que los trabajadores de la economía informal pasen a formar parte del empleo formal. Con la reducción del empleo formal, los trabajadores asumen una carga financiera directa cada vez mayor para atender a las necesidades sociales, lo que incide negativamente en su calidad de vida. Dicha carga también puede debilitar la capacidad de las empresas de competir en la economía mundial” (OIT, 2002). Por ello es que la noción de TD apunta a la universalidad de la cobertura de la protección social, otro objetivo en la promoción del TD que contribuye al crecimiento económico, la paz social, la integración política, la participación de los ciudadanos, el desarrollo de la democracia y el bienestar humano. Además, una población con alto grado de cobertura a la seguridad social es un indicador de un buen gobierno y de policy makers competentes (Wingfield-Digby et al., 2008). La seguridad social puede utilizarse como herramienta útil para aliviar los problemas de pobreza, aumentar la productividad y conseguir el desarrollo socioeconómico sostenible cuando se complementa con una economía creciente y con políticas activas dirigidas al mercado laboral (OIT, 2001).

Si bien en la dimensión "extensión de la seguridad y la protección social" suelen incluirse el pago por cobertura médica, prestaciones de enfermedad, desempleo, vejez, accidentes laborales, circunstancias familiares, maternidad, invalidez y sobrevivientes, entre otros; la implementación empírica en este estudio involucra lacónicamente las variables relacionadas con la realización de descuentos jubilatorios y el pago de una obra social por parte del empleador dada la escasa información de la EPH de los aspectos relacionados a esta dimensión.

Con relación a la última dimensión del TD - "representación y diálogo social"- Sen (1999, p7) afirma "claro está que la vida de la población trabajadora se ve directamente afectada por las normas y los convenios que rigen su trabajo, pero también depende, en última instancia, de sus libertades como ciudadanos con voz y voto, capaces de influir en las decisiones políticas e institucionales". En esta línea Anker et al. (2002) sostienen que el diálogo social es un tipo de negociación o intercambio de información entre gobiernos, empleadores y trabajadores relacionado directamente al trabajo y a las políticas sociales y económicas. La democracia en una sociedad también se refleja por trabajadores con posibilidades de expresarse libremente sobre asuntos relacionados con su empleo por medio de un órgano capaz de representarlo y negociar en su nombre. Sin embargo, la EPH no releva información relacionada a esta dimensión.

Dado que la noción de TD concierne al conjunto de la población ocupada, tanto aquellos que pertenecen a la economía formal como informal, es posible realizar una nueva categorización de los trabajadores combinando ambas perspectivas como la que se presenta en el cuadro 3.

Cuadro 3.

Esquema de categorización desde la perspectiva de la formalidad y el trabajo decente

\begin{tabular}{ccc}
\hline $\begin{array}{c}\text { Perspectiva de la } \\
\text { formalidad }\end{array}$ & \multicolumn{2}{c}{ Perspectiva de trabajo decente } \\
\cline { 2 - 3 } & Decente & No decente \\
\hline Formal & Óptimo & Posible \\
\hline Informal & Imposible & Normal \\
\hline Fuente: Elaboración propia. & &
\end{tabular}

Conforme con este esquema, un empleo es no decente si existe déficit en algunas de las tres dimensiones de TD consideradas previamente. En caso contrario, es decir, si no existe déficit en ninguna de ellas, el trabajo es decente. De acuerdo al cuadro 3, las categorías ocupacionales de la sección previa pueden ser redefinidas desde la perspectiva del TD en:

- Asalariados registrados con y sin déficit de TD

- Trabajadores por cuenta propia formales con y sin déficit de TD,

- Patrones con y sin déficit de trabajo decente,

- Asalariados registrados que trabajan en hogares con y sin déficit de TD

- Todos los trabajadores informales tienen déficit de TD por definición. 
En el cuadro 4 se presenta un esquema alternativo de categorización de los trabajadores combinando las perspectivas del TD y de la formalidad empleada en el análisis econométrico de la sección 4.2 en adelante. Conforme con este esquema más desagregado, se analiza la situación de los trabajadores clasificados según su condición de formalidad en términos de déficit en cada una de las dimensiones de TD previamente analizadas.

Cuadro 4.

Esquema de categorización desde la perspectiva de la formalidad y el trabajo decente

\begin{tabular}{lcccc}
\hline \multirow{2}{*}{$\begin{array}{c}\text { Perspectiva de } \\
\text { la formalidad }\end{array}$} & \multicolumn{3}{c}{ Perspectiva de trabajo decente } & \multirow{2}{*}{ Sin déficit } \\
\cline { 2 - 4 } & \multicolumn{4}{c}{ Con déficit } \\
\hline Formal & Dimensión 1 & Dimensión 2 & Dimensión 3 & G. \\
\hline Informal & D. & B. & C. & Imposible \\
\hline
\end{tabular}

Nota: la dimensión 1 corresponde a la dimensión "promoción del empleo"; la 2, a la dimensión "respeto de los derechos fundamentales en el trabajo" y la 3 a la de "extensión de la seguridad y la protección social". Las características incluidas en cada una de estas dimensiones se encuentran detalladas en los párrafos previos de esta misma sección.

Fuente: Elaboración propia.

En el Cuadro A3 del apéndice se presentan los resultados que surgen de implementar el esquema de categorización anterior para clasificar a los trabajadores desde la perspectiva de la formalidad considerada en la matriz del cuadro 3 y del trabajo decente. Si bien, durante 2004-2009, entre el $34 \%$ y $37.6 \%$ de los trabajadores son AR en EF y tienen un TD, casi la mitad de los empleados en una EF presentan déficit en alguna $O$ en todas las dimensiones de TD. Independientemente del sector en que se desempeñen los asalariados, la mayoría de los registrados tienen déficit en la dimensión "empleo" en tanto que gran parte de los no registrados además de una seguridad y protección social inadecuada, presentan déficit en sus derechos laborales y en la dimensión "empleo". La incidencia de la informalidad entre los trabajadores independientes se mantuvo en niveles altos durante el período de análisis (entre el $89.7 \%$ y el $92 \%$ ). Asimismo, más del $73 \%$ de los trabajadores independientes presentan déficit en la dimensión "empleo" siendo en su mayoría cuenta propias (entre un $69.6 \%$ a un $76.8 \%$ ).

En conclusión, la perspectiva de TD descubre la diversidad al interior de los trabajos registrados $y$, también, de los no registrados. Esta heterogeneidad, que se encontraba poco visible hasta después de la introducción del concepto de economía informal, es considerada por la OIT (2002) consecuencia de importantes fuerzas en movimiento que expanden y cambian muchas de sus características. Esto a su vez, implicaría que la evolución de la economía informal podría acentuar, a lo largo del tiempo, las diferencias en las condiciones laborales entre y dentro de los que se ocupan en el segmento (in)formal del mercado laboral.

\section{Metodología}

En esta sección se realiza una breve descripción de los métodos econométricos implementados con el objetivo de proveer evidencia empírica a favor de la hipótesis principal de esta investigación, es decir, la segmentación del sector formal argentino.

Las teorías sobre mercados laborales segmentados usualmente asocian la existencia de segmentación con una limitada movilidad de los ocupados así como con la existencia de brechas salariales entre los diferentes segmentos del mercado de trabajo que implican la presencia de una estructura laboral no homogénea. A fin de evaluar cada uno de estos aspectos se utilizan tres métodos: matrices de transición, estimación de brechas de ingreso por efectos fijos y de la cantidad de segmentos mediante un modelo mixto finito.

\subsection{Matrices de transición}

Las matrices de transición resumen la información relativa al flujo de trabajadores entre las distintas categorías laborales consideradas. A partir de ellas es posible tabular la probabilidad condicional $\left(P_{i j}\right)$ de encontrar a un trabajador en la categoría ocupacional $\mathrm{j}$ al final del período considerado, dado que el trabajador estuvo en la categoría i. Cada fila de la matriz de transición suma uno y los elementos de la diagonal principal reflejan la probabilidad de permanecer en la misma categoría ocupacional al final del período. La información obtenida de las matrices de transición es descriptiva y se la emplea para una primera exploración de la hipótesis central del estudio. Su construcción permitirá analizar los movimientos de los trabajadores entre categorías ocupacionales definidas a partir de la condición de informalidad y del sector en que se desempeñan, desde la 
perspectiva del TD, principalmente de los movimientos dentro del sector formal. Además, según Maloney (1999), la prueba definitiva de la hipótesis del mercado laboral segmentado requiere datos de panel que verifiquen si los individuos están realmente atrapados en un determinado sector o si pueden desplazarse libremente de un sector a otro.

\subsection{Estimación de brechas de ingreso mediante el modelo de efectos fijos}

Una forma de explorar la hipótesis de segmentación del sector formal, asumiendo que la existencia de segmentos laborales diferentes dentro de un mismo sector se traduce en mecanismos salariales distintos, es a través de la estimación de brechas de ingresos.

Si bien existe una vasta literatura sobre diferenciales salariales para probar segmentación, el principal problema con este enfoque es determinar si la decisión de ser formal o de ocupar un puesto en condiciones de TD es o no exógena. En otras palabras, las diferenciales salariales podrían estar sesgadas debido a un problema de endogeneidad que surge porque existen ciertas características inobservables para el econometrista que podrían estar relacionadas con que el trabajador ocupe un empleo informal y con su ingreso laboral. Dado el objetivo del estudio el método de FE (efectos fijos) es ciertamente el más apropiado pues elimina todas aquellas variables inobservables u omitidas, invariantes en el tiempo, que podrían estar correlacionadas con los salarios y el sector de elección. Es decir, este método permite obtener los cambios en el ingreso experimentados por un mismo individuo al moverse entre puestos formales e informales, manteniendo constantes las características del trabajador tanto las observables como las inobservables que no varían en el tiempo. Así, el estimador FE es más consistente que el de OLS cuando existe heterogeneidad inobservada individual correlacionada con los ingresos y con el tipo de ocupación.

El modelo econométrico a estimar es el siguiente:

$$
\mathrm{W}_{\mathrm{it}}=\mathrm{X}_{\mathrm{it}}^{\prime} \beta+\phi \mathrm{l}_{\mathrm{it}}+\gamma_{\mathrm{t}}+\alpha_{\mathrm{i}}+\varepsilon_{\mathrm{it}}
$$

Donde $\mathrm{W}$ es el logaritmo del ingreso laboral, $\mathrm{X}$ es el vector de características observables del asalariado y del puesto de trabajo; $\alpha$ es el conjunto de características inobservables del trabajador invariantes en el tiempo; I es la variable dummy que indica la condición de informalidad del trabajador o el déficit de TD, $\gamma_{t}$ es una dummy temporal y $\varepsilon$ es el término de error que se asume cumple con el supuesto de exogeneidad estricta, es decir, $E\left(\varepsilon_{i t} \mid X_{i t}^{\prime}, \alpha_{i}, \gamma_{t}, l_{i t}\right)=0$.

El signo y tamaño del parámetro asociado a la dummy $I_{\text {it }}$ indica el sentido y la magnitud del diferencial salarial promedio que produciría de manera independiente la informalidad o el déficit de TD en alguna dimensión, es decir, controlando por el efecto de otros atributos personales y otras características del puesto de trabajo.

Cuando se corrige por sesgo de selección ${ }^{19}$, el estimador de la matriz de varianza robusta asintótica sugerida por Arellano (1987) a partir de los resultados obtenidos por White (1984) es la siguiente:

$$
\operatorname{Avar}\left(\hat{\phi}_{\mathrm{FE}}\right)=\left(\ddot { X } \cdot \ddot { X } ^ { - 1 } ( \sum _ { \mathrm { i } = 1 } ^ { N } \ddot { X } _ { i } ^ { \prime } \hat { \varepsilon } _ { \hat { \varepsilon } } ^ { \prime } \ddot { \mathrm { X } } _ { \mathrm { i } } ) \left(\ddot{\mathrm{X}} \ddot{\mathrm{X}}^{-1}\right.\right.
$$

Donde los efectos fijos residuales estimados son $\hat{\varepsilon}_{i}=\ddot{W}_{i t}-\ddot{X}_{i t} \beta-\phi \ddot{\varphi}_{t}$ con $\dddot{W}_{i t}=W_{i t}-\bar{W}_{i}, \ddot{X}_{i t}=X_{i t}-\bar{X}_{i} y$ $\ddot{l}_{\mathrm{t}}=\mathrm{l}_{\mathrm{it}}-\overline{\mathrm{l}}$.

Este estimador de la varianza es válido aún en presencia de correlación serial y heteroscedasticidad siempre que T sea relativamente pequeña con relación a $\mathrm{N}$ (Wooldridge, 1995). Esta condición se cumple en los datos de panel utilizados.

En síntesis, el estimador de FE es consistente incluso aunque existan características inobservables correlacionadas tanto con los ingresos como con otros factores o efectos individuales constantes en el tiempo. Sin embargo, cuando se utilizan paneles cortos, como en este estudio, es decir, cuando T es fija y $\mathrm{N} \rightarrow \infty$, los únicos estimadores de FE que resultan consistentes son $\beta, \phi$ y $\theta$, pues los estimadores de los efectos individuales $\alpha$ crecen a medida que $\mathrm{N}$ se incrementa perdiendo consistencia. No obstante, el parámetro de interés es $\phi$ que otorga una medida de la penalidad condicional de ingresos experimentada por un asalariado no registrado (ANR) en relación a los ingresos percibidos por él como registrado o el premium salarial de estos trabajadores en situación o no de déficit de TD.

\footnotetext{
${ }^{19}$ El estadístico t computado a partir de errores estándares robustos es válido cuando no se corrige por sesgo de selección, independientemente que el término de error sea homoscedástico y no esté serialmente correlacionado (Wooldridge, 1995).
} 
Un problema que puede sesgar las estimaciones obtenidas con efectos fijos es el de sesgo de selección muestral cuyo tratamiento será descrito en la sección 4.4.1.

\subsection{Exploración de la estructura del mercado laboral y de la cantidad de segmentos del sector formal}

Para explorar la estructura del sector formal y examinar la cantidad segmentos que podrían existir se estimará un modelo mixto finito aplicado por Günther y Launov (2007). Una forma de considerar la heterogeneidad inobservada en los datos y el problema de auto-selección es suponer que los datos provienen de una distribución mixta finita (Arcidiacono y Jones, 2003). Este método permite aproximar el componente de heterogeneidad inobservada no paramétricamente mediante latent classes que capturan los sub-grupos latentes en los datos que difieren con respecto a la variable de resultado. $\mathrm{Si}$ se condiciona sobre latent classes en el modelo mixto finto, se controla por heterogeneidad inobservada y se reduce el sesgo en los parámetros estimados generado por los efectos de variables independientes inobservables que afectan el resultado. Por lo tanto, el modelo mixto finito tiene en cuenta la heterogeneidad inobservada que surge de variables omitidas por medio de la inclusión de latent classes (Holm et al., 2008). La introducción explicita de heterogeneidad en la forma de distintos segmentos con afiliación inobservada ofrece una ventaja relativa en comparación a todos los modelos que están confinados a la elección observada del sector.

El modelo econométrico implementado en esta investigación permite explorar la existencia de un sector formal heterogéneo con afiliación inobservada de los trabajadores a los posibles segmentos que lo conforman y distintas ecuaciones de ingreso laborales en cada uno de ellos (Günther y Launov, 2007).

Se parte del supuesto que el sector formal consiste en $\mathrm{J}$ segmentos disjuntos y que los agentes son maximizadores de ingresos. Los ingresos en cada segmento $\left(W_{j}\right)$ son valores realizados de $n$ vectores aleatorios idénticos e independientemente distribuidos $W_{j}, \ldots, W_{n}$ con una función de densidad común $\mathrm{f}\left(\mathrm{W}_{\mathrm{j}}\right)$ independiente y distinta entre los segmentos. Sea $\mathrm{P}(\mathrm{W} \in J)=\pi_{\mathrm{j}}$ la probabilidad de que un individuo dado gane $\mathrm{W}$ perteneciendo al segmento $\mathrm{J}$, cada valor $\pi_{\mathrm{j}}$ puede también ser interpretado como el tamaño del sector j-ésimo relativo al tamaño del sector formal cuya suma es uno, es decir, $0 \leq \pi_{j} \leq 1(i=1, \ldots, J)$. Con estos supuestos la densidad de los ingresos individuales $W_{i}$ está dada por:

$$
F\left(W_{i}\right)=\sum_{j=1}^{J} f\left(W_{i} \mid \theta_{j}\right) \pi_{j}
$$

Donde $F\left(W_{j}\right)$ es la función de distribución correspondiente a la densidad mixta $f\left(W_{j}\right)$ y $\theta_{j}$ es el vector de parámetros desconocidos en la forma postulada por la iésima densidad componente en el modelo mixto finito.

En otras palabras, se supone que el sector formal contiene un número arbitrario de segmentos con una distribución de ingresos diferentes en cada uno de ellos. Entonces, el modelo empleado es un modelo mixto finito. Los modelos mixtos finitos son un nicho entre los enfoques paramétricos y semiparamétricos. Los enfoques basados en estos modelos mixtos son paramétricos porque la función de densidad $\mathrm{f}\left(\mathrm{W}_{\mathrm{i}} \theta_{\mathrm{j}}\right)$ es especificada en forma paramétrica, pero también pueden considerarse como no paramétricos al permitir que el número de componentes $\mathrm{J}$ crezca. En consecuencia, los modelos mixtos finitos tienen mucho de la flexibilidad de los enfoques no paramétricos pero a la vez retienen algunas de las ventajas de los enfoques paramétricos. Por lo tanto, los modelos mixtos ofrecen un método conveniente de estimación de la densidad basada en un enfoque intermedio entre modelos paramétricos y estimadores de densidad de kernel (McLachlan y Peel, 2000). Así, $\hat{\mathrm{F}}\left(\mathrm{W}_{\mathrm{i}} \theta_{\mathrm{j}}\right)$ es consistente si, con probabilidad $1, \hat{F}\left(\mathrm{~W}_{\mathrm{i}} \theta_{\mathrm{j}}\right)$ converge débilmente a la verdadera distribución mixta $F^{*}\left(W_{i} \mid \theta_{j}\right)$ cuando $n \rightarrow \infty$. Según, Leroux (1992), la consistencia en este sentido implica, bajo condiciones moderadas, que la densidad estimada converge a la verdadera densidad. El autor demuestra que las distribuciones mixtas normales satisfacen las cinco condiciones requeridas para obtener resultados consistentes ${ }^{20}$. Entonces, si $f\left(W_{i} \mid \theta_{j}\right)$ es un mix finito de $j$ distribuciones normales, como se supone en este estudio, las estimaciones resultantes convergen a la representación mixta correcta (James et al., 2001).

En cada segmento j del sector formal, el logaritmo de los ingresos está dado por la siguiente ecuación de ingresos lineal:

\footnotetext{
${ }^{20}$ Las pruebas de los teoremas y de las condiciones necesarias para la consistencia e identificabilidad de los modelos mixtos finitos son desarrollados por Lereoux (2000).
} 


$$
\ln W_{i}=X_{i}^{\prime} \beta+u_{i} ; u_{i} \sim N\left(0, \sigma_{j}^{2} \mid X_{i}, W_{i} \in J\right)
$$

Donde $W_{i}$ es el logaritmo del ingreso individual; $X_{i}^{\prime}$ representa un conjunto de características personales y $u_{i}$ es el término de error correspondiente.

Usando (2) y (3), el log del ingreso esperado de cualquier individuo sorteado del total de trabajadores del sector formal está dado por $E\left(\ln W_{i}\right)=\sum_{j=1}^{J}\left(X_{i}^{\prime} \beta_{j}\right) \pi_{j}$. Entonces, la regresión para el total de trabajadores de ese sector está dada por:

$$
\ln \mathrm{W}_{\mathrm{i}}=\mathrm{E}\left(\ln \mathrm{W}_{\mathrm{i}}\right)+\chi_{\mathrm{i}}^{\prime} \theta+\mathrm{v}_{\mathrm{i}} ; \quad \mathrm{W}_{\mathrm{i}} \in \mathrm{J}
$$

Donde la densidad del término de error $\mathrm{v}_{\mathrm{i}}$ es una combinación de densidades normales estándares y $\chi_{i}^{\prime}$ es el vector de términos que corrigen por sesgo de selección que es necesario considerar porque los ingresos $W_{i}$ son observados solamente si el individuo está empleado en el sector formal.

El modelo mixto en (4) es una generalización del modelo de Heckman con selección muestral que permite la existencia de $\mathrm{J}$ distribuciones condicionales diferentes de la variable dependiente en lugar de una sola. Este modelo mixto finto con selección muestral facilita la estimación consistente de la distribución de los salarios en todos los segmentos del sector formal y la de los coeficientes de las ecuaciones de ingreso en cada uno de ellos (Günter y Launov, 2007). El modelo mixto en (4) es estimado mediante un procedimiento de dos etapas: en la primera etapa se computa el vector $\chi_{\mathrm{i}}^{\prime}$ conforme con el método descrito en la sección 4.4.1 que sigue y en la segunda etapa, se estiman diferentes especificaciones del modelo de regresión mixto finito, incluyendo entre las variables explicativas el vector estimado de términos que corrigen por sesgo, usando el método de estimación de máxima verosimilitud. Las especificaciones son definidas a partir de los supuestos sobre la cantidad de segmentos que podrían existir en el sector formal en Argentina. Es necesario describir adecuadamente los datos para determinar cuán grande es $\mathrm{J}$ y por parsimonia, es preferible especificar modelos menos complejos (Chen et al. 2004).

Para determinar el número de segmentos en el sector formal se usan los criterios de información de Akaike (AIC), el Akaike modificado $\left(\mathrm{AIC}^{3}\right)$ y el Akaike consistente (CAIC) ambos planteados por Bozdogan (1994), Bayesian Information Criteria (BIC) propuesto por Schwarz en 1978, el BIC ajustado definido por Sclove (1987) y el de Hannan-Quinn (H-Q). McLachlan y Peel (2000) afirman que el criterio comúnmente usado de AIC y BIC parecerían ser más adecuados para elegir el número de componentes J en una estimación satisfactoria de la densidad. Aunque para Soromenho (1993), AIC tiende a sobreestimar el número de componentes. Sin embargo, las comparaciones de Monte Carlo realizadas por Celeux y Soromenho (1996) mostraron resultados favorables en relación al AIC y CAIC (Wedel, Kamakura, 2000). Bajo condiciones moderadas de ciertos criterios de penalización del logaritmo de verosimilitud, Leroux (1992) establece que BIC y AIC no subestiman el verdadero número de componentes asintóticamente. La estimación de la densidad que emplea el criterio de información BIC para seleccionar el número de componentes $\mathrm{J}$ en un modelo mixto es consistente cuando se emplea un modelo mixto normal para estimar una densidad no paramétricamente como es el caso de este estudio (Roeder y Wasserman, 1997). Asimismo, Keribin (2000) demuestra que bajo ciertas condiciones de regularidad, el número de componentes de un modelo mixto finito puede ser estimado consistentemente usando un enfoque basado en la penalización de la verosimilitud como el criterio BIC. Además, Smith (2000) compara tres criterios, entre los que se encuentra el BIC, obteniendo similares decisiones sobre el número de componentes en un modelo mixto normal. Otros autores mencionados por McLachlan y Peel (2000), como Biernacki, Celeux y Goveaert (1998) y Solka et al. (1998) obtienen conclusiones satisfactorias mediante la utilización de los criterios AIC y BIC. Cambell et al. (1997) también reportaron resultados favorecedores para aplicar BIC en modelos mixtos. Por su parte, Bozdogan (1987) indica que, en general, CAIC es preferible en modelos mixtos.

El principal problema con estos criterios de información es que dependen de las mismas propiedades que el test de ratio de verosimilitud y sólo pueden ser usados como indicativos del número de segmentos cuando la estadística alcanza su mínimo valor (Wedel y Kamakura, 2000). Entonces, como no existe una respuesta clara para cuál criterio deba aplicarse (Cameron y Trivedi, 2005) se implementan cinco criterios de información previamente mencionados.

Como los modelos mixtos finitos tienen funciones de verosimilitud complicadas que pueden presentar varios máximos locales, se utilizó un algoritmo de búsqueda de los mejores valores iniciales. El algoritmo utilizado es el propuesto por Broyden-Fletcher-Goldfarb-Shanno que realiza un número aleatorio de intentos para encontrar el mejor vector inicial. Este procedimiento, según 
Günther y Launov (2007), garantiza el buen comportamiento y la convergencia del problema numérico del modelo a partir de un amplio rango de valores iniciales.

\subsection{Corrección por sesgo de selección}

Como el modelo econométrico es estimado para un grupo seleccionado endógenamente, los asalariados del sector formal, deben implementarse alguno de los métodos para la corrección del sesgo de selección pues, de lo contrario, las inferencias a partir de los salarios observados estarán sesgadas. Teniendo en cuenta las unidades de análisis de esta investigación, al tomar en cuenta el sesgo de selección se supone que los individuos enfrentan un problema de elección multinomial entre cinco alternativas distintas siendo la primera, un trabajo asalariado en una empresa formal; la segunda, un empleo en una empresa informal; la tercera, incluye un trabajo independiente; la cuarta corresponde a la desocupación e inactividad y finalmente, en la quinta se incluyen a los trabajadores en el hogar y trabajadores sin remuneración ${ }^{21}$.

Bourguignon et al. (2004) presentan un conjunto de métodos disponibles en la literatura para la corrección del problema del sesgo de selección cuando la selección es especificada como un modelo logit multinomial. El método adoptado para la corrección del sesgo de selección en la presente investigación es una variante, propuesta por Bourguignon et al. (2004), del método de DubinMcFadden (1984). Las técnicas anteriores a ésta, como la de Lee (1983), presentan restricciones sobre la estructura de los términos de error. En cambio, el método de Bourguignon et al. (2004) emplea la metodología bietápica generalizada a modelos multivariados completos y examina el problema de heteroscedasticidad presente en la segunda etapa que Dubin y McFadden (1984) ignoraron. En la primera etapa se estima por Máxima verosimilitud (ML), la ecuación de selección en la que la variable dependiente es una variable categórica que describe la elección de un agente económico entre $M$ alternativas posibles basada en la "utilidad" que obtendrá de cada una. Formalmente, la ecuación de selección a estimar es la siguiente:

$$
Y_{j}=Z^{\prime} \gamma_{j}+\eta_{j}, \quad j=1 \ldots M
$$

Donde $Y_{j}$ es la variable categórica que describe la elección de los agentes entre $M$ alternativas posibles basada en las "utilidades" de cada una de las alternativas; $Z^{\prime}$ es el vector que representa el conjunto de variables explicativas para todas las alternativas y $\eta_{j}$ es el término de perturbación que se supone independiente e idénticamente distribuido según una distribución Gumbel que implica un modelo logit multinomial. Este modelo, en general, expresa la probabilidad que un individuo con las características $X_{i}$ elija la categoría ocupacional j-ésima. Bajo los supuestos que todas las variables $X_{i}$ y $Z$ son exógenas y que los disturbios $\eta_{j}$ verifican que $E\left(\eta_{j} \mid X_{j}, Z\right)=0$ y $V\left(\eta_{j} \mid X, Z\right)=\sigma^{2}$, los estimadores ML de la ecuación (8) son consistentes.

En la segunda etapa del procedimiento se estima la ecuación de resultado o ecuación de interés incluyendo entre las variables explicativas el vector $\lambda_{i}$ estimado en la primera etapa a partir de la ecuación de selección. En la presente investigación las ecuaciones de interés es la ecuación salarial (1). Como afirman Bourguignon et al. (2004) a partir de una generalización del modelo de Heckman (1979), el vector $\lambda_{i}$ puede estar basado en la esperanza condicional de $u_{i}$, es decir:

$$
\begin{gathered}
E\left(u_{i} / \varepsilon_{i}<0, \Omega\right)=\lambda\left(P_{1}, \ldots, P_{M}\right) \\
\text { donde } \varepsilon_{i}=\max _{j \neq 1}\left(Y_{j}-Y_{i}\right)=\max _{j \neq 1}\left(Z^{\prime} \gamma_{j}+\eta_{j}-Z^{\prime} \gamma_{i}-\eta_{i}\right) \text { y } \Omega=\left\{Z^{\prime} \gamma_{1}, Z^{\prime} \gamma_{2}, ., Z^{\prime} \gamma_{M}\right\}
\end{gathered}
$$

Finalmente, sin pérdida de generalidad, se supone que el resultado observado pertenece a la categoría $\mathrm{j}=1$ por lo que un estimador consistente de $\beta_{1}$ se obtendría a partir de la estimación de la siguiente ecuación:

$$
\ln W_{1}=X_{1} \beta_{1}+\sigma_{1}\left[\tilde{\rho}_{1} m\left(P_{1}\right)+\sum_{j>1} \tilde{\rho}_{j} \frac{P_{j}}{\left(P_{j}-1\right)} m\left(P_{j}\right)\right]+v_{1}
$$

Donde $\tilde{\rho}_{j}$ es la correlación entre $u_{1}$ que es el error de la ecuación salarial condicional a que la categoría 1 sea elegida) y $\eta_{j}^{*}=J\left(\eta_{j}\right)=\Phi^{-1}\left(G\left(\eta_{j}\right)\right)$, siendo $\Phi$ la distribución acumulada normal estándar, $\mathrm{G}($.$) la distribución acumulada de \eta_{\mathrm{j}}$ que es el error de la ecuación de selección condicionado a que la

\footnotetext{
${ }^{21}$ Se incluyó estas dos categorías ocupacionales en una misma alternativa debido a la escasa cantidad de observaciones existentes en ambas. Además, conforme con el Wald test computado esas dos categorías son indistinguibles con respecto a las variables en el modelo, por lo tanto, es posible obtener estimaciones más eficientes combinándolas. Los resultados no cambian significativamente cuando se separan en categorías distintas a los inactivos de los desocupados y a los asalariados en el hogar de los trabajadores familiares sin remuneración.
} 
categoría j sea la elegida, $m\left(P_{j}\right)=\int J\left(v-\log P_{j}\right) g(v) d v$ siendo $v=\eta_{j}+\log P_{j}, g(v)$ la función de densidad de $v$ y $P_{j}$ la probabilidad que la categoría j sea elegida que está dada por $P\left(z_{j} \gamma_{j}>\varepsilon_{j}\right)=\frac{\exp \left(z_{j} \gamma_{j}\right)}{\sum_{j} \exp \left(z_{i} \gamma_{i}\right)}$ y finalmente $v_{1}$ es un término de error ortogonal a todos los otros términos en (10) y que tiene esperanza cero.

Con el objetivo de verificar la existencia de sesgo de selección en el modelo de FE se emplea el test propuesto por Wooldridge (1995). Para ello, se estima la ecuación de selección de acuerdo al método previamente descrito y se obtienen las inversas de la ratio de Mills $\hat{\lambda}_{\text {it }}$, para todo i y t. Paso seguido, se estima la siguiente ecuación por OLS pooled empleando la muestra seleccionada:

$$
\mathrm{W}_{\mathrm{it}}=\mathrm{X}_{\mathrm{it}}^{\prime} \beta+\hat{\lambda}_{\mathrm{it}}^{\prime} \theta+\varepsilon_{\mathrm{it}}
$$

A partir de (11) es posible testear $\mathrm{H}_{0}: \theta=0$, es decir, la hipótesis nula de que no existe selección muestral. Si los términos de error satisfacen el supuesto de homoscedasticidad y de no correlación serial, entonces el t estadístico resultante es válido y completamente robusto. Si se rechaza la hipótesis nula entonces es necesaria la corrección por sesgo de selección y, por lo tanto, el modelo de FE a estimar es el siguiente:

$$
W_{i t}=X_{i t}^{\prime} \beta+\phi l_{i t}+\lambda_{i t}^{\prime} \theta+\gamma_{t}+\alpha_{i}+\varepsilon_{i t}
$$

Donde $\mathrm{W}$ es el logaritmo del ingreso laboral, $\mathrm{X}$ es el vector de características observables del asalariado y del puesto de trabajo; $\alpha$ es el conjunto de características inobservables del trabajador invariantes en el tiempo; I es la variable dummy que indica la condición de informalidad del trabajador o el déficit de TD, $\gamma_{t}$ es una dummy temporal y $\varepsilon$ es el término de error que se asume cumple con el supuesto de exogeneidad estricta, es decir, $E\left(\varepsilon_{i t} \mid X_{i t}^{\prime} \alpha_{i}, \lambda_{i t}, l_{i t}\right)=0$.

En este caso, la varianza asintótica de los estimadores debe ser corregida por heteroscedasticidad general y correlación serial. Es posible obtener errores estándares robustos por heteroscedasticidad bajo el supuesto débil que los errores son independientes entre los individuos $E\left(\varepsilon_{i t} \varepsilon_{j s}\right)=0$ para todo i $\neq \mathrm{j}$, $E\left(\varepsilon_{i \mathrm{it}} \varepsilon_{\mathrm{j} s}\right)$ no está restringido y $\varepsilon_{\mathrm{it}}$ es heteroscedástico (Cameron y Trivedi, 2007). Por lo tanto, conforme con Green (2001), el método de bootstrap funciona adecuadamente cuando se emplea alguna corrección por sesgo de selección en las estimaciones de datos de panel. Los errores panelrobust se computan a partir del siguiente estimador de la matriz de varianza:

$$
\operatorname{Ava\hat {r}}\left(\hat{\phi}_{\mathrm{FE}}\right)=\frac{1}{\mathrm{~B}-1}\left(\sum_{\mathrm{b}=1}^{\mathrm{N}} \hat{\phi}_{\mathrm{b}}-\overline{\hat{\phi}}\right)\left(\hat{\phi}_{\mathrm{b}}-\overline{\hat{\phi}}\right)^{\prime}
$$

Donde $\overline{\hat{\phi}}=\mathrm{B}^{-1} \sum_{\mathrm{b}} \phi_{\mathrm{b}}$ y $\mathrm{B}$ son la cantidad de pseudo-muestras empleadas para estimar $\hat{\phi}_{\mathrm{b}}$ con $\mathrm{b}=$ $1, \ldots, \mathrm{B}$; a partir de los datos $\left\{\left(\mathrm{W}_{\mathrm{i}}, \mathrm{X}_{\mathrm{i}} \mathrm{l}_{\mathrm{i}}, \lambda_{\mathrm{i}}, \gamma, \alpha\right), \mathrm{i}=1, \ldots, \mathrm{N}\right\}$ que producen las $\mathrm{B}$ pseudo-muestras (Cameron $\mathrm{y}$ Trivedi, 2007).

\section{Resultados}

\subsection{Matrices de transición}

La segmentación implica una movilidad laboral restringida que limita los desplazamientos entre puestos y sectores del mercado laboral. Específicamente, si el sector formal está segmentado se espera que existe en él una restricción no aleatoria al acceso a puestos de trabajo con mejores condiciones laborales -sea en términos de registración o, desde una perspectiva más amplia, en términos de TD-. Por lo tanto, una primera exploración de la hipótesis central de esta investigación es a través de matrices de transición que aportan evidencia empírica sobre los desplazamientos de los trabajadores entre y dentro del sector formal e informal. Esto permitirá observar si existen cambios en la composición interna dentro de ambos sectores y barreras a la entrada a puestos de trabajo registrados y, entre ellos, a puestos de trabajo que pueden calificarse como decentes.

El análisis se desarrolla a partir de la evaluación de la dinámica de los trabajadores en el mercado laboral, examinando la permanencia en o movilidad entre las distintas categorías ocupacionales definidas en función de su condición de (in)formalidad y desde la perspectiva del $T^{22}$. Dado los

\footnotetext{
${ }^{22}$ Ver sección 3.1 y 3.2 para más detalles.
} 
objetivos de esta investigación y como una primera aproximación al estudio de la segmentación del sector formal se pondrán énfasis en los movimientos de los asalariados no registrados y aquellos registrados con déficit de trabajo decente (DTD) y sin él, empleados en empresas formales.

Las matrices anuales computadas para el período 2004-2009 (ver Cuadros A4 a A6) revelan que Ios AR sin DTD en una EF presentan probabilidades crecientes entre los extremos del periodo de permanecer en el mismo empleo. Además, conforme se esperaba, las probabilidades de permanencia en el puesto de estos asalariados son las más altas en comparación con el resto de los trabajadores en cada panel. Específicamente, los resultados indican que del $74.3 \%$ al $76.7 \%$ de los AR con un TD continúan en la misma categoría laboral durante un año.

Un escenario completamente diferente se observa entre los empleados registrados del sector formal con DTD. Más del $64.7 \%$ de estos trabajadores abandonan su puesto laboral y llamativamente, su tasa de movilidad es mayor en todos los años a la de los ANR hasta en $16 \mathrm{pp}$. Este podría ser el caso de empleados que aunque están registrados no tienen protección contra el despido arbitrario, reglamentación de la contratación o estabilidad laboral. También, podría tratarse de asalariados registrados disconformes con sus condiciones laborales por percibir ingresos inadecuados a sus capacidades y nivel educativo o carecer de derechos a la representación colectiva o de oportunidades para desarrollar sus competencias a través del aprendizaje y formación laboral. Con relación a esto, los datos revelaron que del total de AR con DTD, más del $70 \%$ presentan déficit en el empleo, principalmente porque, en su mayoría (del $52 \%$ al $84 \%$ ) no se encuentra satisfecho con su trabajo ni tienen una jornada laboral decente. Entonces, es probable que estos asalariados hayan dejado su puesto y se abocaran a la búsqueda de mejores perspectivas de empleo, asignando una mayor importancia a las condiciones de déficit en esa dimensión que a la propia registración. Una forma de explorar esto último es analizando la dirección de sus desplazamientos. Justamente, como se sospechaba, entre un $47 \%$ a un $68 \%$ de los movimientos de los AR con DTD se dirigen hacia un empleo registrado en el mismo sector sin ningún tipo de déficit. Esto podría indicar que la registración favorece la movilidad laboral "ascendente", en el sentido de mejores condiciones ocupacionales. Asimismo, este resultado sugiere que más de la mitad de los AR con DTD de EF, aunque ya obtienen los beneficios relacionados con la registración, tienen incentivos a conseguir óptimas o mejores condiciones laborales lo que no necesariamente debería estar asociado con un "desplazamiento" en sí mismo, sino, quizás, con la obtención de mejoras en la calidad del empleo en el mismo puesto de trabajo. Justamente, la recuperación económica experimentada por el país a partir del 2003 podría haber incentivado, principalmente a los empleadores de grandes firmas - visibles para el gobierno - a mejorar las condiciones de trabajo de sus empleados. El resto de los AR con DTD que no permanece en la misma categoría, del $32 \%$ al $53 \%$ aproximadamente, no consigue un puesto registrado sin déficit de TD; menos de un $11.6 \%$, se mueve dentro de categorías ocupacionales pertenecientes al sector formal; de $8.6 \%$ a un $12.8 \%$ se dirige a la inactividad o el desempleo y hasta un $10.5 \%$ se desplaza a una El.

En cambio, en el caso de los AR sin DTD empleados en el mismo sector, aunque son pocos los que se desplazan en relación a los que permanecen en su puesto, la mayoría de ellos se dirige hacia un empleo registrado no decente dentro del mismo sector (más del $31 \%$ ) pero menos del $7.6 \%$ y del $4.1 \%$ ocupa un empleo en el sector informal y un trabajo no registrado en una EF, respectivamente. Estas dos últimas probabilidades son menores hasta en 2.9 y 5.9 pp que las correspondientes a los AR con DTD ${ }^{23}$. En efecto, del total de estos asalariados que se movieron, menos de la mitad que no lo hizo hacia un empleo registrado sin déficit de TD, entre un $6 \%$ a un $10.5 \%$ se dirigió a un trabajo en una El y menos de un $10 \%$ se desplazó a un puesto no registrado en el sector formal. Los AR con y sin DTD que transitaron hacia un empleo informal comparten ciertas características individuales. Así, la mayoría de ambos grupos de trabajadores tienen entre 31 a 40 años, no asisten a un establecimiento educativo pero no tienen estudios universitarios, son varones y en su puesto anterior, trabajaban en actividades relacionadas con servicios comunales, personales, sociales, financieros, económicos y empresariales, desarrollando tareas con calificación operativa. Por lo tanto, uno de los factores residuales que podría explicar la mayor intensidad con los AR con DTD transitan hacia un trabajo informal es el déficit en TD, sobre todo, en la dimensión empleo.

Los resultados obtenidos hasta aquí muestran dinámicas diferentes entre los AR con DTD y sin él. Así, los trabajadores registrados que disfrutan de un TD dentro del sector formal presentan una alta tasa de permanencia en sus puestos. Si bien, esto es esperable dada la estabilidad laboral que, por definición poseen, también podría sugerir sus preferencias por el empleo que detentan frente a otro tipo de actividad y, en consecuencia, sus menores incentivos a cambiar de ocupación. Por lo contrario, más del $32 \%$ de los AR con DTD que se desempeñan en el mismo sector no consigue un puesto sin déficit de TD.

\footnotetext{
${ }^{23}$ Conforme con los intervalos de confianza estimados ambas diferencias son estadísticamente significativas.
} 
Un escenario diferente se observa para los ANR. Este grupo de trabajadores presenta una tasa de movilidad mayor que la observada entre los AR sin DTD pero menor que la correspondiente a los AR con DTD. Sin embargo, la probabilidad de permanecer en el mismo puesto disminuye en el tiempo durante 2004-2009. Aunque este resultado podría, a priori, parecer positivo, pues se espera mayor transición ocupacional entre estos conjunto de empleados, debe observarse hacia dónde se dirigen los que se mueven (Bertranou y Paz, 2003). En las tres matrices se observa que, aproximadamente, más del $56.3 \%$ de los ANR en $\mathrm{EF}^{24}$ consiguió dejar esta categoría ocupacional, pero menos del $13 \%$ de los que se desplazaron, terminaron como empleados registrados sin déficit de TD en una EF. Una de las posibles razones que podrían explicar la trayectoria observada de los trabajadores no registrados en una EF es la inestabilidad en el puesto anterior. Efectivamente, la totalidad de los ANR tiene un trabajo con un período de finalización menor al año. Para Beccaria (2007), aun cuando en el conjunto de asalariados no registrados exista un grupo de individuos que dada sus habilidades y atributos personales enfrentan menores probabilidades de conseguir un puesto estable y con cobertura a la seguridad social, éste es minoritario; por lo que la condición de "empleabilidad" es relativa a la situación de la demanda. Por lo tanto, para el autor, la presencia de un amplio segmento de ocupados no registrados es consecuencia de varias décadas de insatisfactoria evolución económica y del empleo. Un resultado llamativo es que la probabilidad de los ANR de trabajar como AR sin DTD (de un 1.9\% a un $7.1 \%$ ) es mayor hasta en 3.8 pp que la de ocuparse como AR con DTD (de un $3.3 \%$ a un $4.9 \%$ ), en los extremos del período. Aunque esta diferencia puede considerarse levemente significativa en términos económicos ${ }^{25}$. Con relación a las características de los ANR que consiguieron un empleo registrado sea con o sin DTD, se observa que la mayoría de estos trabajadores son mujeres, jóvenes, solteras, jefes de hogar, completaron el nivel universitario, como no registradas trabajaban en servicios financieros, empresariales, inmobiliarios, comunales, sociales y personales, desarrollando tareas con calificación operativa y tienen déficit en la dimensión derechos, además de tenerlo en la dimensión de protección social, por definición.

Dado que los AR con DTD comparten con los ANR el déficit en TD, las mayores probabilidades de los primeros de ocuparse como AR sin DTD en una EF, podría sugerir que la registración es utilizada como "puerta de entrada" a esos empleos o como posible generadora de desplazamientos "ascendentes" en el mercado laboral. También puede afirmarse que las calificaciones y demás atributos personales que poseen los AR con DTD ocupados hagan más factibles los desplazamientos hacia puestos de trabajo de mayor calidad dentro del mismo sector o la obtención de mejores condiciones laborales. En relación a esto, los resultados muestran que los ANR y AR con DTD empleados en una EF que transitaron a puestos registrados sin DTD son, en su mayoría, varones, jefes de hogar, con universitario completo que se desempeñaban en ramas asociada con los servicios, trabajaban entre 34 a 36 horas semanales, desarrollaban tareas con calificación operativa y presentan déficit de TD en la dimensión de empleo, dejando de lado la de seguridad y protección social. Sin embargo, mientras los ANR son en su mayoría solteros, con una edad promedio de 33 años, gran parte de los AR con DTD están casados y tienen, en promedio, 39 años.

Por otra parte, si se distingue a los ANR por el sector de ocupación, se observa que para aquellos empleados en una empresa informal (EI) la probabilidad de acceder a un puesto registrado sin déficit de TD en el sector formal es hasta 5.8 pp menor a la de los empleados no registrados de este sector. Esto parecería indicar que la pertenencia a la economía formal otorga ciertas ventajas en términos de movilidad ocupacional "ascendente".

En su gran mayoría, los ANR en empresas formales que dejan su puesto, se dirigen a un empleo en el sector informal (un 37\% en 2004-2005, 36\% en 2006-2007 y $43 \%$ en $2008-2009 \%$ ), ocupando principalmente un puesto no registrado (más del 15\% aproximadamente) o abandonan la actividad laboral (un 35\% en el 2004-2005, 42\% en 2006-2007 y 35\% en 2008-2009). Gran parte de los ANR en EF que transitaron al sector informal son varones, solteros, jefes de hogar, con secundario incompleto que sufren, en su mayoría, de déficit en la dimensión empleo, dejando de lado la de protección y seguridad social. Por otro lado, dado que los ANR suelen ser mayormente trabajadores secundarios, el segundo resultado podría explicarse por la intermitencia laboral de las mujeres debido a la maternidad. Justamente, los trabajadores no registrados que salieron del mercado laboral, se caracterizan por ser, en su mayoría, mujeres, solteras, hijas, de 30 a 38 años, que no completaron el secundario.

En relación con los movimientos de asalariados que no pertenecen al sector formal, cabe destacar algunos resultados encontrados respecto a los asalariados en hogar. En efecto, estos trabajadores son los más desventajados en términos de posibilidades de mejorar sus condiciones de empleo en términos de TD, independientemente de si se encuentran o no registrados. Así, $0 \%$ y $1.1 \%$ de los

\footnotetext{
${ }^{24}$ El $55.7 \%$ en $2004-2005$ y el $60.6 \%$ en los dos paneles restantes correspondientes al período 2006-2009.

${ }^{25}$ Sin embargo, esta diferencia es estadísticamente significativa según los intervalos de confianza estimados.
} 
empleados registrados y no registrados en el hogar acceden a un empleo registrado que califica como decente en el sector formal. En cuanto a las transiciones de los ocupados en el hogar, los resultados señalan, sorprendentemente, que los ARH y los ANRH se trasladan principalmente a empleos no registrados dentro del hogar. Es decir que, en lugar de mejorar sus condiciones laborales, ya sea en términos de TD o de formalidad, los movimientos de este conjunto de trabajadores son "descendentes" en la escala ocupacional. Esta situación desventajosa en términos de transición laboral que permanece en el tiempo -durante el período de análisis- podría explicarse por las insuficientes competencias asociadas usualmente con los ocupados dentro del hogar lo que sumada a su propia dinámica precaria, les dejan como únicas "opciones", permanecer en el mismo trabajo o pasar a la inactividad.

Otros movimientos a destacar son aquellos que ocurren desde y hacia el desempleo. Así, en 2004-2005, la probabilidad de perder el empleo es mayor hasta en 9 pp. entre los trabajadores de El en comparación con los de una EF. En cambio, durante 2006-2007 y 2008-2009, las probabilidades de transitar al desempleo son sorprendentemente superiores hasta en $6.2 \mathrm{pp}$. entre los ocupados del sector formal en relación a los que se desempeñan en empresas informales. Dentro del grupo de trabajadores que pertenecen al sector formal, lo que presentan las probabilidades más altas de quedar desempleado son los ANR en el primer panel pero los patrones y los CPF, ambos sin un TD, en el segundo y último respectivamente. Una vez más, la falta de registración provoca además de déficit en seguridad y protección social, mayores posibilidades de pérdida del empleo de un año a otro. En el caso de los trabajadores independientes, la condición de formalidad, independientemente de las otras características que incluye un TD, parece no garantizar la estabilidad laboral.

Si se observan los movimientos desde el desempleo hacia la ocupación, a lo largo de un año, la mayoría de aquellos que consiguieron un trabajo se insertan como ANR. Sin embargo, estos trabajadores pertenecen a una $\mathrm{El}$, en el primer y último panel, pero a una $\mathrm{EF}$, en el segundo ${ }^{26}$. $\mathrm{El}$ insuficiente capital humano y otros atributos personales pueden ser factores determinantes de este resultado. En relación a esto, Beccaria (2007) sostiene que los jóvenes y los menos educados tienen menor probabilidad de conseguir un puesto estable y con cobertura a la seguridad social. Efectivamente, los resultados indican que tanto los inactivos como los desocupados que transitaron a un empleo no registrado tienen en su mayoría menos de 25 años y no completaron el secundario. También la escasa cobertura del seguro de desempleo podría influir en las restricciones e intensidad de la búsqueda de empleo por parte de los desocupados que probablemente los induce a aceptar, de manera rápida, las posiciones de baja calidad e ingresos, que pueden ser ofrecidas por las firmas con menor cumplimiento de las normas laborales. Sin embargo, también se argumenta que la existencia de seguros de desempleo de cobertura extendida provoca que se prolongue el período de búsqueda reduciendo los movimientos desde el desempleo hacia la ocupación. Las alteraciones en la demanda laboral podría ser otra explicación posible de que la mayoría de los desocupados se dirijan a empleos en el sector informal. Los ajustes de los mercados de trabajo de economías en desarrollo no se producen sólo a través del desempleo sino también por alteraciones en la demanda que favorecen las salidas desde y las entradas hacia puestos informales que constituyen manifestaciones de la subocupación (Beccaria, 2001).

La evolución temporal de los resultados obtenidos en las matrices de transición señala que la tasa de permanencia de los AR sin DTD aumenta, entre 2004-2005 y 2008-2009, aunque no significativamente. Sin embargo, lo que resulta llamativo y, en cierta medida desalentador, teniendo en cuenta el contexto de crecimiento económico del país, durante 2004-2007, son los hallazgos encontrados en relación a los movimientos de los ANR dentro y fuera del sector formal. Así, los desplazamientos de estos trabajadores hacia puestos registrados y decentes en una EF en lugar de aumentar, se mantienen relativamente estables, entre los extremos del período, presentado incluso una importante caída, durante 2004-2005 y 2006-2007, de 5.3 pp. En estos años de recuperación económica, tanto la dificultad que tienen los ANR para ingresar a puestos registrados como sus mayores probabilidades de transitar al desempleo es contraria a lo que la intuición sugiere. En efecto, como afirma Paz (2004), durante una expansión económica, las firmas estarían más dispuestas a mejorar las condiciones laborales de sus empleados y los trabajadores estarían menos dispuestos a aceptar empleos malos y en su lugar, esperarían oportunidades laborales acordes a sus expectativas.

En definitiva, los puestos AR en el sector formal sobre todo aquellos que tienen condiciones decentes de trabajo son un bien escaso en el mercado laboral no sólo para aquellos que provienen de una El sino incluso para trabajadores que se desempeñan en el mismo sector pero que no están registrados. Un resultado que se mantiene a lo largo de todo el período de análisis. Asimismo, la movilidad ocupacional observada principalmente entre los empleados no registrados de una EF

\footnotetext{
${ }^{26}$ La probabilidad que los desocupados encuentren un empleo no registrado en el sector informal es de $12.7 \%$, y $9.5 \%$, en el primer, segundo y tercer panel. Entre 2006-2007, el 12.4\% de los desempleados se dirigen a un puesto no registrado en el sector formal.
} 
refleja una transición "hacia abajo" antes que movimientos "hacia arriba" en la escalera ocupacional porque sus desplazamientos se producen mayoritariamente hacia al desempleo 0 al trabajo asalariado no registrado en el sector informal por lo que sus movimientos no están, en general, asociados con una mejora en la calidad del empleo. Peor aún, sus probabilidades de ascenso laboral futuras empeoran si su sector de llegada es el informal, pues como se observa, los ANR de una El tienen muy pocas probabilidades de obtener un trabajo registrado y decente a lo largo del período, en relación con los ANR de una EF. La dificultad que enfrenta este grupo de empleados para acceder a un puesto registrado en el mismo sector es en alguna medida sorprendente si se considera el contexto económico pues como ya se mencionó, el período de análisis corresponde a una etapa de recuperación que siguió a la crisis del 2001/2002 y también de implementación de programas públicos dirigidos a la regularización del empleo no registrado (como el Plan Nacional de Regularización del Trabajo ${ }^{27}$, el Programa de Simplificación Registral, las campañas de sensibilización en los medios masivos de comunicación y el régimen especial para el servicio doméstico) así como a la promoción del TD, a través del Programa de Trabajo Decente en Argentina cuyos ejes prioritarios son la contribución a la reducción de la economía informal y el empleo no registrado.

En conclusión, el alto porcentaje de ANR así como de AR con déficit de TD que no consiguen insertarse en un puesto registrado sin DTD se encuentra en línea con la hipótesis de segmentación del sector formal. Además, como esos hallazgos se mantienen en el tiempo, durante el período de análisis, la posible segmentación se presenta como un fenómeno no transitorio que se traduce en una movilidad limitada hacia puestos con mejores condiciones laborales.

\subsection{Brechas de ingresos}

El Cuadro A7 presenta los resultados de las brechas de ingresos estimadas por OLS-pooled y FE, entre distintas categorías laborales definidas en función de la perspectiva de la formalidad y del trabajo decente para cada uno de los paneles construidos durante el período 2004-2009. La estimación por OLS-pooled se presenta con fines comparativos y para indagar la importancia de la heterogeneidad inobservada en la estimación del parámetro de interés.

Para cada modelo, se computan dos especificaciones -rotuladas I y II en la Tabla A7 - que difieren en la inclusión o no, de los términos que corrigen por sesgo de selección muestral estimados conforme con el método descrito en la sección 4.4. Conforme con el test de Wooldridge $(1995)^{28}$, computado en cada uno de los paneles, es posible rechazar la hipótesis nula de no existencia de sesgo de selección a un nivel de significancia del $5 \%$ en el primer y último panel. Por lo tanto, la corrección por este sesgo parece ser necesaria en ambos períodos. En cambio, durante 2006-2007, no es posible rechazar la hipótesis nula de no existencia de sesgo de selección a un nivel de significancia del $5 \%$. Sin embargo, las brechas de ingreso estimadas cuando se incluyen las variables que corrigen por sesgo de selección son, en general, similares a las computadas sin corregir en cada uno de los paneles. Esto podría suceder, en parte, porque el problema de selección muestral es invariante en el tiempo y por lo tanto, el modelo de FE lo elimina.

En general, los resultados estimados por FE confirman la existencia de una penalidad salarial asociada a la no registración y al déficit de TD en una EF, estadísticamente significativa en cada panel a un nivel de significancia del $5 \%$. El signo negativo de las brechas estimadas entre los asalariados del sector formal indica que el cambio de un empleo registrado a otro no registrado así como, los desplazamientos entre un puesto con, a otro sin, déficit de TD en ese sector y viceversa, están asociados, en general, con reducciones en los ingresos laborales, ceteris paribus.

En la Tabla A7, la máxima brecha estadísticamente significativa estimada por FE se encuentra, en el primer panel, entre ANR y AR controlando por dummies de ocupación y calificación de la tarea (37\%), en el segundo, entre los asalariados del sector formal con déficit y sin él en todas las dimensiones de TD, controlando por dummies de ocupación (177.6\%) y en el último panel, entre los asalariados de una EF con déficit en todas las dimensiones de TD y otros sin este déficit, sin incluir controles adicionales (82\%). La segunda brecha - la mayor de los tres paneles - sugiere que aquellos empleados del sector formal que cambiaron, en 2006-2007, de un trabajo decente a otro con déficit en todas las dimensiones, sufrieron una mayor penalización en sus ingresos en relación con aquellos que se desplazaron de un puesto registrado a otro que no lo es.

\footnotetext{
${ }^{27}$ A partir del año 2003 se implementó el Plan Nacional de Regularización del Trabajo (PNRT) que tiene por objetivo alcanzar cada vez mayores niveles de registro laboral, apuntado a detectar el trabajo no registrado, el parcialmente registrado, las formas atípicas y encubiertas de relación laboral y la subcontratación "elusiva". Para alcanzar tales metas, el PNRT aumentó la cantidad de inspectores (de 40 a 400 ) y se incrementó sustantivamente el presupuesto. Entre los años 2005 y 2007, se inspeccionaron a nivel nacional a alrededor de 435 mil establecimientos, fiscalizando la situación registral de 1,3 millones de trabajadores (Banco mundial y MTEySS, 2008)

${ }^{28}$ Ver sección 4.4 para más detalles.
} 
El mínimo diferencial salarial estadísticamente significativo se presenta entre los empleados del sector formal con déficit en seguridad y protección social y aquellos sin este déficit (14\%), en el primer panel. Esta brecha es 23.4 pp menor que el diferencial de ingreso más alto estimado en la Tabla A7 durante 2004-2005. Asimismo, cuando se incluyen dummies de ocupación en la regresión salarial del segundo panel, los asalariados de una EF con déficit en empleo $^{29}$ obtienen un ingreso laboral mensual de casi un 14\% menor en relación con el que obtendrían si disfrutaran de condiciones decentes de empleo, siendo esta la brecha más bajo en comparación con el resto de las estimadas en 2006-2007. Además, esta brecha es $164.1 \mathrm{pp}$ menor a la máxima estimada en ese panel. Del mismo modo, los resultados revelan que si se controla por dummies de ocupación en el último panel, los asalariados de una EF reciben $32.5 \%$ menos de ingreso como no registrados que como registrados. Nuevamente, este porcentaje 49.8 pp más bajo en relación con la máxima brecha estimada en 2008-2009.

Por otra parte, los diferenciales de ingreso computados entre ANR y AR incluyendo distintos controles no exhiben diferencias económicamente significativas, ni siquiera cuando se incluye la dummy asociada al déficit de TD, en el primer panel. Sin embargo, este resultado cambia cuando se observa al mismo grupo de trabajadores en el segundo y último panel. Así, en 2005-2006, las brechas estimadas entre los empleados registrados y no registrados de una EF incluyendo algún déficit de TD superan en $12.6 \mathrm{pp}$ a la computada sin ningún control adicional. En tanto que en el último panel, los resultados indican un aumento de hasta $4 \mathrm{pp}$, aproximadamente, en los diferenciales de ingresos entre ANR y AR cuando se incluyen dummies de déficit en TD y de ocupación, en relación a la obtenida sin controles adicionales.

Otro resultado a destacar es que, las máximas brechas computadas entre asalariados del sector formal con y sin déficit de TD, se obtienen cuando se considera la dimensión derechos, en el primer panel, todas las dimensiones de TD, en el segundo y último panel. Estos diferenciales de ingreso son mayores hasta en $4.7 \mathrm{pp}, 164.1 \mathrm{pp}$ y $43 \mathrm{pp}$, respectivamente, a los obtenidos entre empleados con y sin otro tipo de déficit en cada uno de esos paneles. Esto podría sugerir que las condiciones no decentes de trabajo en una EF producen, en promedio, penalizaciones salariales para los trabajadores que se desplaza desde un puesto sin a otro con déficit de TD así como ganancias salariales para los que realizan la transición contraria, controlando por las características observables de los empleados así como por aquellas inobservables constantes en el tiempo al igual que por el sector de ocupación.

Por otra parte, la evolución temporal de las brechas salariales estimadas por OLS-pooled muestra que la mayoría de ellas suben entre 2004-2005 y 2006-2007 para luego bajar en el último período. En cambio, casi la totalidad de los diferenciales de ingresos estimados por FE que resultaron estadísticamente significativos se incrementan a lo largo del período considerado, observándose el mayor crecimiento- de $31 \mathrm{pp}$ - en la brecha computada entre los asalariados del sector formal con y sin déficit en protección social, controlando por dummies de ocupación ${ }^{30}$. Este resultado es sorprendente, al menos, por tres razones. Primero, según Majid (2001) existe una correlación positiva entre las condiciones de TD y el nivel, así como, el crecimiento de los ingresos nacionales. En consecuencia, resulta llamativo que los diferenciales de ingreso se incrementen y no disminuyan durante un período de crecimiento económico como el experimentado en el país entre 2003 y 2007. En segundo lugar, conforme con Majid (2001), la relación entre TD y crecimiento económico en países de bajos ingresos pueden imperiosamente estar basadas en la dimensión empleo y seguridad social, mientras que en aquellos de ingresos promedio todas las dimensiones de TD se encuentran significativamente más vinculadas. Sin embargo, cabe destacar que el crecimiento económico es una condición necesaria para generar altos niveles de empleos, pero no suficiente para que éstos sean calidad. Para crear empleos de calidad es necesario valerse de herramientas que generan ese cambio (como el comercio, las finanzas, las pautas de producción y de consumo, la inversión, las tecnologías, la iniciativa empresarial, el desarrollo de habilidades y la promoción de la formación profesional) pero también de políticas activas del mercado laboral así como de políticas públicas del desarrollo económico que sean capaces de producir mejoras directas en las diferentes dimensiones de TD (OIT, 2002). Por ello también, en alguna medida, es preocupante que el crecimiento del diferencial salarial coincida no sólo con un período de recuperación económica sino de implementación de un conjunto de políticas de empleo y de promoción de TD que se ejecutan en el país desde 2003. Esto podría implicar que para sostener nuevos empleos de calidad es crucial que un contexto estratégico de crecimiento económico se articule con las políticas activas del mercado laboral.

\footnotetext{
${ }^{29}$ En los análisis de esta sección, la dimensión empleo no incluye la condición de que el ingreso laboral sea mayor o igual al SMVM. Para más detalles ver sección 3.3 .

${ }^{30}$ Esta diferencia es estadísticamente significativa conforme con los intervalos de confianza computados.
} 
Los hallazgos más relevantes para la hipótesis de este estudio son las siguientes. En primer lugar, en todos los paneles del período 2004-2009, existen penalizaciones salariales estadísticamente significativas y negativas asociadas con la no registración y con el déficit de TD. Esto, a su vez, implica que las barreras a la entrada a puestos de trabajo registrados o aquellos con condiciones decentes $^{31}$, llevan a los ANR a permanecer en puestos con remuneraciones menores a las que, en promedio, obtendrían si estuviesen registrados. En segundo lugar, los diferenciales salariales, que permanecen estadísticamente significativos a lo largo del período considerado, crecen en el tiempo. En tercer lugar, aunque las brechas de ingreso pueden explicarse por cambios en las características personales, ocupacionales o en el contexto socioeconómico del país, el modelo de FE empleado en esta investigación controla por aquellos factores observables como por los inobservables que permanecen invariantes en el tiempo así como por los cambios ocurridos en el contexto económico del país por medio de la dummy temporal. La inclusión de variables dummies temporales permite aislar el efecto que algunas políticas públicas -como el incremento en el SMVM o el programa de TDpodrían tener en los salarios y a través de estos, en las estimaciones de los diferenciales de ingreso (Wooldrigde, 2005, Baltagi, 2005). Por lo tanto, si las brechas estimadas no se explican por este conjunto de variables, los resultados obtenidos probablemente sugieren que la desigualdad salarial entre empleados registrados y no registrados así como entre aquellos con y sin condiciones decentes de trabajo es un posible detonador de malestar o conflicto social, sobre todo si son injustificadas e injustas. Aunque hay quienes sostienen que esa desigualdad salarial puede incrementar el esfuerzo productivo de los trabajadores, también suele afirmarse que es un factor desincentivador de la productividad.

Por otra parte, los resultados encontrados tienen importantes implicancias políticas. Es relevante conocer los niveles y la evolución de los diferenciales de ingreso para poder formular políticas públicas efectivas tendientes a cerrar esas brechas. Además, los diferenciales salariales entre empleados del sector formal con y sin déficit en derechos laborales de hasta un $49.2 \%$ pueden estar relacionados con fallas institucionales y legales por naturaleza. Del mismo modo, una brecha de ingreso de un $41.4 \%$ asociada con la falta de registración, controlando por la existencia de déficit de empleo, puede tener efectos distributivos directos sobre el nivel y el crecimiento del ingreso nacional. Por lo tanto, las políticas que tienen como objetivo producir progresos en alguna o en todas las dimensiones de TD pueden también tener impactos distributivos tendientes a mejorar la equidad social (Majid, 2001). Sin embargo, como se mencionó previamente, las políticas públicas deben ser acompañadas de un proceso prolongado y persistente de crecimiento económico para que esos grupos de trabajadores tengan mayores chances de alcanzar un empleo con condiciones decentes que perduren en el tiempo (Beccaria, 2007).

En conclusión, los resultados obtenidos son consistentes con la hipótesis de segmentación del sector formal en la Argentina. Los hallazgos indican la existencia de una relación negativa entre los ingresos laborales y la ausencia de registración o de condiciones laborales decentes que se mantiene durante el período 2004-2009. Si se cumplen los supuestos bajo los cuales FE es consistente, esta correlación negativa implica además, que dentro de un mismo sector, el conformado por el conjunto de empresas formales, existen mecanismos salariales y de empleo distintos para trabajadores registrados y no registrados así como para aquellos con y sin déficit en alguna dimensión de TD. Sin embargo, es necesario tener presente las debilidades previamente mencionadas del método econométrico implementado (ver sección 4.2). En primer lugar, la falta de significancia estadística de algunas brechas salariales computadas puede estar asociada con la escasa variabilidad temporal de los datos, dado la corta extensión de los paneles ${ }^{32}$. En segundo lugar, Maloney (1999) señala que los diferenciales que incluyen características inobservables relacionadas con el trabajo no pueden ser prueba de segmentación, pues podrían existir ciertas ventajas no pecuniarias asociadas con puestos informales, atractivas para algunos individuos, que podrían compensar, total o parcialmente, la penalización salarial computada. Sin embargo, las ventajas no pecuniarias como la flexibilidad, la independencia, la posibilidad de adquirir experiencia laboral, etc., están, en general, más asociadas con trabajados independientes que con empleados asalariados. Además, el supuesto implícito en esta afirmación de Maloney (1999) es que los trabajadores eligen entre ser formal e informal basándose en la maximización de su utilidad ${ }^{33}$. No obstante, ese supuesto puede ser válido en mercados laborales perfectamente competitivos y en países desarrollados con bajo nivel de desocupación. En países en desarrollo como la Argentina, con mayores niveles de desocupación es poco probable que el trabajador, sobre todo el asalariado, tenga posibilidades de realizar tal elección.

\footnotetext{
${ }^{31}$ Los resultados de las matrices de transición sugieren la existencia de barreras a la entrada dentro de las EF. Ver sección 5.1 para más detalles.

${ }^{32}$ Cabe recordar que el método $\mathrm{FE}$ explota la variabilidad de los datos en el tiempo.

${ }^{33}$ Es por esto que para Maloney (1999) la combinación tradicional de los problemas de la informalidad y el dualismo del mercado laboral es inadecuada conceptualmente.
} 
Es decir, si bien pueden existir diversas modalidades en el empleo informal asociadas con ciertas características deseables para el trabajador, el empleo formal es un bien escaso, sobre todo en países en desarrollo (Fields, 2004). Por lo tanto, las brechas negativas de ingresos encontradas en este estudio, probablemente estén asociadas con barreras a la entrada a puestos registrados en el sector formal. En tercer lugar, la estimación de los diferenciales de ingresos por FE no permite controlar por la posible heterogeneidad inobservable que varía en el tiempo. Sin embargo, el posible sesgo que esto causaría en las brechas de ingresos estimadas podría ser pequeño o irrelevante considerando que son escasos los factores inobservables correlacionados con los ingresos que varían en el tiempo. Finalmente, aunque los resultados de esta sección están basados en paneles cortos, Cameron y Trivedi (2007) afirman que es posible estimar consistentemente el parámetro de interés aun cuando los efectos individuales y la media condicional no estén identificados. Además, a pesar de que una de las principales debilidades prácticas del modelo de FE sea la imposibilidad de estimar coeficientes regresores invariantes en el tiempo, en este caso, el parámetro de interés puede ser consistentemente estimado por FE, bajo los supuestos ya analizados.

\subsection{Cantidad de segmentos en el sector formal}

En esta sección se examina la estructura del sector formal en Argentina analizando la cantidad de segmentos posibles a partir de los resultados obtenidos de la estimación de modelos mixtos finitos con diferentes especificaciones para cada panel. Las especificaciones de los modelos estimados fueron básicamente dos: uno restringido que representa a un sector formal homogéneo y otro sin restringir que denota a un sector compuesto de dos o más segmentos.

Como una primera aproximación estadística a la investigación de la estructura del sector formal se examinan las distribuciones del ingreso laboral mensuales de los asalariados en ese sector que fueron clasificados según su condición de informalidad y la presencia de algún déficit en términos de trabajo decente.

Las densidades del logaritmo del ingreso laboral (en \$ constantes de 2006) estimadas por Kernel correspondientes a los AR con DTD y sin él así como a los ANR en las EF para cada panel muestran diferencias significativas (Gráficos B1 a B3). En primer lugar, mientras la distribución salarial de los la de los AR con déficit de TD y sin él es unimodal, la estimada entre los ANR parece ser bimodal en los dos primeros paneles y multimodal en el último. Este hallazgo es sumamente interesante pues una distribución bimodal además de ser poco común, sugiere la existencia de poblaciones con dos puntos máximos diferentes cuyas distribuciones deberían ser analizadas en forma independiente. Esto, a su vez, implica la existencia de diferenciales salariales entre los ANR, todos ellos empleados en una empresa formal. Este hallazgo es fuertemente relevante para la hipótesis de segmentación del sector formal. Una distribución con esas características podría sugerir que dentro de ese sector existen tres segmentos - uno homogéneo constituido por puestos formales ya sean con déficit de TD o sin él y otros dos, comprendidos por empleos no registrados en las EF - con características particulares distintas.

En segundo lugar, las distribuciones salariales de los AR son más apuntaladas que la estimada entre los ANR. Además, esta distribución se aplana considerablemente entre 2004-2005 y 2008-2009, en comparación con las estimadas entre los AR, que permanecen más apuntaladas a lo largo del período analizado. Esto podría sugerir que los salarios mensuales de los ANR no sólo son más volátiles que el de los AR, sino también más desiguales. En efecto, el coeficiente de Gini de la distribución salarial de los empleados no registrados de una EF, es 0.53 en el primer panel, 0.43 en el segundo y 0.40 en el último. En cambio, entre los AR sin DTD ese índice permanece alrededor de 0.32 en los dos primeros paneles y luego cae a 0.30 en el último período. Asimismo, para los AR con DTD, el coeficiente de Gini es de 0.31 en 2004-2005, 0.30 en $2006-2007$ y 0.28 en 2008-2009 $9^{34}$. Esto sugiere que dentro del grupo de empleados no registrados existen amplias disparidades en el ingreso laboral percibido que conducen a que existan grupos distintos, en términos salariales, dentro de una misma población, la de los no registrados.

Finalmente, gran parte de la distribución de los ANR se encuentra a la izquierda de la estimada entre los AR con DTD y sin él, pero una porción de ella se superpone una con otra. Esto significa que si bien los AR presentan una considerable ventaja salarial respecto de los empleados no registrados, existe una parte, posiblemente exigua, de estos últimos trabajadores cuyo ingreso laboral no es inferior a la de los empleados registrados. Por otra parte, cabe destacar que toda la densidad de los ANR presenta un desplazamiento a la derecha entre el primer y último panel lo que podría indicar un aumento de la remuneración promedio para este grupo de asalariados. En efecto, el ingreso laboral

\footnotetext{
${ }^{34}$ Las diferencias entre los coeficientes de Gini obtenidos para los ANR y los computados entre los AR son estadísticamente significativos a un nivel del $5 \%$.
} 
promedio de los ANR pasó de $\$ 530.7$ en el 2004-2005 a $\$ 1260.9$ en 2008-2009. Sin embargo, mientras el primer modo de la distribución parece no variar, el segundo se incrementa a lo largo del período bajo análisis. Esto justamente indicaría, a priori, que no existe una situación laboral homogénea en términos salariales, para los trabajadores no registrados, aun cuando todos ellos pertenecen al sector formal. Por lo tanto, las formas de las densidades estimadas son consistentes con la hipótesis de que ese sector está compuesto por más de un segmento durante el período considerado.

En el Cuadro 5 se reportan los criterios de información correspondientes a los distintos modelos mixtos finitos estimados para cada panel ${ }^{35}$ con el método descrito en la sección 4.3. El resultado más importante es que la especificación del modelo con más de tres componentes produce un mejor ajuste en cada año que el modelo restringido y sin restringir con dos componentes, conforme con todos los criterios de información computados. Esto implica que, dentro del sector formal, existen al menos tres poblaciones de asalariados con distribuciones salariales distintas: una perteneciente a los registrados y dos a los empleados sin registrar, cuyas distribuciones salariales presentan características distintas. Además, estos resultados son consistentes con lo que sugieren las distribuciones salariales estimadas en cada panel. Por otra parte, cabe destacar que, en el último panel, 2008-2009, el modelo que presenta un mejor comportamiento y es uniformemente superior a una especificación restringida es el de cuatro componentes conforme se esperaba a partir del análisis de las densidades salariales estimadas que muestran cuatro distribuciones distintas, tres para los ANR y una para los AR.

Cuadro 5

Criterios de información para distintas especificaciones del modelo mixto finito, 2004-2009

\begin{tabular}{cccccccc}
\hline \hline & Componentes & AIC & AIC $^{3}$ & CAIC & BIC & BIC ajustado & H-Q \\
\hline \multirow{2}{*}{$2004-2005$} & Uno & 1314966.20 & 1314979.20 & 1315130.88 & 1315117.88 & 1315076.57 & 1315008.19 \\
& Dos & 1260296.80 & 1260309.80 & 1260462.79 & 1260449.79 & 1260408.47 & 1260338.98 \\
& Tres & 1062917.00 & 1062930.00 & 1063082.99 & 1063069.99 & 1063028.67 & 1062959.18 \\
\hline \multirow{3}{*}{$2006-2007$} & Uno & 1254345.60 & 1254358.60 & 1254508.38 & 1254495.38 & 1254454.06 & 1254387.31 \\
& Dos & 1153174.00 & 1153187.00 & 1153336.78 & 1153323.78 & 1153282.46 & 1153215.71 \\
& Tres & 964457.20 & 964470.20 & 964619.98 & 964606.98 & 964565.66 & 964498.91 \\
\hline \multirow{3}{*}{$2008-2009$} & Uno & 1444949.40 & 1444962.40 & 1445115.39 & 1445102.39 & 1445061.07 & 1444991.58 \\
& Dos & 1209691.40 & 1209704.40 & 1209855.87 & 1209842.87 & 1209801.56 & 1209693.48 \\
& Tres & 1052257.20 & 1052270.20 & 1052421.67 & 1052408.67 & 1052367.36 & 1052299.16 \\
& Cuatro & 881750.60 & 881763.60 & 881915.07 & 881902.07 & 881860.76 & 881792.56 \\
\hline
\end{tabular}

Nota: El modelo con un componente es el modelo restringido en tanto que los modelos con más de un componente corresponde al modelo no restringido. Todos los modelos estimados incluyen como variables dependiente el ingreso laboral mensual y como variables explicativas sexo, edad, educación, estado civil, posición en el hogar, presencia de un jefe ocupado en el hogar y términos que corrigen por sesgo de selección. En el primer y segundo panel las estimaciones por máxima verosimilitud del modelo mixto con cuatro componentes no convergen. En el tercer panel, la no convergencia en la estimación tiene lugar para un modelo mixto con cinco componentes.

Fuente: Elaboración propia en base a EPH-INDEC.

A partir de los resultados del cuadro 6 se puede analizar otra característica del sector formal. Según las estimaciones del modelo mixto con tres componentes, el tamaño estimado de cada uno de los segmentos del sector formal, representa un $34 \%$, un $64 \%$ y apenas un $2 \%$ de ese sector, en el primer panel. En cambio, las participaciones de los dos primeros segmentos son relativamente proporcionales en 2006-2007 pero la correspondiente al último segmento es de sólo un 4\%. Por su otra parte, las estimaciones del modelo mixto con cuatro componentes en el 2008-2009 indican que el tamaño del segundo segmento, es el más alto y constituye el $82 \%$ de aquel sector. Por lo tanto, las estimaciones indican que el sector formal es altamente desproporcionado en el tamaño de sus segmentos considerados individualmente. Esto podría sugerir que existe un conjunto significativo de EF con una estructura compleja. En efecto, como se trata de medianas y grandes empresas, es probable que, en general, sean registradas por parte de sus ventas, pero que presenten distintos grados de registración por parte de sus empleados, es decir, distintos niveles de cumplimiento de las debidas regulaciones laborales y sociales. Esto último, a su vez, parece traducirse en la existencia de mecanismos salariales diferentes. La cuestión empírica crítica es qué proporción de este sector corresponde a quienes trabajan como formales versus aquellos que no, es decir, qué segmento representa la parte desventajada dentro de una empresa que aparenta ser completamente formal.

\footnotetext{
${ }^{35}$ En el primer y segundo panel las estimaciones por máxima verosimilitud del modelo mixto con cuatro componentes no convergen. En el tercer panel, la no convergencia en la estimación tiene lugar para un modelo mixto con cinco componentes.
} 
Cuadro 6.

Tamaño de los segmentos del sector formal, 2004-2009

\begin{tabular}{ccccc}
\hline Período & Segmento & $\pi_{\mathrm{j}}$ & \multicolumn{2}{c}{ Intervalo de confianza (95\%) } \\
\hline \multirow{4}{*}{$2004-2005$} & Uno & $\begin{array}{c}0.339 \\
(0.002)\end{array}$ & 0.335 & 0.343 \\
& Dos & $\begin{array}{c}0.640 \\
(0.002)\end{array}$ & 0.637 & 0.644 \\
& Tres & $\begin{array}{c}0.020 \\
(0.0002)\end{array}$ & 0.020 & 0.021 \\
\hline \multirow{2}{*}{$2006-2007$} & Uno & $\begin{array}{c}0.525 \\
(0.002)\end{array}$ & 0.522 & 0.528 \\
& Dos & $\begin{array}{c}0.435 \\
(0.002)\end{array}$ & 0.432 & 0.439 \\
& Tres & $\begin{array}{c}0.039 \\
(0.0002)\end{array}$ & 0.039 & 0.040 \\
\hline \hline \multirow{2}{*}{$2008-2009$} & Uno & $\begin{array}{c}0.129 \\
(0.0005) \\
0.823\end{array}$ & 0.128 & 0.130 \\
& Dos & $\begin{array}{c}0.0006) \\
0.033\end{array}$ & 0.822 & 0.824 \\
& Tres & $\begin{array}{c}0.0002) \\
0.015\end{array}$ & 0.032 & 0.033 \\
& Cuatro & $(0.0001)$ & 0.014 & 0.015 \\
\hline
\end{tabular}

Nota: El tamaño estimado de los segmentos del sector formal corresponden al modelo con mejor ajuste, en cada panel, conforme con los criterios de información. Entre paréntesis figuran los errores estándares.

Fuente: Elaboración propia en base a EPH-INDEC.

En conclusión, los resultados obtenidos sugieren que el sector formal consiste de al menos tres segmentos. Esto a su vez, implica que los trabajadores se enfrentan a distintas condiciones salariales, dentro de un sector considerado tradicionalmente como homogéneo, que no se explican por diferencias en los atributos observables incluidos en los modelos estimados. Incluso, la situación en términos salariales, podría empeorar si se consideran que existen ciertas habilidades y atributos no observados que son menos recompensados en algunos segmentos dentro de una EF que en otros. Es decir que a pesar de la expansión del empleo formal durante el período de auge económico y de implementación de políticas de formalización tendientes a regularizar la situación laboral de los trabajadores informales, la calidad de la inserción laboral, incluso dentro del sector formal, al menos en términos salariales, parece no haber mejorado. Por lo tanto, estos hallazgos aportan evidencia empírica adicional a favor de la hipótesis que segmentación del sector formal en Argentina, al menos durante el período considerado.

\section{Conclusiones}

El objetivo principal de esta investigación fue explorar, desde una perspectiva dinámica, el impacto del fenómeno de la informalidad, analizado en términos de déficit de trabajo decente, en la estructura del mercado laboral argentino, es decir, la hipótesis de que el sector formal no es homogéneo sino que consiste en más de un segmento con una estructura compleja, diferente a la que se le asignó tradicionalmente en la literatura. Además de la exploración de esta hipótesis, otro de los aspectos novedoso de la presente investigación es la incorporación de la perspectiva del TD en el estudio de la informalidad y de la estructura del mercado laboral argentino.

A partir de la información obtenida de la EPH para el período 2004 - 2009 se analizaron algunas características que asume la informalidad laboral dentro del sector formal en la Argentina cuando se considera la perspectiva del TD. A pesar del crecimiento económico de los últimos años y las políticas de formalización implementadas en el país, el empleo informal sigue mostrando cifras alarmantes.

Considerando los primeros estudios que asocian segmentación laboral con barreras a la entrada y una limitada movilidad de los trabajadores entre los distintos sectores del mercado laboral, se estimaron matrices de transición, observando particularmente los movimientos de los trabajadores dentro y fuera del sector formal. Los resultados mostraron, en todos los años, una elevada permanencia de los AR sin déficit de trabajo decente, empleados en empresas formales así como escasos movimientos de los ANR hacia empleos registrados dentro del mismo sector. En promedio, casi el 33\% de los ANR de EF permanecen en la misma categoría ocupacional, mientras que sólo un $6.8 \%$ logra trasladarse hacia puestos registrados sin DTD en una EF. Sin embargo, este conjunto de trabajadores deberían ser el segmento más permeable a las políticas activas de fiscalización y regularización, por ser los más visibles. 
Una forma de contrastar la hipótesis de investigación es examinando la existencia de dos segmentos laborales diferentes con características salariales distintas. Con este fin, se estimaron brechas de ingreso para los asalariados del sector formal con déficit en distintas dimensiones de TD y sin él. Los resultados obtenidos muestran la existencia de diferencias salariales significativas. La brecha de ingresos más alta fue la estimada por EF, en el segundo panel, entre los asalariados del sector formal con déficit en todas las dimensiones de TD y sin él (177\%). La importancia de este hallazgo radica en sus implicaciones respecto a la estructura del sector formal.

Otro método econométrico implementado para explorar la hipótesis de investigación fue la estimación de la cantidad de segmentos del sector formal en Argentina. Las estimaciones de modelos mixtos finitos revelaron que ese sector presenta, al menos, tres componentes con mecanismos salariales distintos. Además, en general, el sector formal es altamente desproporcionado en el tamaño de sus segmentos considerados individualmente.

Por lo tanto, a la luz de los resultados obtenidos, la hipótesis de segmentación del sector formal y, por ende, del mercado laboral, parece ser plausible en nuestro país para el período 2004-2009. En consecuencia, un modelo de mercado laboral tradicional con un sector formal que presenta una estructura homogénea no parece ser adecuado para la Argentina. Además, como afirma Fields (2008), un número considerable de políticas pueden ser entendidas usando modelos de mercado laboral segmentado pues el análisis de un único mercado simplemente no puede explicar lo que vemos. Por lo tanto, los hallazgos encontrados en esta investigación son particularmente importantes para la elaboración de políticas específicas que tiendan a reducir la informalidad en unidades productivas que se suponen altamente permeables a las políticas de supervisión por parte del gobierno. Aunque, para algunas firmas la evasión de normas impositivas y laborales es una forma de ampliar el margen de beneficios, para muchas, principalmente las de menor tamaño, la formalización se presenta como un obstáculo que puede, no sólo perjudicar su viabilidad inicial al momento de emprender la actividad productiva, sino también dificultar su crecimiento y sustentabilidad. Los hallazgos empíricos del estudio que sugieren una estructura compleja para el mercado laboral argentino $\mathrm{y}$, en particular, para el sector formal, ponen de manifiesto la necesidad implementar políticas integrales a fin de solucionar el déficit de trabajo decente, que apunten a no sólo de los trabajadores, sino también, a las unidades productivas, reconociendo especificidades sectoriales y atendiendo al desarrollo económico sostenible de las empresas.

Si bien no existen soluciones rápidas que se adapten a la realidad compleja de la economía informal, las estrategias deben enmarcarse en la promoción no sólo de la formalidad sino del trabajo decente. Para ello, es importante contar con un plan de acción integrado de amplio alcance que abarque un conjunto de áreas de política, elimine los aspectos negativos de la informalidad, preserve el potencial de crear empleo en la economía formal y promueva la protección de los trabajadores así como de las unidades económicas.

\section{Referencias bibliográficas}

Alzúa, M. L. (2008). "Are Informal Workers Secondary Workers?: Evidence for Argentina" Documento de Trabajo $N^{\circ} 73$. CEDLAS. Universidad Nacional de La Plata.

Anker, R, Chernyshev, I, Egger, P., Mehran, F. y Ritter, J. (2002). "Measuring Decent Work with Statistical Indicators". Unidad de Desarrollo y Análisis Estadístico del Departamento de Integración de Políticas de la OIT. Documento de trabajo, 2. Ginebra, OIT, octubre.

Arcidiacono, P. y Jones J. B. (2002). "Finite Mixture Distributions, Sequential Likelihood and the EM Algorithm," Econometrica.

Arellano, M. (1987). "Computing Robust Standard Errors for Within-Groups Estimators," Oxford Bulletin of Economics and Statistics $N^{\circ} 49$, pp: 431-434.

Arias, O. y Escudero, S. W. (2007). "Assessing Trends in Informality in Argentina: a Cohorts Panel VAR Approach". mimeo, Banco Mundial, UDESA, CEDLAS-UNLP.

Arias, O. y Khamis, M. (2008). "Comparative Advantage, Segmentation and Informal Earnings: A Marginal Treatment Effects Approach", Institute for the Study of Labor (IZA), Discussion Paper N 3916.

Banco mundial y MTEySS (2008). Aportes a una Nueva Visión de la Informalidad Laboral en la Argentina. $1^{\underline{a}}$ ed. Buenos Aires. Agosto.

Beccaria, L. (2001). "Movilidad Laboral e Inestabilidad de Ingresos en Argentina", en Estudios del Trabajo $\mathrm{N}^{\circ} 21$, Buenos Aires.

Beccaria, L. (2007). "El Mercado de Trabajo Luego de la Crisis. Avances y Desafíos". Colección de Documentos de proyectos. CEPAL. 
Beccaria, L. y Groisman, F. (2007). "Informalidad y pobreza en Argentina", Anales de la Asociación Argentina de Economía Política, Buenos Aires. Disponible en: www.aaep.or.ar.

Beccaria, L., Groisman, F. y Monsalvo, P. (2006). "Informalidad y pobreza en Argentina", Anales de la Asociación Argentina de Economía Política, Buenos Aires. Disponible en: www.aaep.or.ar

Bergesio, L., Golovanevsky, L. y Marcoleri, M.E. (2007). "Debate Teórico Metodológico y un Nuevo Intento de Medición del Sector Informal Urbano para el Caso del Barrio Alto Comedero. (San Salvador de Jujuy, Jujuy, Argentina)", en Lavboratorio, Año 8, N²0. Instituto de Investigaciones Gino Germani, Facultad de Ciencias Sociales, Universidad Nacional de Buenos Aires, Buenos Aires.

Bertranou, F. y Paz, J. (2003), "Lo Bueno, lo Malo y lo Feo. Empleo, desempleo y exclusión social en la Argentina, Anales de la Asociación Argentina de Economía Política, Buenos Aires. Disponible en: www.aaep.or.ar.

Bescond, D., Châtaignier A. y Mehran F. (2003). "Seven Indicators to Measure Decent Work: An International Comparison", International Labour Review, 142(1), pp: 179-211.

Bonnet, F., Figueiredo, J. B., y Standing, G. (2003). "A Family of Decent Work Indexes", International Labor Review, Vol. 142, N².

Bosch, M. y Maloney, W. F. (2006). "Gross Worker Flows in the Presence of Informal Labor Markets. The Mexican Experience 1987-2002", Centre for Economic Perfomance, Discussion paper № 753, Octubre.

Bourguignon, F., Fournier, M. y Gurgand, M. (2004). "Selection Bias Correction Based on the Multinomial Logit Model: Monte-Carlo Comparisons", Mimeo Delta, Paris.

Cahuc, P. y Zylberberg, Z. (2004). Labor Economics, MIT Press.

Camargo, J. M. y García, N. E. (1992). "El salario mínimo como señal para el mercado de trabajo", PREALC 371, Santiago. Press.

Cameron y Trivedi, P. (2007). Microeconometrics: Methods and Applications, Cambridge University

Chen, H., Chen, J., y Kalbfleisch, J. D. (2004). "Testing for a Finite Mixture Model with Two Components", Journal of the Royal Statistical Society. Vol. N66, pp. 95-115.

Del Río, C., Gradïn, C. y Cantó, O. (2006). "The Measurement of Gender Wage Discrimination: the Distributional Approach Revisited", ECINEQ, Working paper N²5.

Development?," Proceedings of the World Bank Annual Conference on Development Economics 1992, Special Supplement to the World Bank Economic Review and World Bank Research Observer, pp: 117-144.

Doeringer, P. B. y Piore, J. M. (1971). Internal Labor Markets and Manpower Analysis, Heath Lexington Books.

Dubin, J. A. y McFadden, D. L. (1984). "An econometric analysis of residential electric appliance holdings and consumption", Econometrica $\mathrm{N}^{\circ} 52$, pp: 345-362.

Fields, G. S. (1975). "Rural-Urban Migration, Urban Unemployment and Underemployment, and Job Search Activity in LDC's," Journal of Development Economics, 2, pp: 165-188.

Fields, G. S. (2004). "A Guide to Multisector Labor Market Models", Banco Mundial, Washington, Noviembre.

Fields, G. S. (2008). "Segmented Labor Market Models in Developing Countries". ILR Collection Articles and Chapters. Cornell University ILR School. Marzo.

Foster, J. E., Greer, E. y Thorbecke, E. (1984). "A Class of Decomposable Poverty Indices", Econometrica, 52, pp: 761-766.

Freeman, R. (1993). "Labor Market Institutions and Policies: Help or Hindrance to Economic

Galiani., S. y Weinschelbaum., F. (2007). "Modeling Informality Formally: Households and Firms".

CEDLAS, Documento de Trabajo N 47, La Plata, Marzo.

Galli, R. y Kucera, D. (2004), "Labor Standards and Informal Employment in Latin America", World

Development, 32(5), pp: 809-828.

Gasparini, L. y Tornarolli, L. (2007). "Labor Informality in Latin American and the Caribbean:

Patterns and Trends from Household Surveys Microdata", CEDLAS, Documento de Trabajo № 46, La

Plata, Febrero.

Gasparini, L., Haimovich, O. y Olivieri., S. (2007). "Labor Informality Effects of a Poverty-Alleviation

Program". CEDLAS, Documento de Trabajo № 53, La Plata, Junio.

Ghai, D. (2002). "Decent Work: Concepts, Models and Indicators". IILS, DP/139, Suiza.

Ghai, D. (2003). "Trabajo Decente: Conceptos e Indicadores". Revista Internacional del Trabajo, vol. $122, N^{\circ} .2$.

Green, W. (2001). "Estimating Econometric Models with Fixed Effects". Department of Economics, Stern School of Business, New York University. 
Günther, I. y Launov, A. (2007). "Competitive and Segmented Informal Labor Markets", The Institute for the Study of Labor (IZA), Marzo.

Harris, J.R. y Todaro, M.P. (1970). "Migration, Unemployment, and Development: A Two-Sector Analysis", American Economic Review, N60, pp: 126-42.

Hart, K. (1973). "Informal Income Opportunities and Urban Employment in Ghana," Journal of Modern African Studies, N¹1, pp: 61-89.

Holm, A., Jæger M. M., y Pedersen, M. (2008). "Unobserved Heterogeneity in the Binary Logit Model with Cross-Sectional Data and Short Panels: A Finite Mixture Approach". Working paper N ${ }^{\circ}$ 2009-04. Centre for Applied Microeconometrics. Department of Economics University of Copenhagen. Hussmans, R. (2004). "Defining and Measuring Informal Employment", OIT, Ginebra.

Keribin, C. (2000), "Consistent estimation of the order of mixture models," Sankhya, ser. A, 62, pp: 49-66.

Kerr, C. (1954). The Balcanization of Labour Markets, in Labour Mobility and Economic Opportunity, MIT Press, Cambridge Mass, pp: 92-110.

Lanari, M.E. (2005). Trabajo Decente: Diagnóstico y Aportes para la Medición del Mercado Laboral Local. Mar del Plata 1996-2002. Ed. Suárez, Mar del Plata.

Lee, L. F. (1983). "Generalized econometric models with selectivity", Econometrica, N51, pp: 507512.

Lewis, W. (1954). "Economic Development with Unlimited Supplies of Labour", Manchester School, $N^{\circ} 22$, pp: 139-191.

Maddala, G., S. (1999). Limited Dependent and Qualitative Variables in Econometrics, Ed. Cambridge University Press, Cambridge.

Majid, N. (2001), "Economic Growth, Social Policy and Decent Work", Emplyment Paper, International Labour Office, Geneva.

Maldonado C. (1995). "Sector Informal: ¿Legalización o Laissez-Faire?", Revista Internacional del Trabajo (Ginebra), vol.114, ํㅜ 6, pp: 809.

Maloney, W., F. (1999). "Does Informality Imply Segmentation in Urban Labor Markets? Evidence from Sectoral Transitions in Mexico", The World Bank Economic Review, $N^{\circ} 13$, pp: 275-302.

Maloney, W., F. y Nuñez, J. (2002). "Measuring the Impact of Minimum Wages: Evidence from Latin America", World Bank Policy Research Working Paper Nº 2597.

Maloney, William F. (2004). "Informality Revisited," World Development 32(7), pp: 1159-1178.

Marcouiller, D., Ruiz de Castilla, V., y Woodruff, Ch. (1997). "Formal Measures of the Informal

Sector Wage Gap in Mexico, El Salvador, and Peru," Economic Development and Cultural Change, $\mathrm{N}^{\circ}$ 45, pp: 367-392.

Marshall, A. y Perelman, L. (2006). "Salario mínimo, mercado de trabajo y pobreza - Argentina (2003-2005)", Buenos Aires, julio. Disponible en http://oit.org.ar/documentos/marshall adriana dic06.pdf.

McLachlan, G.J., y Peel, D. (2000). Finite Mixture Models. New York: John Wiley \& Sons.

McLeod, D. y Lustig, N. (1997). "Minimum Wages and Poverty in Developing Countries: Some

Empirical Evidence," in Labor Markets in Latin America, S. Edwards and N. Lustig (eds.), Washington:

Brookings Institution, pp: 62-103.

Monza, A. (2000). "La Evolución de la Informalidad en el Área Metropolitana en los Años 90,

Resultados e Interrogantes", en Carpio, J., Klein, E., Novakovsky, I., compiladores, "Informalidad y exclusión social", OIT/Siempro/Fondo de Cultura Económica, Buenos Aires.

MTEySS - OIT (2007). Los trabajadores independientes y la seguridad social, Buenos Aires, Serie de publicaciones de la Secretaría de Seguridad Social. Año IV. № 4.

OIT. (1991). "El Dilema del Sector No Estructurado", Memoria del Director General, 78

Conferencia Internacional del Trabajo, Ginebra.

OIT. (2001). "Promoción de las cooperativas", Memoria del Director General, 89ª Conferencia Internacional del Trabajo, Ginebra.

OIT. (2002). "El Trabajo Decente y la Economía Informal", 90ª Conferencia Internacional del Trabajo, Ginebra.

OIT. (2006). "Trabajo Decente en las Américas: Una Agenda Hemisférica, 2006-2015”, Informe del

Director General, XVI Reunión Regional Americana, Brasil.

OIT. (2008). "Decent Work Country Programme Argentina", Ministerio de Trabajo, Empleo y Seguridad Social, Argentina.

OIT. (2008). "Decent Work Indicators for Asia and the Pacific, A Guidebook for Policy-makers and

Researchersand the Informal Economy", International Labour Office, Regional Office for Asia and the Pacific, Bangkok: 1 v., Geneva. 
Paz, J. A. (2004). "Argentina: Dinámica de la Protección Social y el Mercado Laboral, 1995-2002". En Protección Social y Mercado Laboral (ISBN 92-2-316538-5). OIT, Santiago de Chile.

Paz, J. A. (2009). "El Empleo de Bajos Ingresos en la Argentina", Anales de la Asociación Argentina de Economía Política, Buenos Aires. Disponible en: www.aaep.or.ar

Perry, G. E., Maloney, W., Arias, O., Fajnzylber, P., Mason, A. y Saavedra, J. (2007). "Informality:

Exit and Exclusion", Estudios del Banco Mundial sobre América Latina y el Caribe, Washington.

Disponible en: www.siteresources.worldbank.org/INTLAC/Resources.

Portes, A., Castells, M. y Benton, L. (1989). The Informal Economy. Studies in Advanced and Less Developed Countries. Baltimore y Londres, The Johns Hopkins University Press.

Pratap, S. y Quintín, E. (2006). "Are Labour Markets Segmented in Developing Countries? A Semiparametric Approach", European Economic Review N50, pp: 507-542.

Rosenbaum, P. y Rubin, D. (1983). "The Central Role of the Propensity Score in Observational Studies for Causal Effects", Biometrika, 70 (1), pp: 41-55, Abril.

Roy, A.D. (1951). "Some Thoughts on the Distribution of Earnings." Oxford Economic Papers, $N^{\circ} 3$, pp: $135-146$.

Salvia E. A., y Lepore A. R. (2008). "Trabajo Decente, Inclusión Social y Desarrollo Humano en la Argentina: Progresos Reciente y Desafíos Pendientes". Universidad Católica Argentina. Observatorio de la Deuda Social Argentina., Serie Documentos de Trabajo, Banco Galicia, 82p, Buenos Aires.

Sen, A. (1999). "El Trabajo Decente, un Derecho Humano", Discurso preparado para la 87ª Conferencia Internacional del Trabajo.

Somavia, J. (2000). Discurso del 1ํ de mayo de 2000 en presencia del Papa Juan Pablo II, Comunicado de prensa OIT/00/15.

Titterington, D. M., Smith, A. F. M., y Markov, U. E. (1985). Statistical Analysis of Finite Mixture Distributions, New York: Wiley.

Tokman., V. E. (2001). De la Informalidad a la Modernidad, en Délano, M. (ed.), Oficina Internacional del Trabajo (OIT), Santiago.

Tokman., V. E. (2009). "Informality in Latin America: Interpretations, Facts and Opportunities". Economic Commission for Latin America and the Caribbean (ECLAC). Working Paper Series 2009-01, Marzo.

Uriarte, E. O. (2000). "Concepto y medición del trabajo decente". Documento preparado para el Secretariado pro tempore del Grupo Bologna/Castilla-La Mancha. Montevideo.

Viollaz, Mariana (2010). "Empleo Informal y Apertura Comercial: Evidencia de 20 años de Reformas en Argentina". Tesis de la Maestría en Economía, Facultad de Ciencias Económicas, Universidad Nacional de La Plata. La Plata. Buenos Aires.

Waisgrais, S. (2001). "Segmentación del Mercado de Trabajo en Argentina: una Aproximación a Través de la Economía Informal", Asociación Argentina de Especialista en Estudios del trabajo. Disponible en: www.aset.org.ar.g.

Waisgrais, S. y Sarabia, M. (2008). "La Heterogeneidad de la Informalidad", en Aportes a una nueva visión de la informalidad laboral en Argentina. The World Bank- Ministerio de Trabajo, Empleo y Seguridad Social. Buenos Aires.

Wedel, M. y Kamakura, W. A. (2000). Market Segmentation: Conceptual and Methodological Foundations, 2nd ed, Boston: Kluwer Academic Publishers.

White, H. (1984). Asymptotic Theory for Econometricians. Orlando, FL: Academic Press.

Wingfield-Digby, Chernyshev I., Kapsos, S., y Elder, S. (2008). "Decent Work Indicators for Asia and the Pacific. A Guidebook for Policy Makers and Researchers". International Labour Office, Regional Office for Asia and the Pacific, Bangkok.

Wooldridge, J. M. (1995). "Selection Corrections for Panel Data Models Under Conditional Mean Independence Assumptions," Journal of Econometrics, 68, pp: 115-132.

Wooldridge, J. M. (2002). Econometric Analysis of Cross Section and Panel Data, Cambridge, MA and London, MIT Press. 


\section{Anexo A: Cuadros}

Cuadro A.1. Número de observaciones, matching y attrition

\begin{tabular}{|c|c|c|c|c|c|c|c|c|c|c|}
\hline \multirow[b]{2}{*}{ Onda } & \multicolumn{5}{|c|}{ Muestra sin ponderar } & \multicolumn{5}{|c|}{ Muestra ponderada } \\
\hline & Total & $\%$ & $\begin{array}{c}\text { Asalariados } \\
\text { del sector } \\
\text { formal }\end{array}$ & $\%$ & Atrición & Total & $\%$ & $\begin{array}{l}\text { Asalariados } \\
\text { del sector } \\
\text { formal }\end{array}$ & $\%$ & Atrición \\
\hline $4^{\circ}$ Trimestre 2004 & 46850 & 100 & 7043 & 100 & & 23434149 & 100 & 3611926 & 100 & \\
\hline $4^{\circ}$ Trimestre 2005 & 18282 & 39 & 3373 & 48 & 2 & 8952489 & 38 & 1732733 & 48 & 2 \\
\hline $4^{\circ}$ Trimestre 2006 & 64384 & 100 & 11095 & 100 & & 24039574 & 100 & 4101259 & 100 & \\
\hline $4^{\circ}$ Trimestre 2007 & 23994 & 37 & 4830 & 44 & 6 & 8482452 & 35 & 1740710 & 42 & 8 \\
\hline $4^{\circ}$ Trimestre 2008 & 62107 & 100 & 11026 & 100 & & 24510898 & 100 & 4467586 & 100 & \\
\hline $4^{\circ}$ Trimestre 2009 & 23510 & 38 & 4722 & 43 & 7 & 9026171 & 37 & 1846224 & 41 & 9 \\
\hline
\end{tabular}


Cuadro A. 2. Definición y valores promedios de las variables

\begin{tabular}{|c|c|c|c|c|c|c|c|c|c|c|c|c|c|}
\hline \multirow{3}{*}{$\begin{array}{l}\text { Años } \\
\text { Rótulo de la variable } \\
\end{array}$} & \multirow{3}{*}{ Definición } & \multirow{3}{*}{ Todos } & \multirow{2}{*}{$\begin{aligned} 2004-2005 \\
\text { Asalariados no registrados }\end{aligned}$} & \multirow{2}{*}{\multicolumn{2}{|c|}{ Asalariados registrados }} & \multirow{3}{*}{ Todos } & \multirow{2}{*}{\begin{aligned} & $2006-2007 \multicolumn{1}{c}{} \\
&$ Asalariados no registrados \end{aligned}} & \multirow{2}{*}{\multicolumn{2}{|c|}{ Asalariados registrados }} & \multirow{3}{*}{ Todos } & \multirow{3}{*}{$\begin{array}{l}2008-2009 \\
\begin{array}{c}\text { Asalariados no registrados } \\
\text { No decente }\end{array}\end{array}$} & \multirow{2}{*}{\multicolumn{2}{|c|}{ Asalariados registrados }} \\
\hline & & & & & & & & & & & & & \\
\hline & & & & & & & & $\begin{array}{l}\text { Decente } \\
11498011\end{array}$ & $\begin{array}{l}\text { No decente } \\
156454\end{array}$ & & & & No decente \\
\hline Ingreso & Ingreso mensual de la ocupación principal & $\begin{array}{r}696.63 \\
(0.083)\end{array}$ & $\begin{array}{r}530.59 \\
(0.007)\end{array}$ & $\begin{array}{l}971.07 \\
0.505\end{array}$ & $\begin{array}{r}933.26 \\
(0.007)\end{array}$ & $\begin{array}{l}1161.198 \\
(0.420)\end{array}$ & $\begin{array}{l}785.24 \\
(0.945)\end{array}$ & $\begin{array}{l}1498.01 \\
(0.894)\end{array}$ & $\begin{array}{l}1564.54 \\
(0.693)\end{array}$ & $\begin{array}{l}1675.54 \\
(0.495)\end{array}$ & $\begin{array}{l}1190.02 \\
(1287\end{array}$ & $\begin{array}{l}2124.61 \\
(1.148)\end{array}$ & $\begin{array}{l}2222.21 \\
(0.80)\end{array}$ \\
\hline Educación & & 6.50 & 9.72 & 11.61 & 11.14 & 6.57 & 10.68 & 11.07 & 11.77 & 6.54 & 10.47 & 11.28 & 11.79 \\
\hline Educación & Años de educación formal* & $(0.002)$ & $(0.007)$ & $(0.005)$ & $(0.007)$ & $(0.002)$ & $(0.008)$ & $(0.006)$ & $(0.005)$ & $(0.002)$ & $(0.008)$ & $(0.006)$ & $(0.004)$ \\
\hline Varón & $=1$ si el individuo es varón; ( = 0 si es mujer) & 0.47 & 0.53 & 0.59 & 0.69 & 0.11 & 0.20 & 0.18 & 0.15 & 0.91 & 1.00 & 1.00 & 1.00 \\
\hline Edad & Años cumplidos & 33.86 & 36.24 & 39.94 & 38.84 & 33.87 & 34.31 & 38.28 & 39.70 & 34.12 & 36.50 & 38.45 & 40.02 \\
\hline & & $(0.002)$ & $(0.014)$ & $(0.008)$ & $(0.011)$ & $(0.005)$ & $(0.017)$ & $(0.011)$ & $(0.008)$ & $(0.005)$ & $(0.018)$ & $(0.010)$ & $(0.007)$ \\
\hline Edad $^{2}$ & Años cumplidos al cuadrado & 1635.59 & 1485.17 & 1735.76 & 1643.93 & 1637.21 & 1364.82 & 1599.15 & 1715.71 & 1651.32 & 1533.07 & 1607.63 & 1735.43 \\
\hline Experiencia & & & 19.47 & $\begin{array}{l}(0.108) \\
21.64\end{array}$ & $\begin{array}{l}(0.913) \\
22.20\end{array}$ & $(0.438)$ & $\begin{array}{c}(1.427) \\
15.94\end{array}$ & $\begin{array}{l}(0.913) \\
21.75\end{array}$ & $(0.675)$ & $(0.907)$ & $\left(\begin{array}{l}1.539) \\
1712\end{array}\right.$ & $(0.849)$ & $(0.603)$ \\
\hline Experiencia & Años de experiencia potencial** & $(0.007)$ & $(0.026)$ & $(0.018)$ & $(0.023)$ & $(0.007)$ & $(0.027)$ & $(0.021)$ & $(0.017)$ & $(0.413)$ & $(0.031)$ & $(0.019)$ & $\begin{array}{l}21.13 \\
(0.015)\end{array}$ \\
\hline Experiencia ${ }^{2}$ & Años de experiencia potencialal al cuadrado. & $\begin{array}{l}598.24 \\
(0.402)\end{array}$ & $\begin{array}{r}592.53 \\
(1.365)\end{array}$ & 662.11 & 672.76 & 582.17 & 448.14 & 641.49 & 640.34 & 585.85 & 523.05 & 585.42 & 618.14 \\
\hline Actividades primarias & $\begin{array}{l}\text { Rama de actividad, Actividades primarias (agricultura, } \\
\text { ganadería, caza, silvivultura, pesca y servicios } \\
\text { conexos y explotación de minas y canteras = 1); en } \\
\text { otro caso }=0\end{array}$ & 0.01 & 0.03 & 0.01 & 0.01 & 0.01 & 0.02 & 0.02 & 0.01 & 0.02 & 0.01 & 0.02 & 0.01 \\
\hline Industria & Rama de actividad, Industria $=1 ;$ en otro caso $=0$ & 0.15 & 0.17 & 0.18 & 0.22 & 0.15 & 0.14 & 0.19 & 0.17 & 0.15 & 0.17 & 0.20 & 0.18 \\
\hline Electricidad, gas y agua & $\begin{array}{l}\text { Rama de actividad, Electricidad, gas y agua }=1 ; \text { en } \\
\text { otro caso }=0\end{array}$ & 0.01 & 0.01 & 0.01 & 0.01 & 0.004 & 0.001 & 0.01 & 0.01 & 0.005 & 0.001 & 0.01 & 0.01 \\
\hline Construcción & Rama de actividad, Construcción $=1 ;$ en otro caso $=0$ & 0.08 & 0.06 & 0.03 & 0.04 & 0.08 & 0.09 & 0.05 & 0.03 & 0.09 & 0.10 & 0.05 & 0.03 \\
\hline $\begin{array}{l}\text { Comercio, restaurant y } \\
\text { hoteles }\end{array}$ & $\begin{array}{l}\text { Rama de actividad, Comercio, restaurant y hoteles }=1 \\
\text { en otro caso }=0\end{array}$ & 0.25 & 0.15 & 0.15 & 0.19 & 0.24 & 0.22 & 0.20 & 0.15 & 0.23 & 0.22 & 0.19 & 0.14 \\
\hline $\begin{array}{l}\text { Transporte y } \\
\text { comunicaciones }\end{array}$ & $\begin{array}{l}\text { Rama de actividad, Transporte y comunicaciones }=1 \\
\text { en otro caso }=0\end{array}$ & 0.06 & 0.10 & 0.06 & 0.08 & 0.07 & 0.09 & 0.10 & 0.08 & 0.07 & 0.09 & 0.09 & 0.06 \\
\hline $\begin{array}{l}\text { Servicios financieros, } \\
\text { inmobiliarios y } \\
\text { empresariales }\end{array}$ & $\begin{array}{l}\text { Rama de actividad, Sevicios financieros, inmobiliarios } \\
\text { y empresariales; en otro caso }=0\end{array}$ & 0.09 & 0.07 & 0.10 & 0.08 & 0.10 & 0.09 & 0.10 & 0.10 & 0.09 & 0.09 & 0.08 & 0.09 \\
\hline $\begin{array}{l}\text { Servicios comunales, } \\
\text { sociales y personales }\end{array}$ & $\begin{array}{l}\text { Rama de actividad, Servicios comunales, sociales y } \\
\text { personales }=1 ; \text { otro caso }=0\end{array}$ & 0.35 & 0.42 & 0.46 & 0.37 & 0.34 & 0.35 & 0.34 & 0.45 & 0.35 & 0.32 & 0.37 & 0.47 \\
\hline Conyuocuh & $\begin{array}{l}=1 \text { si el individuo pertenece a un hogar en el que el } \\
\text { cónyuge está ocupado; en otro caso }=0\end{array}$ & 0.24 & 0.21 & 0.25 & 0.27 & 0.24 & 0.25 & 0.28 & 0.26 & 0.25 & 0.25 & 0.25 & 0.25 \\
\hline Jefeocuh & $\begin{array}{l}=1 \text { si el individuo pertenece a un hogar en el que el } \\
\text { jefe está ocupado; } \text { en otro caso }=0\end{array}$ & 0.51 & 0.38 & 0.29 & 0.25 & 0.52 & 0.42 & 0.26 & 0.32 & 0.50 & 0.42 & 0.30 & 0.33 \\
\hline Men14h & Cantidad de menores de 14 años en el hogar & 1.19 & 1.15 & 0.81 & 0.89 & 1.19 & 1.02 & 0.93 & 0.80 & 1.15 & 1.03 & 0.88 & 0.80 \\
\hline Asiste & $\begin{array}{l}=1 \text { si el individuo asiste a un establecimiento } \\
\text { educativo: en otro caso }=0\end{array}$ & 0.31 & 0.11 & 0.09 & 0.08 & 0.30 & 0.14 & 0.08 & 0.08 & 0.31 & 0.12 & 0.07 & 0.08 \\
\hline Casado & $=1$ si el individuo está casado; en otro caso $=0$ & 0.31 & 0.32 & 0.52 & 0.49 & 0.30 & 0.28 & 0.51 & 0.51 & 0.29 & 0.32 & 0.48 & 0.50 \\
\hline GBA & $\begin{array}{l}=1 \text { s i el individuo reside en la región del Gran Buenos } \\
\text { Aires; en otro caso }=0\end{array}$ & 0.53 & 0.55 & 0.58 & 0.61 & 0.50 & 0.50 & 0.53 & 0.51 & 0.51 & 0.54 & 0.53 & 0.53 \\
\hline Patagonia & $\begin{array}{l}=1 \text { si el individuo reside en la región patagónica en otro } \\
\text { caso }=0\end{array}$ & 0.03 & 0.01 & 0.04 & 0.03 & 0.03 & 0.02 & 0.05 & 0.05 & 0.03 & 0.02 & 0.05 & 0.05 \\
\hline Pampa & $\begin{array}{l}=1 \text { si el individuo reside en la región pampeana; en } \\
\text { otro caso }=0\end{array}$ & 0.23 & 0.20 & 0.21 & 0.19 & 0.24 & 0.22 & 0.23 & 0.24 & 0.24 & 0.19 & 0.23 & 0.23 \\
\hline Cuyo & $\begin{array}{l}=1 \text { s e el individuo reside en la región cuyana; en otro } \\
\text { caso }=0\end{array}$ & 0.06 & 0.07 & 0.06 & 0.06 & 0.07 & 0.09 & 0.08 & 0.07 & 0.07 & 0.09 & 0.07 & 0.06 \\
\hline NEA & $\begin{array}{l}=1 \text { si el individuo reside en la región del Noreste; en } \\
\text { otro caso }=0\end{array}$ & 0.05 & 0.04 & 0.03 & 0.03 & 0.05 & 0.04 & 0.02 & 0.03 & 0.05 & 0.04 & 0.03 & 0.03 \\
\hline NOA & $\begin{array}{l}=1 \text { si e i individuo reside en la región del Noroeste; en } \\
\text { otro casso } 0\end{array}$ & 0.10 & 0.12 & 0.09 & 0.09 & 0.11 & 0.13 & 0.09 & 0.09 & 0.10 & 0.12 & 0.10 & 0.09 \\
\hline
\end{tabular}

Nota: se presentan los valores promedios para las variables continuas y la proporción muestral para las discretas. Los errores estándares figuran entre paréntesis. Los ingresos están expresados en pesos constantes del 2006 . "La variable Educación se obtuvo convirtiendo la variable ordinal reportada por la EPH en una numérica siguiendo la siguiente escala: 0 años $=\sin$ instrucción, 3 años $=$ primaria incompleta, 7 años $=$ primaria completa, 9 años = secundaria incompleta, 12 años = secundario completo, 13 anos = universitario incompleto, 17 años = universitario completo. "Los años de experiencia potencial se calcularon como años de edad, menos años de Fuente: Elaboración propia en base a EPH-INDEC. 
Cuadro A. 3. Clasificación de los trabajadores según la perspectiva de la formalidad y del trabajo decente (\%)

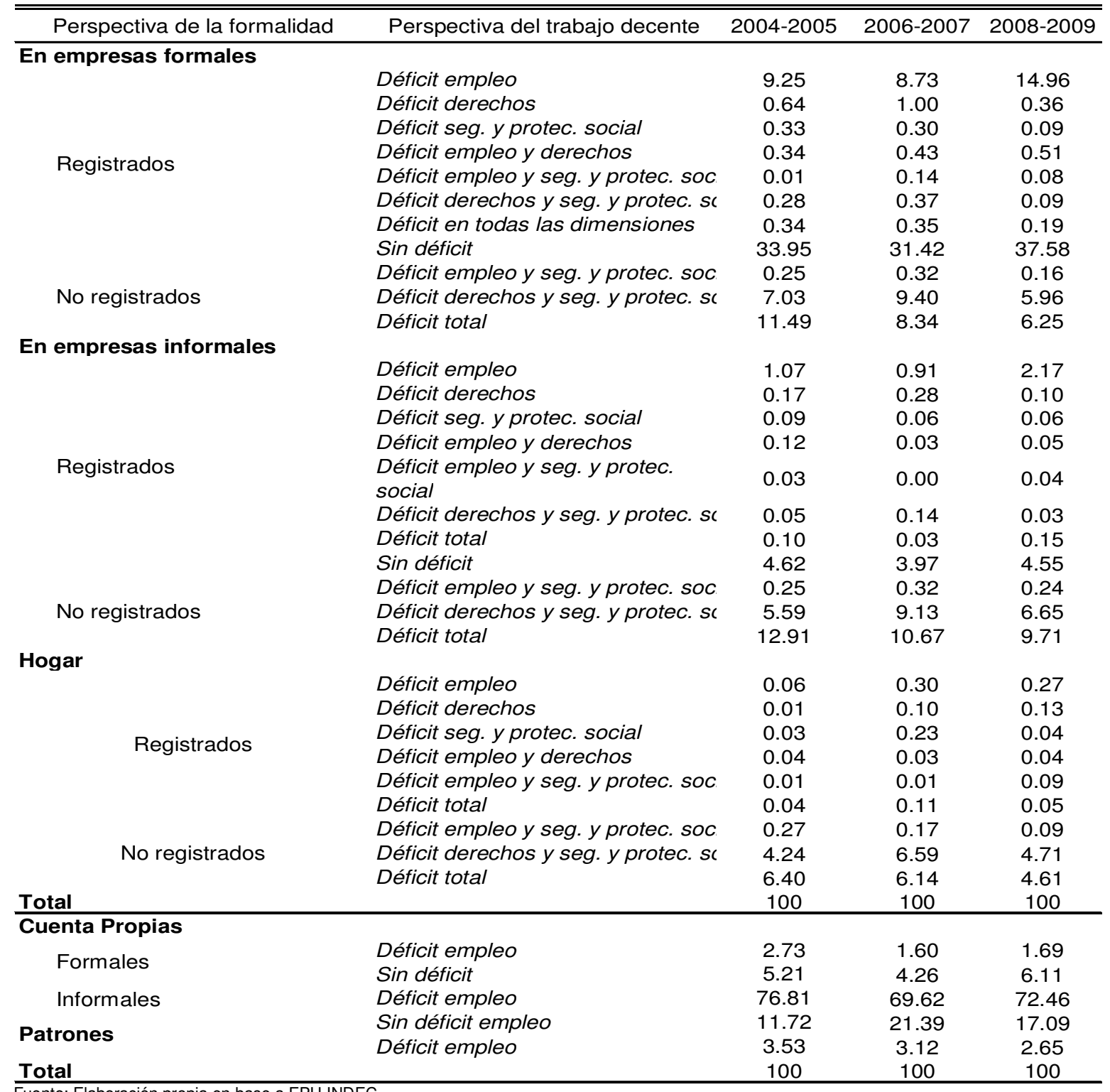

Fuente: Elaboración propia en base a EPH-INDEC. 


\begin{tabular}{|c|c|c|c|c|c|c|c|c|c|c|c|c|c|c|c|c|c|c|}
\hline \multirow{3}{*}{ Formalidad/Trabajo decente } & \multirow{3}{*}{ Inactivos } & \multirow{3}{*}{ Desempleados } & \multicolumn{7}{|c|}{ Empresas Formales } & \multicolumn{5}{|c|}{ Empresas Informales } & \multicolumn{2}{|c|}{ Hogares } & \multirow{3}{*}{$\begin{array}{l}\text { Trabajadores } \\
\text { fam. sin } \\
\text { remuneración } \\
\text { No decente }\end{array}$} & \multirow{3}{*}{ Total } \\
\hline & & & \multicolumn{2}{|c|}{ Asalariados registrados } & \multirow{2}{*}{$\begin{array}{c}\text { Asalariados no } \\
\text { registrados } \\
\text { No decente }\end{array}$} & \multicolumn{2}{|c|}{ Patrones } & \multicolumn{2}{|c|}{ Cuenta propias formales } & \multicolumn{2}{|c|}{ Asalariados registrados } & \multirow{2}{*}{$\begin{array}{l}\text { Asalariados no } \\
\text { registrados } \\
\text { No decente }\end{array}$} & \multicolumn{2}{|c|}{ Cuenta propias informales } & \multirow{2}{*}{$\begin{array}{l}\text { Asalariados } \\
\text { registriados } \\
\text { No decente }\end{array}$} & \multirow{2}{*}{$\begin{array}{l}\text { Asalariados no } \\
\text { registrados } \\
\text { No decente }\end{array}$} & & \\
\hline & & & Decente & No decente & & Decente & No decente & Decente & No decente & Decente & No decente & & Decente & No decente & & & & \\
\hline Inactivos & 88.81 & 3.43 & 0.42 & 0.39 & 1.43 & 0.06 & 0.07 & 0.06 & 0.01 & 0.08 & 0.08 & 1.72 & 0.46 & 1.26 & 0.00 & 1.34 & 0.39 & 100 \\
\hline Desempleados & 26.42 & 30.33 & 3.83 & 1.46 & 6.86 & 0.07 & 0.39 & 0.15 & 0.00 & 0.40 & 0.91 & 12.68 & 2.58 & 9.34 & 0.00 & 3.67 & 0.91 & 100 \\
\hline \multicolumn{19}{|l|}{ Empresas Formales } \\
\hline Decente & 2.65 & 2.55 & 74.34 & 12.99 & 2.13 & 0.89 & 0.03 & 0.14 & 0.02 & 2.15 & 0.42 & 1.06 & 0.18 & 0.38 & 0.00 & 0.03 & 0.04 & 100 \\
\hline No decente & 4.07 & 4.51 & 46.31 & 31.78 & 5.61 & 0.95 & 0.00 & 0.00 & 0.00 & 2.39 & 0.19 & 1.46 & 0.07 & 1.93 & 0.00 & 0.73 & 0.00 & 100 \\
\hline Asalariados no registrados & 13.37 & 6.56 & 7.14 & 3.33 & 43.66 & 0.04 & 0.32 & 1.01 & 0.10 & 0.78 & 0.10 & 13.62 & 1.82 & 4.30 & 0.00 & 3.80 & 0.06 & 100 \\
\hline \multicolumn{19}{|l|}{ Patrones } \\
\hline Decente & 5.28 & 1.83 & 4.08 & 0.00 & 3.30 & 41.78 & 7.19 & 3.84 & 0.31 & 1.25 & 0.00 & 1.04 & 12.08 & 15.79 & 0.00 & 0.73 & 1.49 & 100 \\
\hline No decente & 3.98 & 5.02 & 4.70 & 0.00 & 0.00 & 18.02 & 8.49 & 1.23 & 9.43 & 0.00 & 0.00 & 9.09 & 9.95 & 24.41 & 0.00 & 4.01 & 1.66 & 100 \\
\hline \multicolumn{19}{|l|}{ Cuenta propias formales } \\
\hline Decente & 3.36 & 2.52 & 8.55 & 0.00 & 3.47 & 5.42 & 3.04 & 41.79 & 20.85 & 0.00 & 1.39 & 1.17 & 5.67 & 2.78 & 0.00 & 0.00 & 0.00 & 100 \\
\hline No decente & 11.94 & 0.00 & 0.00 & 3.98 & 0.76 & 0.00 & 0.00 & 27.04 & 40.63 & 0.00 & 0.00 & 2.49 & 0.00 & 13.17 & 0.00 & 0.00 & 0.00 & 100 \\
\hline \multirow{2}{*}{\multicolumn{19}{|c|}{$\begin{array}{l}\text { Empresas Informales } \\
\text { Asalariados registrados }\end{array}$}} \\
\hline & & & & & & & & & & & & & & & & & & \\
\hline Decente & 4.57 & 3.54 & 24.14 & 7.04 & 0.52 & 0.87 & 0.00 & 0.00 & 0.00 & 47.02 & 9.08 & 1.25 & 0.50 & 0.83 & 0.00 & 0.63 & 0.00 & 100 \\
\hline No decente & 1.85 & 7.54 & 11.30 & 4.82 & 9.41 & 0.00 & 0.00 & 0.00 & 0.00 & 19.80 & 23.53 & 16.22 & 4.78 & 0.75 & 0.00 & 0.00 & 0.00 & 100 \\
\hline Asalariados no registrados & 15.65 & 10.52 & 1.38 & 4.05 & 12.95 & 0.26 & 0.19 & 0.50 & 0.13 & 0.94 & 1.28 & 36.27 & 2.42 & 10.23 & 0.00 & 2.29 & 0.94 & 100 \\
\hline \multicolumn{19}{|l|}{ Cuenta propias informales } \\
\hline Decente & 9.37 & 3.85 & 0.63 & 0.00 & 1.04 & 7.14 & 1.27 & 0.17 & 0.79 & 0.27 & 0.21 & 5.72 & 39.32 & 28.66 & 0.00 & 0.25 & 1.31 & 100 \\
\hline No decente & 11.96 & 6.60 & 2.73 & 1.18 & 7.23 & 1.00 & 1.28 & 0.33 & 0.34 & 0.40 & 0.09 & 7.37 & 19.27 & 38.09 & 0.00 & 1.63 & 0.51 & 100 \\
\hline \multicolumn{19}{|l|}{ Hogares } \\
\hline \multicolumn{19}{|l|}{ Asalariados registrados } \\
\hline No decente & 0.00 & 0.00 & 0.00 & 0.00 & 0.00 & 0.00 & 0.00 & 0.00 & 0.00 & 0.00 & 0.00 & 0.00 & 0.00 & 0.00 & 0.00 & 100.00 & 0.00 & 100 \\
\hline Asalariados no registrados & 19.16 & 6.53 & 1.09 & 0.14 & 2.66 & 0.19 & 0.00 & 0.00 & 0.00 & 0.58 & 0.00 & 3.04 & 0.27 & 2.18 & 0.79 & 62.55 & 0.83 & 100 \\
\hline $\begin{array}{l}\text { Trabajadores fam. sin } \\
\text { remunera. }\end{array}$ & & & & & & & & & & & & & & & & & & \\
\hline No decente & 37.17 & 8.51 & 0.00 & 0.00 & 0.00 & 5.32 & 5.06 & 0.00 & 0.00 & 0.00 & 0.00 & 8.35 & 5.41 & 14.43 & 0.00 & 1.17 & 14.58 & 100 \\
\hline Total & 51.30 & 6.18 & 9.45 & 3.02 & 5.61 & 1.32 & 0.43 & 0.60 & 0.38 & 1.26 & 0.48 & 5.82 & 3.58 & 6.27 & 0.03 & 3.72 & 0.56 & 100 \\
\hline
\end{tabular}

Fuente: Elaboración propia en base a EPH-INDEC. 


\begin{tabular}{|c|c|c|c|c|c|c|c|c|c|c|c|c|c|c|c|c|c|c|}
\hline \multirow{3}{*}{ Formalidad/Trabajo decente } & \multirow{3}{*}{ Inactivos } & \multirow{3}{*}{ Desempleados } & \multicolumn{7}{|c|}{ Empresas Formales } & \multicolumn{5}{|c|}{ Empresas Informales } & \multicolumn{2}{|c|}{ Hogares } & \multirow{3}{*}{$\begin{array}{c}\text { Trabajadores fam. } \\
\text { sin remuneración } \\
\text { No decente }\end{array}$} & \multirow{3}{*}{ Total } \\
\hline & & & \multicolumn{2}{|c|}{ Asalariados registrados } & \multirow{2}{*}{$\begin{array}{l}\text { Asalariados } \\
\text { no } \\
\text { registrados } \\
\text { Nodecente }\end{array}$} & \multicolumn{2}{|c|}{ Patrones } & \multicolumn{2}{|c|}{ Cuenta propias formales } & \multicolumn{2}{|c|}{ Asalariados registrados } & \multicolumn{3}{|c|}{$\begin{array}{c}\text { Asalariados } \\
\text { no Cuenta propias informales }\end{array}$} & \multirow{2}{*}{$\begin{array}{l}\text { Asalariados } \\
\text { registrados } \\
\text { No decente }\end{array}$} & \multirow{2}{*}{$\begin{array}{l}\text { Asalariados no } \\
\text { registrados } \\
\text { No decente }\end{array}$} & & \\
\hline & & & Decente & No decente & & Decente & No decente & Decente & No decente & Decente & Nodecente & No decente & Decente & No decente & & & & \\
\hline Inactivos & 88.87 & 3.60 & 0.06 & 0.38 & 1.46 & 0.28 & 0.12 & 0.00 & 0.02 & 0.05 & 0.00 & 2.29 & 0.13 & 0.24 & 0.02 & 1.73 & 0.74 & 100 \\
\hline Desempleados & 36.68 & 30.10 & 1.24 & 2.81 & 12.38 & 0.20 & 0.14 & 0.00 & 0.06 & 0.75 & 0.53 & 9.34 & 0.77 & 1.83 & 0.00 & 2.99 & 0.19 & 100 \\
\hline \multicolumn{19}{|l|}{ Empresas Formales } \\
\hline Decente & 8.75 & 1.29 & 55.63 & 20.83 & 4.12 & 1.48 & 0.66 & 0.00 & 0.00 & 2.06 & 1.67 & 1.40 & 0.07 & 0.79 & 0.00 & 0.77 & 0.47 & 100 \\
\hline No decente & 5.86 & 6.95 & 30.71 & 35.23 & 10.07 & 1.49 & 0.00 & 0.00 & 0.00 & 0.47 & 2.18 & 3.37 & 0.53 & 2.20 & 0.00 & 0.93 & 0.00 & 100 \\
\hline Asalariados no registrados & 20.04 & 4.86 & 1.86 & 6.16 & 40.90 & 1.04 & 0.25 & 0.00 & 0.00 & 1.17 & 0.99 & 14.12 & 2.10 & 2.75 & 0.62 & 2.78 & 0.36 & 100 \\
\hline \multicolumn{19}{|l|}{ Patrones } \\
\hline Decente & 6.20 & 0.63 & 0.00 & 0.00 & 3.77 & 67.89 & 5.43 & 1.76 & 0.00 & 0.37 & 0.00 & 0.97 & 10.67 & 2.07 & 0.00 & 0.00 & 0.24 & 100 \\
\hline No decente & 7.12 & 7.61 & 0.82 & 0.00 & 8.63 & 46.85 & 8.41 & 0.00 & 0.00 & 0.00 & 0.48 & 5.97 & 6.66 & 7.06 & 0.00 & 0.00 & 0.39 & 100 \\
\hline \multicolumn{19}{|l|}{ Cuenta propias formales } \\
\hline Decente & 34.06 & 0.00 & 0.00 & 0.00 & 12.51 & 20.82 & 1.68 & 0.00 & 0.00 & 9.24 & 0.00 & 0.00 & 21.31 & 0.37 & 0.00 & 0.00 & 0.00 & 100 \\
\hline No decente & 21.05 & 3.56 & 0.00 & 0.00 & 9.32 & 12.41 & 4.01 & 15.09 & 0.00 & 0.00 & 0.00 & 0.00 & 19.86 & 14.70 & 0.00 & 0.00 & 0.00 & 100 \\
\hline \multicolumn{19}{|l|}{ Empresas Informales } \\
\hline \multicolumn{19}{|l|}{ Asalariados registrados } \\
\hline Decente & 12.11 & 1.51 & 8.10 & 11.91 & 5.06 & 1.07 & 0.00 & 0.00 & 3.68 & 36.30 & 10.41 & 6.24 & 3.39 & 0.00 & 0.00 & 0.00 & 0.21 & 100 \\
\hline No decente & 2.16 & 3.79 & 2.99 & 23.88 & 4.82 & 0.56 & 0.00 & 0.00 & 0.00 & 7.32 & 16.37 & 27.37 & 1.96 & 0.00 & 0.62 & 8.15 & 0.00 & 100 \\
\hline Asalariados no registrados & 15.55 & 8.55 & 1.06 & 2.94 & 13.56 & 2.82 & 0.15 & 0.03 & 0.00 & 1.58 & 0.95 & 42.52 & 2.12 & 2.28 & 0.03 & 5.29 & 0.54 & 100 \\
\hline \multicolumn{19}{|l|}{ Cuenta propias informales } \\
\hline Decente & 29.11 & 2.19 & 1.74 & 1.25 & 4.04 & 13.17 & 0.55 & 1.60 & 0.30 & 0.88 & 0.06 & 13.87 & 21.11 & 4.32 & 0.00 & 3.31 & 2.50 & 100 \\
\hline No decente & 27.43 & 6.58 & 1.35 & 1.25 & 4.10 & 5.79 & 2.00 & 1.15 & 0.73 & 0.00 & 0.11 & 15.09 & 15.92 & 12.01 & 0.00 & 4.26 & 2.23 & 100 \\
\hline \multicolumn{19}{|l|}{ Hogares } \\
\hline \multicolumn{19}{|l|}{ Asalariados registrados } \\
\hline No decente & 3.79 & 4.30 & 0.00 & 0.00 & 1.51 & 0.00 & 0.00 & 0.00 & 0.00 & 0.00 & 0.00 & 3.73 & 0.00 & 0.00 & 24.74 & 61.94 & 0.00 & 100 \\
\hline Asalariados no registrados & 25.38 & 3.72 & 0.15 & 1.60 & 1.99 & 0.21 & 0.00 & 0.00 & 0.00 & 0.00 & 0.05 & 4.48 & 0.00 & 0.83 & 2.29 & 59.23 & 0.09 & 100 \\
\hline $\begin{array}{l}\text { Trabajadores fam. sin } \\
\text { remunera. }\end{array}$ & & & & & & & & & & & & & & & & & & \\
\hline No decente & 54.06 & 0.74 & 0.13 & 0.00 & 3.58 & 8.05 & 0.00 & 1.41 & 0.00 & 0.50 & 0.00 & 10.68 & 2.59 & 1.38 & 0.00 & 0.00 & 16.86 & 100 \\
\hline Total & 62.82 & 5.22 & 4.20 & 2.98 & 5.33 & 2.50 & 0.36 & 0.16 & 0.07 & 0.65 & 0.39 & 6.49 & 1.87 & 1.31 & 0.19 & 4.61 & 0.82 & 100 \\
\hline
\end{tabular}

Fuente: Elaboración propia en base a EPH-INDEC. 


\begin{tabular}{|c|c|c|c|c|c|c|c|c|c|c|c|c|c|c|c|c|c|c|}
\hline \multirow{3}{*}{ Formalidad/Trabajo decente } & \multirow{3}{*}{ Inactivos } & \multirow{3}{*}{ Desempleados } & \multicolumn{7}{|c|}{ Empresas Formales } & \multicolumn{5}{|c|}{$\begin{array}{c}\text { Empresas Informales } \\
\text { Asalariados }\end{array}$} & \multicolumn{2}{|c|}{ Hogares } & \multirow{3}{*}{$\begin{array}{l}\text { Trabajadores } \\
\text { fam. sin } \\
\text { remuneración } \\
\text { No decente }\end{array}$} & \multirow{3}{*}{ Total } \\
\hline & & & \multicolumn{2}{|c|}{ Asalariados registrados } & \multirow{2}{*}{$\begin{array}{c}\text { Asalariados } \\
\text { no } \\
\text { registrados } \\
\text { No decente }\end{array}$} & \multicolumn{2}{|c|}{ Patrones } & \multicolumn{2}{|c|}{ Cuenta propias formales } & \multicolumn{2}{|c|}{ Asalariados registrados } & \multirow{2}{*}{$\begin{array}{l}\text { Asalariados } \\
\text { no } \\
\text { registriados } \\
\text { No decente }\end{array}$} & \multicolumn{2}{|c|}{ Cuenta propias informales } & \multirow{2}{*}{$\begin{array}{l}\text { Asalariados } \\
\text { registrados } \\
\text { No decente }\end{array}$} & \multirow{2}{*}{$\begin{array}{l}\text { Asalariados no } \\
\text { registriados } \\
\text { No decente }\end{array}$} & & \\
\hline & & & Decente & No decente & & Decente & No decente & Decente & No decente & Decente & No decente & & Decente & No decente & & & & \\
\hline Inactivos & 88.14 & 3.66 & 0.50 & 0.26 & 1.29 & 0.14 & 0.05 & 0.09 & 0.00 & 0.09 & 0.10 & 2.01 & 0.85 & 1.08 & 0.02 & 1.23 & 0.46 & 100 \\
\hline Desempleados & 35.10 & 25.79 & 6.38 & 1.21 & 3.40 & 0.36 & 1.22 & 0.40 & 0.00 & 0.53 & 0.08 & 9.50 & 3.59 & 6.66 & 0.00 & 5.37 & 0.41 & 100 \\
\hline \multicolumn{19}{|l|}{$\begin{array}{l}\text { Empresas Formales } \\
\text { Asalariados registrados }\end{array}$} \\
\hline Decente & 4.26 & 1.50 & 76.72 & 7.23 & 1.68 & 0.59 & 0.00 & 0.26 & 0.03 & 3.78 & 0.85 & 1.44 & 0.66 & 0.88 & 0.00 & 0.13 & 0.00 & 100 \\
\hline No decente & 4.62 & 4.86 & 56.09 & 16.89 & 5.72 & 0.06 & 0.03 & 0.25 & 0.99 & 2.88 & 1.33 & 3.40 & 0.40 & 2.47 & 0.00 & 0.00 & 0.00 & 100 \\
\hline \multicolumn{19}{|l|}{ Patrones } \\
\hline Decente & 6.69 & 0.58 & 2.29 & 0.10 & 0.41 & 51.32 & 2.84 & 4.29 & 0.37 & 0.64 & 0.48 & 6.43 & 14.98 & 8.25 & 0.00 & 0.00 & 0.32 & 100 \\
\hline $\begin{array}{l}\text { No decente } \\
\text { Cuenta propias formales }\end{array}$ & 11.94 & 2.96 & 0.00 & 0.00 & 0.53 & 19.29 & 4.17 & 2.11 & 1.95 & 1.24 & 0.00 & 10.75 & 8.07 & 34.07 & 0.00 & 0.00 & 2.92 & 100 \\
\hline Decente & 7.23 & 0.32 & 4.25 & 0.80 & 0.00 & 11.43 & 0.69 & 45.74 & 10.19 & 0.98 & 0.00 & 1.26 & 13.49 & 0.12 & 0.00 & 0.77 & 2.72 & 100 \\
\hline No decente & 1.94 & 11.02 & 0.00 & 0.00 & 10.77 & 2.85 & 0.00 & 15.68 & 10.61 & 0.00 & 0.00 & 11.14 & 23.76 & 12.22 & 0.00 & 0.00 & 0.00 & 100 \\
\hline \multicolumn{19}{|l|}{$\begin{array}{l}\text { Empresas Informales } \\
\text { Asalariados registrados }\end{array}$} \\
\hline Decente & 6.46 & 0.37 & 19.64 & 3.32 & 0.30 & 0.45 & 0.08 & 0.38 & 0.00 & 45.09 & 5.45 & 9.92 & 3.95 & 3.92 & 0.00 & 0.43 & 0.26 & 100 \\
\hline No decente & 8.41 & 5.15 & 37.85 & 5.23 & 0.00 & 0.00 & 0.00 & 0.00 & 0.00 & 31.80 & 1.57 & 1.30 & 0.93 & 0.26 & 0.00 & 2.29 & 5.21 & 100 \\
\hline $\begin{array}{l}\text { Asalariados no registrados } \\
\text { Cuenta propias informales }\end{array}$ & 16.30 & 7.28 & 2.56 & 2.08 & 12.14 & 0.75 & 1.53 & 0.00 & 0.14 & 2.77 & 1.48 & 37.65 & 4.55 & 7.68 & 0.00 & 1.62 & 1.46 & 100 \\
\hline Decente & 16.16 & 1.98 & 1.32 & 0.03 & 1.98 & 6.53 & 0.62 & 1.51 & 0.08 & 0.72 & 0.06 & 7.73 & 43.84 & 15.79 & 0.00 & 1.01 & 0.64 & 100 \\
\hline No decente & 20.13 & 6.70 & 2.61 & 0.70 & 3.46 & 1.76 & 1.90 & 0.71 & 0.46 & 0.61 & 0.06 & 8.85 & 26.55 & 23.91 & 0.00 & 1.40 & 0.18 & 100 \\
\hline \multicolumn{19}{|l|}{ Hogares } \\
\hline \multicolumn{19}{|l|}{ Asalariados registrados } \\
\hline No decente & 21.21 & 0.00 & 0.00 & 0.00 & 1.44 & 0.00 & 0.00 & 0.00 & 0.00 & 0.00 & 0.00 & 0.00 & 0.00 & 0.00 & 14.46 & 62.89 & 0.00 & 100 \\
\hline \multicolumn{19}{|l|}{$\begin{array}{l}\text { Trabajadores fam. sin } \\
\text { remunera. }\end{array}$} \\
\hline No decente & 42.40 & 5.01 & 3.47 & 0.00 & 2.48 & 3.68 & 0.00 & 0.00 & 0.00 & 0.00 & 0.00 & 2.74 & 9.99 & 7.38 & 0.00 & 5.06 & 17.80 & 100 \\
\hline Total & 53.24 & 4.61 & 12.73 & 1.94 & 3.49 & 2.01 & 0.37 & 0.74 & 0.17 & 1.81 & 0.42 & 5.49 & 5.17 & 3.99 & 0.10 & 3.19 & 0.53 & 100 \\
\hline
\end{tabular}


Cuadro A.7. Brechas de ingresos de ingresos estimadas por OLS-pooled y Efectos Fijos, 2004-2009.

\begin{tabular}{|c|c|c|c|c|c|c|c|c|c|c|c|c|c|c|c|}
\hline \multirow{3}{*}{ Brechas salariales (\%) } & \multirow{3}{*}{$\begin{array}{l}N^{\circ} \text { de } \\
\text { observ. }\end{array}$} & \multicolumn{4}{|c|}{$2004-2005$} & \multirow{3}{*}{$\begin{array}{l}N^{\circ} \text { de } \\
\text { observ. }\end{array}$} & \multicolumn{4}{|c|}{$2006-2007$} & \multirow{3}{*}{$\begin{array}{l}N^{\circ} \text { de } \\
\text { observ. }\end{array}$} & \multicolumn{4}{|c|}{$2008-2009$} \\
\hline & & \multicolumn{2}{|c|}{ OLS-pooled } & \multicolumn{2}{|c|}{ Efectos Fiijos } & & \multicolumn{2}{|c|}{ OLS-pooled } & \multicolumn{2}{|c|}{ Efectos Fiios } & & \multicolumn{2}{|c|}{ OLS-pooled } & \multicolumn{2}{|c|}{ Efectos Fiios } \\
\hline & & 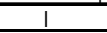 & II & 1 & II & & 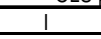 & II & & II & & $I$ & $\|$ & 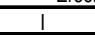 & II \\
\hline \multicolumn{16}{|l|}{ Asal. no registrado/registrado del sector formal } \\
\hline Sin dummies de déficit de TD & 1726 & $\begin{array}{c}-0.680^{\star * *} \\
(0.029)\end{array}$ & $\begin{array}{c}-0.674^{\star \star \star} \\
(0.029)\end{array}$ & $\begin{array}{c}-0.334^{\star \star \star} \\
(0.084)\end{array}$ & $\begin{array}{c}-0.352^{\star \star \star} \\
(0.087)\end{array}$ & 2409 & $\begin{array}{l}-0.661^{\star \star \star} \\
(0.027)\end{array}$ & $\begin{array}{c}-0.651^{\star \star \star} \\
(0.027)\end{array}$ & $\begin{array}{c}-0.284^{\star} \\
(0.160)\end{array}$ & $\begin{array}{c}-0.297^{\star} \\
(0.155)\end{array}$ & 2323 & $\begin{array}{c}-0.623^{\star \star \star} \\
(0.027)\end{array}$ & $\begin{array}{c}-0.651^{\star \star \star} \\
(0.027)\end{array}$ & $\begin{array}{c}-0.343^{* *} \\
(0.168)\end{array}$ & $\begin{array}{l}-0.331^{*} \\
(0.171)\end{array}$ \\
\hline Con dummies de déficit en $\mathrm{TD}^{\mathrm{a}}$ & 1604 & $\begin{array}{c}-0.590^{* * *} \\
(0.031)\end{array}$ & $\begin{array}{c}-0.588^{\star \star *} \\
(0.031)\end{array}$ & $\begin{array}{l}-0.333^{\star \star \star *} \\
(0.085)\end{array}$ & $\begin{array}{l}-0.352^{\star \star *} \\
(0.089)\end{array}$ & 1909 & $\begin{array}{l}-0.576^{\star \star *} \\
(0.030)\end{array}$ & $\begin{array}{l}-0.600^{\star \star * *} \\
(0.030)\end{array}$ & $\begin{array}{l}-0.410^{* *} \\
(0.198)\end{array}$ & $\begin{array}{l}-0.414^{* *} \\
(0.196)\end{array}$ & 2249 & $\begin{array}{c}-0.575^{\star \star \star *} \\
(0.028)\end{array}$ & $\begin{array}{c}-0.551^{\star \star \star *} \\
(0.028)\end{array}$ & $\begin{array}{l}-0.341^{* *} \\
(0.166)\end{array}$ & $\begin{array}{l}-0.325^{*} \\
(0.172)\end{array}$ \\
\hline Con dummies de ocupación ${ }^{b}$ & 1588 & $\begin{array}{l}-0.548^{* * *} \\
(0.032)\end{array}$ & $\begin{array}{c}-0.552^{* * *} \\
(0.033)\end{array}$ & $\begin{array}{c}-0.334^{* * *} \\
(0.085)\end{array}$ & $\begin{array}{l}-0.354^{* * \star} \\
(0.090)\end{array}$ & 1898 & $\begin{array}{c}-0.518^{\star \star \star *} \\
(0.030)\end{array}$ & $\begin{array}{c}-0.502^{* \star *} \\
(0.030)\end{array}$ & $\begin{array}{c}-0.381^{* * *} \\
(0.128)\end{array}$ & $\begin{array}{c}-0.392^{* * *} \\
(0.130)\end{array}$ & 2224 & $\begin{array}{c}-0.581^{* * *} \\
(0.029)\end{array}$ & $\begin{array}{l}-0.562^{* * \star} \\
(0.029)\end{array}$ & $\begin{array}{l}-0.363^{* *} \\
(0.171)\end{array}$ & $\begin{array}{l}-0.361^{* \star} \\
(0.177)\end{array}$ \\
\hline Otros controles ${ }^{c}$ & 1588 & $\begin{array}{l}-0.537^{* * \star} \\
(0.032)\end{array}$ & $\begin{array}{l}-0.542^{* * *} \\
(0.032)\end{array}$ & $\begin{array}{l}-0.355^{\star \star *} \\
(0.093)\end{array}$ & $\begin{array}{c}-0.374^{* \star *} \\
(0.098)\end{array}$ & 1445 & $\begin{array}{l}-0.480^{* * *} \\
(0.036)\end{array}$ & $\begin{array}{l}-0.465^{* * *} \\
(0.036)\end{array}$ & $\begin{array}{l}-0.363 \\
(0.228)\end{array}$ & $\begin{array}{l}-0.321^{* * *} \\
(0.215)\end{array}$ & 2223 & $\begin{array}{c}-0.572^{* * *} \\
(0.029)\end{array}$ & $\begin{array}{l}-0.555^{\star \star *} \\
(0.029)\end{array}$ & $\begin{array}{l}-0.353^{\star *} \\
(0.168)\end{array}$ & $\begin{array}{l}-0.341^{*} \\
(0.176)\end{array}$ \\
\hline \multicolumn{16}{|l|}{ Asal. con déficit /sin déficit del sector formal } \\
\hline En empleo & 1604 & $\begin{array}{c}-0.390^{\star * *} \\
(0.031)\end{array}$ & $\begin{array}{l}-0.378^{\star \star \star} \\
(0.030)\end{array}$ & $\begin{array}{l}0.0004 \\
(0.046)\end{array}$ & $\begin{array}{c}0.003 \\
(0.046)\end{array}$ & 1909 & $\begin{array}{l}-0.500^{\star \star \star} \\
(0.032)\end{array}$ & $\begin{array}{c}-0.501^{\star \star *} \\
(0.032)\end{array}$ & $\begin{array}{c}-0.153 \\
(0.104)\end{array}$ & $\begin{array}{c}-0.152 \\
(0.103)\end{array}$ & 2249 & $\begin{array}{l}-0.281^{\star \star *} \\
(0.025)\end{array}$ & $\begin{array}{l}-0.266^{* \star *} \\
(0.024)\end{array}$ & $\begin{array}{r}-0.0170 \\
(0.053)\end{array}$ & $\begin{array}{c}-0.010 \\
(0.053)\end{array}$ \\
\hline Controlando por déficit en otra dimensión de TD & 1603 & $\begin{array}{l}-0.217^{* * *} \\
(0.031)\end{array}$ & $\begin{array}{c}-0.210^{\star * *} \\
(0.029)\end{array}$ & $\begin{array}{c}0.020 \\
(0.046)\end{array}$ & $\begin{array}{c}0.022 \\
(0.046)\end{array}$ & 1909 & $\begin{array}{l}-0.334^{* * *} \\
(0.030)\end{array}$ & $\begin{array}{c}-0.340^{\star * \star} \\
(0.030)\end{array}$ & $\begin{array}{l}-0.129 \\
(0.083)\end{array}$ & $\begin{array}{r}-0.130 \\
(0.082)\end{array}$ & 2249 & $\begin{array}{c}-0.138^{* \star *} \\
(0.023)\end{array}$ & $\begin{array}{c}-0.133^{* * *} \\
(0.023)\end{array}$ & $\begin{array}{c}0.004 \\
(0.049)\end{array}$ & $\begin{array}{c}0.012 \\
(0.048)\end{array}$ \\
\hline Con dummies de ocupación ${ }^{b}$ & 1587 & $\begin{array}{l}-0.215^{* *+*} \\
(0.029)\end{array}$ & $\begin{array}{l}-0.210^{* \star *} \\
(0.029)\end{array}$ & $\begin{array}{r}0.020 \\
(0.048)\end{array}$ & $\begin{array}{r}0.016 \\
(0.048)\end{array}$ & 1898 & $\begin{array}{l}-0.327^{* \star * *} \\
(0.029)\end{array}$ & $\begin{array}{l}-0.333^{* \star \star} \\
(0.029)\end{array}$ & $\begin{array}{l}-0.135^{*} \\
(0.076)\end{array}$ & $\begin{array}{l}-0.135^{*} \\
(0.075)\end{array}$ & 2224 & $\begin{array}{l}-0.148^{* * *} \\
(0.024)\end{array}$ & $\begin{array}{l}-0.144^{* * *} \\
(0.024)\end{array}$ & $\begin{array}{c}0.024 \\
(0.052)\end{array}$ & $\begin{array}{c}0.034 \\
(0.051)\end{array}$ \\
\hline Otros controles ${ }^{c}$ & 1587 & $\begin{array}{c}-0.202^{* * *} \\
(0.029)\end{array}$ & $\begin{array}{l}-0.195^{* * *} \\
(0.029)\end{array}$ & $\begin{array}{r}0.037 \\
(0.045)\end{array}$ & $\begin{array}{r}0.035 \\
(0.045)\end{array}$ & 1445 & $\begin{array}{c}-0.342^{* * *} \\
(0.031)\end{array}$ & $\begin{array}{c}-0.353^{* * *} \\
(0.031)\end{array}$ & $\begin{array}{c}-0.202^{* *} \\
(0.092)\end{array}$ & $\begin{array}{r}-0.124 \\
(0.092)\end{array}$ & 2223 & $\begin{array}{l}-0.144^{* * *} \\
(0.024)\end{array}$ & $\begin{array}{l}-0.143^{* * *} \\
(0.023)\end{array}$ & $\begin{array}{r}-.0009 \\
(0.047)\end{array}$ & $\begin{array}{c}-0.005 \\
(0.046)\end{array}$ \\
\hline En derechos & 1725 & $\begin{array}{l}-0.658^{* * *} \\
(0.028)\end{array}$ & $\begin{array}{l}-0.649^{\star * *} \\
(0.028)\end{array}$ & $\begin{array}{l}-0.181^{\star \star \star *} \\
(0.066)\end{array}$ & $\begin{array}{c}-0.181^{\star \star \star \star} \\
(0.069)\end{array}$ & 2409 & $\begin{array}{l}-0.700^{* * *} \\
(0.026)\end{array}$ & $\begin{array}{l}-0.700^{\star \star *} \\
(0.026)\end{array}$ & $\begin{array}{l}-0.317^{\star \star} \\
(0.132)\end{array}$ & $\begin{array}{c}-0.330^{* \star \star} \\
(0.127)\end{array}$ & 2249 & $\begin{array}{l}-0.621^{* * *} \\
(0.026)\end{array}$ & $\begin{array}{l}-0.595^{\star \star *} \\
(0.026)\end{array}$ & $\begin{array}{c}-0.463^{* \star *} \\
(0.140)\end{array}$ & $\begin{array}{c}-0.492^{* * *} \\
(0.139)\end{array}$ \\
\hline Controlando por déficit en otra dimensión de TD & 1603 & $\begin{array}{l}-0.565^{* * *} \\
(0.031)\end{array}$ & $\begin{array}{c}-0.563^{\star \star \star} \\
(0.031)\end{array}$ & $\begin{array}{c}-0.186^{\star \star \star *} \\
(0.070)\end{array}$ & $\begin{array}{c}-0.186^{\star \star \star} \\
(0.0719)\end{array}$ & 1909 & $\begin{array}{c}-0.629^{\star * *} \\
(0.029)\end{array}$ & $\begin{array}{c}-0.614^{\star \star \star} \\
(0.029)\end{array}$ & $\begin{array}{c}-0.454^{\star \star \star} \\
(0.134)\end{array}$ & $\begin{array}{c}-0.455^{\star \star \star} \\
(0.130)\end{array}$ & 2323 & $\begin{array}{c}-0.574^{\star \star \star} \\
(0.027)\end{array}$ & $\begin{array}{c}-0.551^{\star \star \star} \\
(0.027)\end{array}$ & $\begin{array}{c}-0.496^{\star \star \star} \\
(0.145)\end{array}$ & $\begin{array}{c}-0.460^{\star \star \star} \\
(0.135)\end{array}$ \\
\hline Con dummies de ocupación ${ }^{b}$ & 1587 & $\begin{array}{l}-0.522^{* *+*} \\
(0.032)\end{array}$ & $\begin{array}{c}-0.523^{* * *} \\
(0.032)\end{array}$ & $\begin{array}{c}-0.183^{* * *} \\
(0.070)\end{array}$ & $\begin{array}{l}-0.182^{* *} \\
(0.073)\end{array}$ & 1898 & $\begin{array}{l}-0.580^{* * * *} \\
(0.029)\end{array}$ & $\begin{array}{l}-0.565^{* * *} \\
(0.029)\end{array}$ & $\begin{array}{c}-0.400^{* * * *} \\
(0.098)\end{array}$ & $\begin{array}{c}-0.393^{* * * *} \\
(0.097)\end{array}$ & 2224 & $\begin{array}{l}-0.581^{* * *} \\
(0.029)\end{array}$ & $\begin{array}{c}-0.563^{\text {t*x }} \\
(0.029)\end{array}$ & $\begin{array}{l}-0.392^{* * *} \\
(0.134)\end{array}$ & $\begin{array}{c}-0.402^{* * *} \\
(0.135)\end{array}$ \\
\hline Otros controles $^{c}$ & 1587 & $\begin{array}{c}-0.507^{\star * *} \\
(0.032)\end{array}$ & $\begin{array}{c}-0.510^{\star * \star} \\
(0.032)\end{array}$ & $\begin{array}{c}-0.190^{\star \star \star} \\
(0.068)\end{array}$ & $\begin{array}{c}-0.187^{\star \star \star \star} \\
(0.071)\end{array}$ & 1445 & $\begin{array}{c}-0.546^{\star \star \star} \\
(0.035)\end{array}$ & $\begin{array}{c}-0.530^{\star \star *} \\
(0.035)\end{array}$ & $\begin{array}{c}-0.239^{\star} \\
(0.143)\end{array}$ & $\begin{array}{c}-0.178 \\
(0.144)\end{array}$ & 2323 & $\begin{array}{c}-0.573^{\star \star *} \\
(0.028)\end{array}$ & $\begin{array}{c}-0.557^{\star \star \star} \\
(0.028)\end{array}$ & $\begin{array}{c}-0.403^{\star \star \star} \\
(0.129)\end{array}$ & $\begin{array}{c}-0.407^{* * *} \\
(0.132)\end{array}$ \\
\hline En seguridad y proteción social & 1726 & $\begin{array}{l}-0.663^{+* * *} \\
(0.28)^{2}\end{array}$ & $\begin{array}{l}-0.655^{* * *} \\
(0.028)\end{array}$ & $\begin{array}{l}-0.144^{*} \\
(0.075)\end{array}$ & $\begin{aligned}-0.140^{*} \\
(0.82)\end{aligned}$ & 2409 & $\begin{array}{l}-0.651^{+* *} \\
(0.06)\end{array}$ & $-0.640^{* * * x}$ & $\begin{array}{l}-0.288^{*} \\
(0.164)\end{array}$ & $\begin{array}{l}-0.305^{*} \\
(0.199)\end{array}$ & 2323 & $-0.616^{* * *+}$ & $\begin{array}{l}-0.592^{t+x} \\
(0.066\end{array}$ & $\begin{array}{l}-0.413^{* *} \\
(0.12)\end{array}$ & $\begin{array}{l}-0.402^{* *} \\
(0.174)\end{array}$ \\
\hline Controlando por déficit en otra dimensión de TD & 1604 & $\begin{array}{l}-0.570^{* * *} \\
(0.030)\end{array}$ & $\begin{array}{l}-0.568^{* * *} \\
(0.031)\end{array}$ & $\begin{array}{l}-0.144^{*} \\
(0.077)\end{array}$ & $\begin{array}{l}-0.141^{*} \\
(0.084)\end{array}$ & 1909 & $\begin{array}{l}-0.563^{* \star *} \\
(0.030)\end{array}$ & $\begin{array}{l}-0.546^{* * *} \\
(0.030)\end{array}$ & $\begin{array}{l}-0.379^{* *} \\
(0.185)\end{array}$ & $\begin{array}{l}-0.379^{* *} \\
(0.183)\end{array}$ & 2249 & $\begin{array}{l}-0.600^{* * *} \\
(0.027)\end{array}$ & $\begin{array}{c}-0.546^{* * *} \\
(0.027)\end{array}$ & $\begin{array}{l}-0.407^{\star *} \\
(0.171)\end{array}$ & $\begin{array}{l}-0.393^{* *} \\
(0.176)\end{array}$ \\
\hline Con dummies de ocupación ${ }^{b}$ & 1588 & $\begin{array}{l}-0.532^{* * *} \\
(0.032)\end{array}$ & $\begin{array}{l}-0.534^{* * *} \\
(0.032)\end{array}$ & $\begin{array}{c}-0.141^{*} \\
(0.077)\end{array}$ & $\begin{array}{r}-0.136 \\
(0.085)\end{array}$ & 1898 & $\begin{array}{l}-0.505^{* * *} \\
(0.030)\end{array}$ & $\begin{array}{l}-0.500^{* * *} \\
(0.030)\end{array}$ & $\begin{array}{c}-0.356^{* * *} \\
(0.118)\end{array}$ & $\begin{array}{c}-0.366^{* * *} \\
(0.119)\end{array}$ & 2224 & $\begin{array}{l}-0.575^{* * *} \\
(0.029)\end{array}$ & $\begin{array}{l}-0.558^{* * *} \\
(0.029)\end{array}$ & $\begin{array}{c}-0.452^{* * *} \\
(0.168)\end{array}$ & $\begin{array}{c}-0.449^{* * *} \\
(0.173)\end{array}$ \\
\hline Otros controles ${ }^{c}$ & 1588 & $\begin{array}{c}-0.520^{* * *} \\
(0.032)\end{array}$ & $\begin{array}{l}-0.521^{* * *} \\
(0.032)\end{array}$ & $\begin{array}{l}-0.153^{*} \\
(0.081)\end{array}$ & $\begin{array}{c}-0.148^{*} \\
(0.089)\end{array}$ & 1445 & $\begin{array}{c}-0.500^{\star \star \star} \\
(0.036)\end{array}$ & $\begin{array}{c}-0.452^{* * \star} \\
(0.036)\end{array}$ & $\begin{array}{r}-0.260 \\
(0.218)\end{array}$ & $\begin{array}{l}-0.210 \\
(0.215)\end{array}$ & 2223 & $\begin{array}{c}-0.566^{\star * *} \\
(0.029)\end{array}$ & $\begin{array}{l}-0.552^{* * *} \\
(0.029)\end{array}$ & $\begin{array}{c}-0.438^{* * *} \\
(0.167)\end{array}$ & $\begin{array}{l}-0.428^{* *} \\
(0.173)\end{array}$ \\
\hline Déficit en todas las dimensiones de TD & 967 & $\begin{array}{l}-0.825^{* * *} \\
(0.036)\end{array}$ & $\begin{array}{c}-0.816^{* * *} \\
(0.036)\end{array}$ & $\begin{array}{r}-0.202 \\
(0.174)\end{array}$ & $\begin{array}{r}-0.183 \\
(0.189)\end{array}$ & 933 & $\begin{array}{c}-0.997^{\star \star *} \\
(0.042)\end{array}$ & $\begin{array}{c}-1.100^{* * \star} \\
(0.042)\end{array}$ & $\begin{array}{c}-1.693^{* * *} \\
(0.292)\end{array}$ & $\begin{array}{c}-1.581^{* \star *} \\
(0.267)\end{array}$ & 1226 & $\begin{array}{c}-0.741^{* * \star} \\
(0.029)\end{array}$ & $\begin{array}{l}-0.712^{* * *} \\
(0.035)\end{array}$ & $\begin{array}{l}-0.859^{* * *} \\
(0.281)\end{array}$ & $\begin{array}{l}-0.823^{* * *} \\
(0.244)\end{array}$ \\
\hline Con dummies de ocupación ${ }^{b}$ & 955 & $\begin{array}{l}-0.786^{* * *} \\
(0.038)\end{array}$ & $\begin{array}{l}-0.780^{* \star *} \\
(0.038)\end{array}$ & $\begin{array}{l}-0.221^{\star} \\
(0.134)\end{array}$ & $\begin{array}{c}-0.225 \\
(0.137)\end{array}$ & 925 & $\begin{array}{l}-0.936^{* * *} \\
(0.044)\end{array}$ & $\begin{array}{l}-0.946^{* \star *} \\
(0.044)\end{array}$ & $\begin{array}{l}-1.776^{* * *} \\
(0.480)\end{array}$ & $\begin{array}{c}-1.633^{* * *} \\
(0.561)\end{array}$ & 1208 & $\begin{array}{l}-0.751^{* * *} \\
(0.038)\end{array}$ & $\begin{array}{l}-0.730^{* * *} \\
(0.038)\end{array}$ & $\begin{array}{l}-0.841^{* * *} \\
(0.271)\end{array}$ & $\begin{array}{l}-0.808^{*+*} \\
(0.249)\end{array}$ \\
\hline Otros controles ${ }^{c}$ & 955 & $\begin{array}{l}-0.762^{* * *} \\
(0.039)\end{array}$ & $\begin{array}{c}-0.755^{\star \star \star} \\
(0.039)\end{array}$ & $\begin{array}{r}-0.215 \\
(0.142) \\
\end{array}$ & $\begin{array}{c}-0.220 \\
(0.146)\end{array}$ & 802 & $\begin{array}{l}-0.910^{\star \star *} \\
(0.046)\end{array}$ & $\begin{array}{c}-0.917^{\star \star \star} \\
(0.046)\end{array}$ & $\begin{array}{c}0.526 \\
(0.752)\end{array}$ & $\begin{array}{c}0.188 \\
(0.815)\end{array}$ & 1208 & $\begin{array}{c}-0.740^{\star * *} \\
(0.038)\end{array}$ & $\begin{array}{l}-0.721^{\star \star *} \\
(0.038)\end{array}$ & $\begin{array}{c}-0.767^{\star \star \star *} \\
(0.272)\end{array}$ & $\begin{array}{c}-0.766^{* * *} \\
(0.252)\end{array}$ \\
\hline
\end{tabular}

Nota: Los errores estándares robustos por heteroscedasticidad figuran entre paréntesis. ${ }^{*}$ denota significancia menor al $10 \%,{ }^{* *}$ denota significancia estadística menor al $5 \%$ y ${ }^{* \star \star}$ denota significancia estadística menor al $1 \%$. Las brechas reportadas corresponden a los coeficientes estimados de las dummies referidas a la no registración y a la existencia de deficit en alguna o todas las dimensiones de TD en el modelo que tiene como variable dependiente el logaritmo del ingreso laboral mensual de la ocupación principal expresado en pesos constantes de 2006 con el IPC de Buenos Aires City y como controles básicos años de educacion, horas trabajadas, experiencia y su cuadrado, una dummy para la posición en el hogar, que indica si el individuo es jefe, y una dummy temporal. I y ll corresponden a los modelos estimados sin y con los términos que corrigen por sesgo de selección, respectivamente. "El modelo estimado incluye además de los controles básicos, una dummy de déficit en el empleo. ${ }^{\circ}$ El modelo estimado incluye además de los controles básicos, dummies de rama de actividad y de tamaño de la firma. ' El modelo estimado incluye además de los controles básicos, dummies de rama de actividad, de tamaño de la firma y de calificación de la tarea. Para todos estas estimaciones, en la dimensión déficit

de empleo se excluyó la condición que los ingresos sean menores al SMVM (Para más detalles ver sección 3.3). 


\section{Anexo B: Gráficos}

\section{Gráfico B.1}

Densidades salariales estimadas por Kernel para los empleados registrados y no registrados en empresas formales en 2004-2005, 2006-2007 y 2008-2009
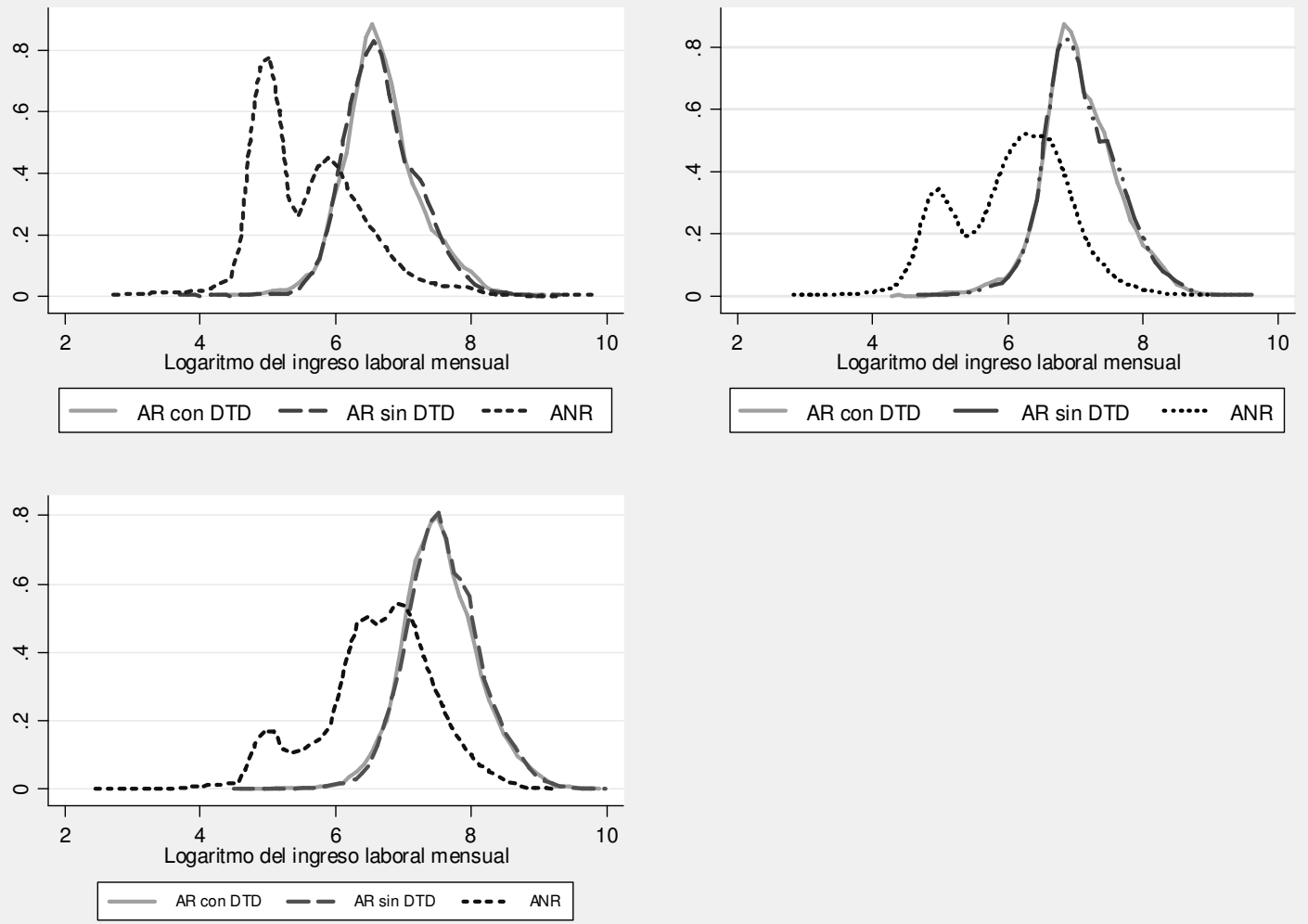

Nota: los ingresos están expresados en pesos constantes del 2006. ANR=Asalariados no registrados en empresas formales, AR con DTD= Asalariados registrados en empresas formales con déficit en alguna dimensión de trabajo decente y AREF= Asalariados registrados en empresas formales con déficit en alguna dimensión de trabajo decente. Las densidades salariales son estimadas por Kernel con el ancho de banda óptimo calculado minimizando la integral del error cuadrático medio si los datos fuesen Gaussian o Gaussian Kernel. Sin embargo, como éste no es óptimo en el sentido global, también se estimaron densidades salariales por Kernel con el ancho de banda igual al doble del óptimo y a la mitad del óptimo obteniendo resultados similares.

Fuente: Elaboración propia en base a EPH-INDEC. 